\title{
Clinical efficacy and immune regulation with peanut oral immunotherapy
}

Stacie M. Jones, MD, ${ }^{a}$ Laurent Pons, PhD, Joseph L. Roberts, MD, PhD, ${ }^{b}$ Amy M. Scurlock, MD, ${ }^{a}$ Tamara T. Perry, MD, ${ }^{a}$ Mike Kulis, PhD, ${ }^{b}$ Wayne G. Shreffler, MD, PhD, ${ }^{c}$ Pamela Steele, CPNP, ${ }^{b}$ Karen A. Henry, RN, ${ }^{a}$ Margaret Adair, MD, ${ }^{b}$ James M. Francis, PhD, ${ }^{d}$ Stephen Durham, MD, ${ }^{d}$ Brian P. Vickery, MD, ${ }^{b}$ Xiaoping Zhong, MD, PhD, ${ }^{b}$ and A. Wesley Burks, MD $^{\mathbf{b}} \quad$ Little Rock, Ark, Durham, NC, New York, NY, and London, United Kingdom

Background: Oral immunotherapy (OIT) has been thought to induce clinical desensitization to allergenic foods, but trials coupling the clinical response and immunologic effects of peanut OIT have not been reported.

Objective: The study objective was to investigate the clinical efficacy and immunologic changes associated with OIT. Methods: Children with peanut allergy underwent an OIT protocol including initial day escalation, buildup, and maintenance phases, and then oral food challenge. Clinical response and immunologic changes were evaluated.

Results: Of 29 subjects who completed the protocol, 27 ingested $3.9 \mathrm{~g}$ peanut protein during food challenge. Most symptoms

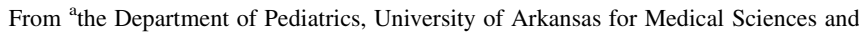
Arkansas Children's Hospital; ' be Department of Pediatrics, Duke University Medi-

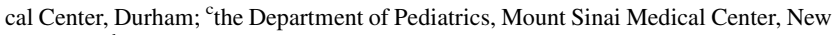
York; and ${ }^{\mathrm{d}}$ Imperial College, London.

Supported by the Food Allergy and Anaphylaxis Network, the Gerber Foundation, National Institutes of Health grant 1R01-AI068074-01A1, the Arkansas Biosciences Institute, the Dorothy and Frank Robins Family, the Food Allergy Project, and Clinical and Translational Science Award 5M01-R000030-45.

Disclosure of potential conflict of interest: A. W. Burks is a consultant for ActoGeniX $\mathrm{NV}$, Intelliject, McNeil Nutritionals, and Novartis; is a minority stockholder of Allertein Therapeutics and MastCell Pharmaceuticals, Inc; is on the advisory board for The Dannon Company, Inc.; is on the expert panel for Nutricia; has received research support from the National Institutes of Health, the Food Allergy and Anaphylaxis Network, and the Wallace Research Foundation; has served as an expert witness regarding food allergy; is on the Medical Board of Directors for the Food Allergy and Anaphylaxis Network; is on the Dermatological Allergy Committee for American College of Allergy, Asthma \& Immunology; is a study section member of the National Institutes of Health Hypersensitivity, Autoimmunity, and Immunodeficiency; and is on the Journal of Allergy and Clinical Immunology review board. S. M. Jones is a consultant and board member for the Food Allergy and Anaphylaxis Network and has received research support from the National Institutes of Health, the Food Allergy and Anaphylaxis Network, the National Peanut Board, Mead Johnson, and Dyax Corp. J. L. Roberts has received research support from the National Institutes of Health. A. M. Scurlock has received research support from the National Institutes of Health/ National Institute of Allergy and Infectious Diseases and Genocea Biosciences. T. T. Perry has received research support from the National Institutes of Health/National Institute of Allergy and Infectious Diseases, the Robert Wood Johnson Foundation, and Arkansas Biosciences Institute, Lyon. M. Kulis has received research support from the Food Allergy Initiative. W. G. Shreffler has received research support from the Food Allergy and Anaphylaxis Network. S. Durham has provided consultancy and lectures for and has received research support from GlaxoSmithKline and ALKAbelló. B. P. Vickery has received research support from the National Institutes of Health and Ception Therapeutics. X. Zhong has received research support from the National Institutes of Health, the American Cancer Society, and the American Heart Association. The rest of the authors have declared that they have no conflict of interest. Received for publication November 19, 2008; revised April 28, 2009; accepted for publication May 12, 2009.

Available online July 6, 2009.

Reprint requests: A. Wesley Burks, MD, Duke University Medical Center, Box 2644, Durham, NC 27710. E-mail: wesley.burks@duke.edu.

$0091-6749 / \$ 36.00$

(C) 2009 American Academy of Allergy, Asthma \& Immunology

doi:10.1016/j.jaci.2009.05.022 noted during OIT resolved spontaneously or with antihistamines. By 6 months, titrated skin prick tests and activation of basophils significantly declined. Peanut-specific IgE decreased by 12 to 18 months, whereas $\operatorname{IgG}_{4}$ increased significantly. Serum factors inhibited IgE-peanut complex formation in an IgE-facilitated allergen binding assay. Secretion of IL-10, IL-5, IFN- $\gamma$, and TNF- $\alpha$ from PBMCs increased over a period of 6 to 12 months. Peanut-specific forkhead box protein $3 \mathrm{~T}$ cells increased until 12 months and decreased thereafter. In addition, T-cell microarrays showed downregulation of genes in apoptotic pathways.

Conclusion: Oral immunotherapy induces clinical desensitization to peanut, with significant longer-term humoral and cellular changes. Microarray data suggest a novel role for apoptosis in OIT. (J Allergy Clin Immunol 2009;124:292-300.)

Key words: Peanut hypersensitivity, immunotherapy, immune tolerance, apoptosis, IgE, IgG, IL-5, IL-10

In industrialized countries, peanut allergy affects $0.8 \%$ of children and $0.5 \%$ to $1 \%$ of the general population, ${ }^{1-3}$ and the prevalence appears to be increasing. Peanuts and tree nuts account for the vast majority of life-threatening or fatal reactions to foods. ${ }^{4,5}$ Currently, the primary treatment for peanut allergy is a peanut-free diet and ready access to self-injectable epinephrine and antihistamines. ${ }^{6}$ Strict avoidance diets can be complicated by difficulty in interpreting labels ${ }^{7}$ and undeclared allergens in commercially prepared foods. ${ }^{8,9}$ As many as $50 \%$ of patients with food allergy have an allergic reaction during a given 2-year period. ${ }^{10}$ The combination of avoidance diets and risks of accidental exposures and life-threatening reactions creates a tremendous burden to patients and families.

Traditional subcutaneous immunotherapy is useful in treating forms of inhalant allergen sensitivity such as allergic rhinoconjunctivitis and asthma ${ }^{11}$ but is unsafe in food allergy. ${ }^{12,13}$ Oral immunotherapy (OIT) and sublingual immunotherapy have been reported by our group and others to result in induction of clinical tolerance to a variety of food proteins. ${ }^{14-16}$ Yet most studies have not attempted to couple clinical efficacy with long-term immunologic changes.

We conducted an open-label study of peanut OIT in children with peanut allergy. Our goals were to evaluate the ability of peanut OIT to induce clinical desensitization and to investigate the immunologic mechanisms associated with clinical efficacy. The term desensitization was used to mean a change in threshold of ingested food antigen needed to cause allergic symptoms, whereas tolerance referred to the induction of long-term immunologic changes associated with the ability to ingest food without symptoms and without ongoing therapy. We hypothesized that 

Abbreviations used
FAB: Facilitated allergen binding
FoxP3: Forkhead box protein 3
MIP: Macrophage inflammatory protein
OFC: Oral food challenge
OIT: Oral immunotherapy
PBMC: Peripheral blood mononuclear cell
SPT: Skin prick test
Treg: Regulatory $\mathrm{T}$ cell

subjects with peanut allergy who underwent OIT would be shifted toward a $\mathrm{T}_{\mathrm{H}} 1$-type profile.

\section{METHODS}

\section{Subject recruitment}

Subjects age 1 to 16 years were recruited from the allergy and immunology clinics or surrounding community physician offices at Duke University Medical Center and Arkansas Children's Hospital. Ethics approval was obtained through the Institutional Review Boards at Duke University Medical Center and University of Arkansas for Medical Sciences. Written informed consent was obtained in accordance with each institution's ethics guidelines for research in children.

\section{Subject selection}

Included subjects had a clinical history of reaction to peanut within 60 minutes of ingestion, a positive peanut skin prick test ([SPT] $\geq 3 \mathrm{~mm}$ of negative control), and a peanut CAP FEIA $\geq 15 \mathrm{kU} / \mathrm{L}$ (Phadia AB; Pharmacia, Inc, Uppsala, Sweden). Subjects were also included if they had a CAP FEIA $\geq 7 \mathrm{kU} / \mathrm{L}$ and a clinical reaction within the previous 6 months. Subjects were excluded for history of severe, life-threatening anaphylaxis (with hypotension) to peanut, severe or poorly controlled asthma, or a medical condition preventing undergoing a food challenge.

\section{Peanut flour and dosing}

Peanut protein (from Partially Defatted Peanut Flour 12\% Fat Light Roast; Golden Peanut Company, Alpharetta, $\mathrm{Ga} ; 2 \mathrm{~g}$ flour $=1 \mathrm{~g}$ peanut protein) doses were premeasured and mixed in a food vehicle of the subject's choosing and taken in 2 or 3 bites. Approximately $240 \mathrm{mg}$ peanut protein equals 1 whole peanut. ${ }^{17}$

\section{OIT protocol}

Peanut OIT consisted of 3 phases: initial day escalation, buildup, and maintenance. Patients were instructed to eliminate peanut protein otherwise from their diets. During dosing, subjects were asked to keep a diary of any missed doses or adverse symptoms. Self-administered epinephrine was provided to all patients. A member of the study team was available by pager and phone at all times throughout the study.

Initial day escalation phase. The initial day escalation phase was undertaken at the research unit at each institution. Intramuscular epinephrine, oral and intravenous doses of diphenhydramine, and albuterol were at the bedside at all times. Dosing began at $0.1 \mathrm{mg}$ peanut protein, followed by an approximate doubling every 30 minutes, up to $50 \mathrm{mg}$. The highest tolerated single dose was the starting dose for the buildup phase, which was initiated in the research unit the following day.

Buildup phase. Subjects were instructed to ingest the daily dose of peanut protein with other safe foods in 2 or 3 bites at home every day. Doses were increased $25 \mathrm{mg}$ every 2 weeks until $300 \mathrm{mg}$ was reached. Subjects returned to the clinic for dose escalations. For subjects who stopped dosing at lower than $50 \mathrm{mg}$ on the initial day escalation, their doses were doubled every
2 weeks until they reached $50 \mathrm{mg}$, and then the increases were $25 \mathrm{mg}$. Buildup dosing was delayed if subjects had evidence of illness (eg, viral infection) at the time of scheduled up-dosing; therefore, the time to reach maintenance dosing varied between subjects.

Maintenance phase. After reaching $300 \mathrm{mg}$ peanut protein daily, subjects continued this dose until the food challenge. After oral food challenge, subjects were increased to a daily OIT dose of $1800 \mathrm{mg}$ if the peanut $\mathrm{IgE}$ remained $>2 \mathrm{kU} / \mathrm{L}$ after 12 months on maintenance dose (this escalation occurred in all subjects reported). Subjects were evaluated every 4 months while on continued maintenance dosing (total of 36 months).

\section{Oral food challenge}

The first cohort of subjects $(n=7)$ underwent an open oral food challenge (OFC) to peanut protein after 13 to 22 months of maintenance OIT, and the second cohort $(n=22)$ did after 4 to 7 months. The time to OFC was reduced because early basophil and skin test data as well as OFC data indicated a lack of clinical reactivity sooner than hypothesized. Before the OFC, subjects were asked to restrict use of antihistamines (short-acting, 72 hours; long-acting, 7 days), $\beta$-agonists (12 hours), theophylline (12 hours), and montelukast (12 hours). The OFC consisted of 4 doses ( $300 \mathrm{mg}, 600 \mathrm{mg}, 1200 \mathrm{mg}, 1800 \mathrm{mg}$ ) of peanut protein given every 30 minutes up to a total of $3.9 \mathrm{~g}$ peanut protein $(7.8$ $\mathrm{g}$ peanut flour). The OFC was discontinued at $3.9 \mathrm{~g}$ or with objective symptoms.

\section{Purified peanut protein reagent}

Peanut proteins were extracted from defatted peanut flour (Golden Peanut Co) in PBS, clarified by centrifugation $(30,000 \mathrm{~g}$ for 30 minutes), and sterilized by filtration.

The major peanut allergen, Ara h 2, was purified and lyophilized as previously described, ${ }^{18}$ diluted in PBS, and sterilized. All protein concentrations were determined by using the bicinchoninic acid assay (BCA; Pierce, Rockford, Ill).

\section{Titrated skin prick testing}

Titrated skin prick tests (SPTs) with peanut extract (Greer Laboratories, Inc, Lenoir, NC) and saline and histamine controls were performed at enrollment, after 4 months of maintenance therapy, and every 4 months thereafter. Tests to peanut were measured and followed at the same dilution $(1: 20,1: 200,1: 2000$, or 1:20,000) that initially showed a wheal $>5 \mathrm{~mm}$. Wheal size was the average of the largest diameter and the perpendicular midpoint diameter. Data were analyzed using a mixed-model repeated-measures ANOVA. The response variable was the highest dilution causing $>5 \mathrm{~mm}$ wheal at enrollment. Time and subject were treated as factors. Inferences about wheal size changes over time were made by comparing the mean at each time point back to time 0 using a multiple comparisons procedure. Restricted maximum likelihood was used to fit the ANOVA model and estimate model parameters.

\section{Basophil activation assay}

Basophil activation was measured as previously described. ${ }^{19}$ Briefly, peripheral blood was collected in sodium heparin tubes, aliquoted, and stimulated for 30 minutes with basophil medium alone (RPMI with 4 $\mathrm{ng} / \mathrm{mL}$ human IL-3) or the medium with 10,1 , or $0.1 \mu \mathrm{g} / \mathrm{mL}$ peanut extract; $1 \mu \mathrm{g} / \mathrm{mL}$ anti-IgE (polyclonal rabbit antihuman; Bethyl Laboratories, Montgomery, Tx); or $2 \mu \mathrm{mol} / \mathrm{L}$ fMLP (VWR Scientific, West Chester, $\mathrm{Pa}$ ). Cells were stained for 30 minutes at $4^{\circ} \mathrm{C}$ with the following mAbs: CD63-fluorescein isothiocyanate (clone H5C6), CD203c-phycoerythrin (IM3575), CD123 phycoerythrin-Cy5 (9F5), CD69-APC-Cy7 (FN50), CD3-allophycocyanin (SK7), CD14-APC (M5E2), CD19-APC (H1B19), CD41a-allophycocyanin (HIP8), and HLA-DR-phycoerythrin-Cy7 (L243) (IM3575, Beckman Coulter, Fullerton, Calif; all others, BD Biosciences, San Jose, Calif). CD63 upregulation was assessed by flow cytometry. CD3, CD14, CD19, and CD41a-positive events were excluded, and a 
minimum $1000 \mathrm{CD}_{123}{ }^{+} \mathrm{HLA}^{-\mathrm{DR}^{-}}$events were acquired. Data were analyzed by using FlowJo software (TreeStar, Ashland, Ore).

\section{Assays for $\lg E$, $\lg G$, and $\lg _{\mathbf{4}}$}

Peanut-specific $\mathrm{IgE}, \mathrm{IgG}$, and $\mathrm{IgG}_{4}$ levels were measured in serum samples by using the ImmunoCAP 100 instrument (Phadia AB) according to the manufacturer's instructions. The same statistical approach as for the titrated skin tests analysis was carried out, except that the natural log of the immunoglobulin concentrations was taken to meet the constant variance and normality assumptions of the ANOVA model better.

\section{IgE-facilitated allergen binding assay for peanut}

Indicator serum containing high concentrations of peanut-specific IgE (RAST >100 IU/mL) was purchased from PlasmaLab, Everett, Wash. Equal volumes $(10 \mu \mathrm{L})$ of serum obtained from the clinical study and indicator serum were incubated with peanut extract $(0.04 \mu \mathrm{g} / \mathrm{mL}$ in $2.5 \mu \mathrm{L})$ for 1 hour at $37^{\circ} \mathrm{C}^{20}$ Results of flow cytometry are expressed as relative binding, where binding observed by indicator serum alone is normalized to $100 \%$, and changes in binding caused by the addition of patients' serum to the indicator serum is related to this value. Statistical differences between pre-OIT and post-OIT sera were determined by using SPSS 15.0 for Windows (SPSS Inc, Chicago, Ill). The 2-tailed Wilcoxon signed-rank test was used to compare pre-OIT and post-OIT sera ability to inhibit peanut-specific facilitated allergen binding (FAB). $P$ values $<.05$ were considered statistically significant.

\section{Cytokine assay and regulatory T-cell analyses}

Peripheral blood mononuclear cells (PBMCs) were isolated from $\sim 25 \mathrm{~mL}$ heparinized blood by using Ficoll-based density separation (LymphoH; Atlanta Biologicals, Lawrenceville, Ga). For cytokine assays, suspended PBMCs were distributed into 96-well flat-bottom plates at a concentration of $4 \times 10^{5}$ cells/well in triplicate and incubated with crude peanut protein $(40 \mu \mathrm{g} / \mathrm{well})$, Ara h 2 (20 $\mu \mathrm{g} /$ well), concanavalin A ( $8 \mu \mathrm{g} /$ well; Sigma, St Louis, Mo), or medium alone (RPMI-1640 with $2 \mathrm{mmol} / \mathrm{L} \mathrm{L}$-glutamine, $25 \mathrm{mmol} / \mathrm{L}$ HEPES buffer containing $10 \%$ human $\mathrm{AB}$ serum, $100 \mathrm{IU} / \mathrm{mL}$ penicillin, and $100 \mu \mathrm{g} /$ $\mathrm{mL}$ streptomycin; Mediatech, Manassas, Va). Cells were cultured at $37^{\circ} \mathrm{C}$ in $5 \% \mathrm{CO}_{2}$ humidified atmosphere for 24,48 , and 96 hours. Culture supernatants were collected at each time point and analyzed in duplicate for 14 different analytes by using a multiplex bead assay (R\&D Systems, Minneapolis, Minn) for the Luminex 100 platform. To analyze the cytokine data, linear mixed-effects models were run in Splus (Insightful Co, Palo Alto, Calif) with subject as the random effect, and fixed effects given by culture condition, culture condition $\times$ months on immunotherapy, and time of culture. The response variable was

$$
\log (y+1)
$$

where $y$ is the mean cytokine concentration. Slope comparisons were against the null hypothesis that slope $=0$ for RPMI. A positive or negative coefficient was considered statistically significant at the .05 level and was a measure of the trend over time of each cytokine.

For flow cytometry, PBMCs $\left(2 \times 10^{6}\right.$ cells/well $)$ were cultured in 24-well plates under the same stimulation conditions as described. After 6 days, cells were collected and stained with fluorescent mAbs: anti-CD3-PerCP, CD4fluorescein isothiocyanate, and CD25-phycoerythrin (BD Biosciences). Additional intracellular staining with anti-forkhead box protein 3 (Foxp3)-allophycocyanin was carried out after fixation/permeabilization of the cells (eBioscience). Isotype controls were included for each condition. The samples were run for 3-color detection in a FACSCalibur flow cytometer (Beckman-Coulter). At least 10,000 events were acquired for each experimental condition, and data were analyzed by using the FlowJo software.

\section{Microarray analysis}

RNA isolated from resting PBMC CD3 ${ }^{+} \mathrm{T}$ cells (EasySep T-cell Enrichment; Stem Cell Technologies, Inc, Vancouver, British Columbia, Canada) with the RNeasy Total RNA Isolation kit (Qiagen, Inc, Valencia, Calif) was used for target preparation and hybridization with the GeneChip human genome U133 Plus 2.0 array (Affymetrix, Inc, Santa Clara, Calif) according to the manufacturer instructions. Hybridized microarrays were scanned by using an Affymetrix GeneChip 3000 scanner. Microarray assays and statistical analyses of experimental data were performed by Expression Analysis, Inc, Durham, NC, and included assessment of data quality by standard quality checks and principal components analysis by sample of the probe-level data, along with normalization and signal summarization using the robust multiarray algorithm. Determination of differential expression of genes in subject samples before and after OIT was performed by repeated-measures analysis accounting for multiple testing using a variant of Significance Analysis of Microarrays ${ }^{21}$ to detect statistically significant transcripts. Enrichment analysis of the set of transcripts identified as differentially expressed between subjects by repeatedmeasures analysis was then performed by GeneGo, Inc, (St Joseph, Mich) using the MetaCore software suite (GeneGo, Inc). This enrichment analysis matched Entrez (National Center for Biotechnology Information, National Institutes of Health, Bethesda, Md) geneIDs for common, similar, and unique sets of the OIT subjects differentially expressed transcript list with Entrez geneIDs in functional ontologies in MetaCore. The ontologies included canonical pathway maps, GeneGo cellular processes, gene ontology cellular processes, and disease categories. The degree of relevance to different categories for the OIT subjects dataset was defined by $P$ values, so that the lower $P$ value received higher priority.

\section{Quantitative real-time PCR}

Resting PBMC CD3 ${ }^{+}$T-cell RNA isolated for microarray assays was used for cDNA synthesis and quantification of experimental and control (18s rRNA) transcripts by Expression Analysis, Inc, using a 7900 HT Fast RealTime PCR System (Applied Biosystems, Foster City, Calif) and TaqMan Gene Expression Assay (Applied Biosystems) gene-specific primer and probe sets. Experimental transcript levels were normalized to those for 18s rRNA in each sample.

\section{RESULTS \\ Subject demographics}

Thirty-nine subjects were enrolled. Twenty five $(64 \%)$ were male. The median age at enrollment was 57.5 months (range, 12111 months). The median age at first reaction to peanut was 15 months (range, 8-48 months). All but 3 subjects had allergic disease other than food allergy, including atopic dermatitis $(69 \%)$, asthma (62\%), and allergic rhinitis (62\%). Fifty-four percent had an additional food allergy: $38 \%$ tree nuts, $23 \%$ egg, $13 \%$ cow's milk, $5 \%$ fish, and $3 \%$ soy.

All 39 subjects completed the initial day escalation protocol. Ten $(25 \%)$ subjects subsequently withdrew. Six discontinued for personal reasons, including transportation issues, parental anxiety, and failure to perform home dosing. These 6 had reactions during the initial escalation day that were similar to reactions of patients who continued in the study. The remaining 4 subjects discontinued because of allergic reactions to the OIT that did not resolve with continued treatment or dose reduction. Three had gastrointestinal complaints, and 1 had symptoms of asthma. Twenty-nine subjects completed all 3 phases of the study and peanut challenges.

\section{Clinical responses during initial day escalation}

During the initial day escalation, 10 (26\%) subjects tolerated the highest dose of $50 \mathrm{mg}$ peanut protein (Table I), $15(38 \%)$ tolerated $25 \mathrm{mg}, 6(15 \%)$ tolerated $12 \mathrm{mg}, 5(13 \%)$ tolerated $6 \mathrm{mg}$, $1(3 \%)$ tolerated $3 \mathrm{mg}$, and $2(5 \%)$ tolerated $1.5 \mathrm{mg}$. Thirty-six patients $(92 \%)$ experienced some symptoms during the initial escalation day. Most common were upper respiratory symptoms, with 


\begin{tabular}{|c|c|c|c|}
\hline & Initial day escalation $(n=39)$ & Buildup + maintenance $(n=29)$ & OFC (n = 29) \\
\hline Dose (mg) first symptom, median (range) & $6(0.1-50)$ & & $1800(300-1800)$ \\
\hline No. $(\%)$ reached highest dose & $10(26)$ & & $27(93)$ \\
\hline No. (\%) without symptoms & $3(8)$ & & $11(38)$ \\
\hline Therapy received, $\mathrm{n}(\%)$ & $22(56)$ & & $11(38)$ \\
\hline None & $17(44)$ & & $18(62)$ \\
\hline Diphenhydramine & 19 (49) & & $11(38)$ \\
\hline Albuterol & $5(13)$ & & $1(3)$ \\
\hline Epinephrine & $4(10)$ & & $1(3)$ \\
\hline Total home doses, $\mathrm{n}$ & & 14,773 & \\
\hline Days with symptoms, $\mathrm{n}$ (\% of total home doses) & & $545(3.7)$ & \\
\hline Days with home treatment, $\mathrm{n}$ ( $\%$ of total home doses) & & $111(0.8)$ & \\
\hline
\end{tabular}
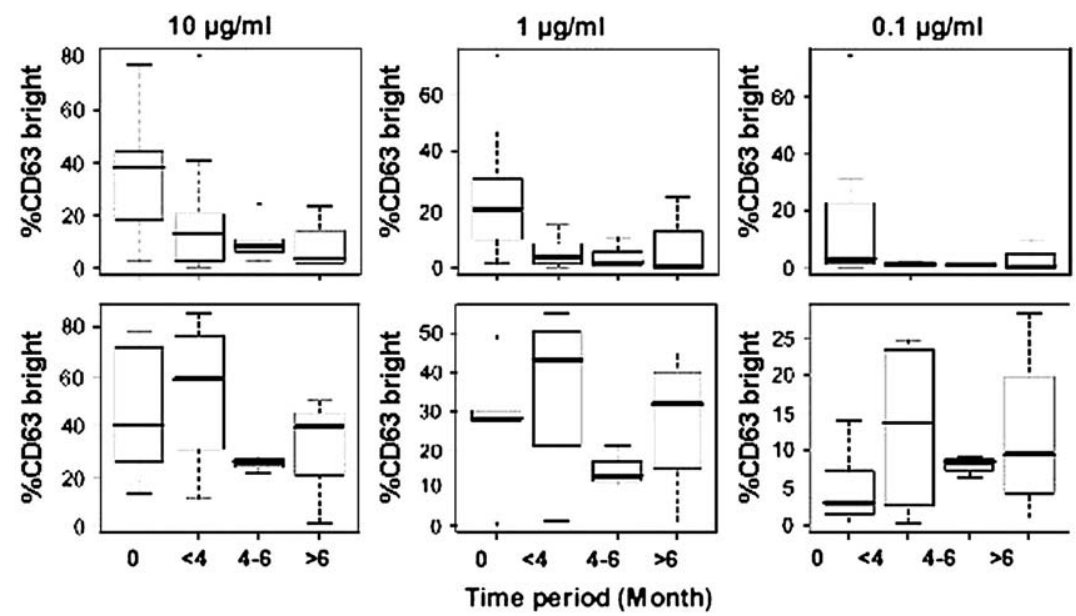

FIG 1. Effect of peanut OIT on basophil activation. Top row, Subjects who received peanut OIT. Bottom row, Subjects in an observational study of peanut allergy. At a peanut concentration of $10 \mu \mathrm{g} / \mathrm{mL}$, OIT results in significant initial changes in basophil responsiveness $\left({ }^{*} P<.001\right)$.

27 patients $(69 \%)$ reporting mild sneezing/itching and mild laryngeal symptoms. No patients experienced severe upper respiratory or laryngeal symptoms. Seventeen patients $(44 \%)$ reported mild to moderate nausea or abdominal pain, and 8 patients $(21 \%)$ had mild diarrhea/emesis. Twenty-four subjects $(62 \%)$ had mild or moderate skin symptoms. A total of 6 patients experienced chest symptoms during the initial escalation day; all 6 had mild wheezing, and 2 progressed to moderate wheezing. Three of the subjects with chest symptoms during the initial day escalation also had a previous diagnosis of asthma.

\section{Buildup/maintenance}

Subjects had symptoms after $46 \%$ of buildup doses. Subjects were on maintenance dosing at home prior to OFC for a median of 4.7 months (range, 4-22 months). All subjects experienced rare, and typically minor, symptoms during some point of home dosing (3.7\% of 14,773 doses given; Table I). Upper respiratory (1.2\%) and skin $(1.1 \%)$ were the most common. Treatment was given with $0.8 \%$ of home doses. Only 2 subjects received epinephrine after home dosing, and each of the 2 had only 1 such incident.

\section{OFC}

Twenty-nine subjects participated in the open OFC to peanut. Overall, 27 of 29 (93\%) reached the total peanut dose of $3.9 \mathrm{~g}$ with no more than mild symptoms, suggesting successful desensitization to peanut protein. Two subjects did not ingest the maximal dose and stopped after $2.1 \mathrm{~g}$. One stopped because of parental anxiety, and the other because of mild urticaria and 1 vomiting episode.

\section{Titrated SPTs}

Titrated SPTs showed a significant decrease of $4 \mathrm{~mm}$ beginning at 6 months $(P<.0001)$ and remained decreased throughout the study.

\section{Basophil activation}

Basophil reactivity to peanut antigen was evaluated at 3 peanut concentrations: $10 \mu \mathrm{g} / \mathrm{mL}, 1 \mu \mathrm{g} / \mathrm{mL}$, and $0.1 \mu \mathrm{g} / \mathrm{mL}$; and 4 time points: before OIT $(\mathrm{n}=15),<4$ months $(\mathrm{n}=9), 4$ to 6 months $(\mathrm{n}=6)$, and $>6$ months $(\mathrm{n}=4$; Fig 1$)$. At a peanut concentration of $10 \mu \mathrm{g} / \mathrm{mL}$, basophil activation was significantly reduced within 4 months $(P<.001)$. We also evaluated basophil reactivity in subjects in an observational study of peanut allergy, and these patients did not experience reduced basophil activity.

\section{Peanut-specific serum $\lg E_{,} \lg G$, and $\lg _{\mathbf{4}}$}

The initial median concentration of serum peanut-specific $\mathrm{IgE}$ was $85.4 \mathrm{kU} / \mathrm{L}$ (range, 9.1-840.0 kU/L). After 3 months of treatment, median peanut-specific $\operatorname{IgE}$ increased nearly 3 -fold 

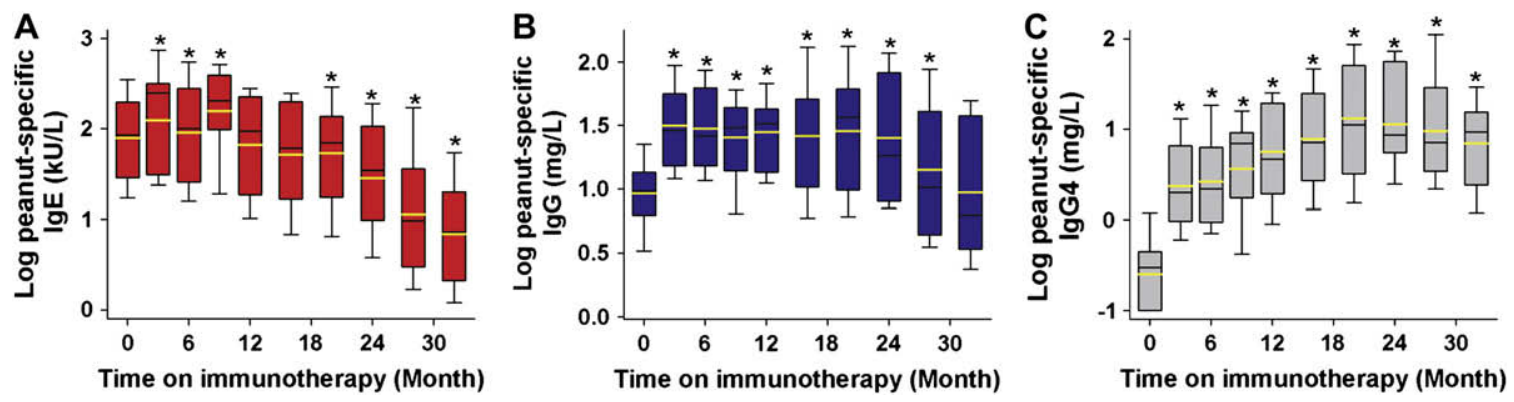

FIG 2. Serum levels of peanut-specific immunoglobulins during peanut OIT. In the serum of 28 subjects undergoing immunotherapy, peanut-specific $\lg E(A), \lg G(B)$, and $\lg _{4}$ (C) were measured by using the $\operatorname{lm}$ munoCAP instrument. Values are log-transformed, and median and mean values are represented by black and yellow horizontal lines, respectively. A mixed model, repeated-measures ANOVA was used to determine the statistical significance between baseline and treatment time points $\left({ }^{*} P<.0005\right)$.

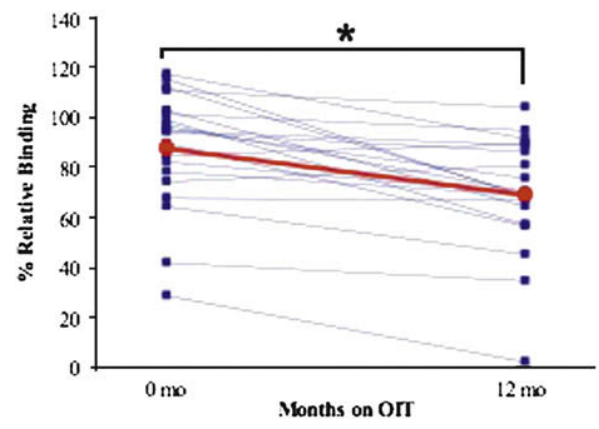

FIG 3. Peanut OIT leads to $F A B$ inhibition. Blue lines represent individual data points, red line the mean. Statistical differences between pre-OIT and 12-month-post-OIT serum were determined by Wilcoxon signed-rank test $\left({ }^{*} P<.001\right)$.

$(249.0 \mathrm{kU} / \mathrm{L} ; P<.0005)$. At 12 and 18 months, no significant decrease from baseline was found, but for all subsequent time points (until 33 months), peanut-specific IgE levels were significantly decreased $(P<.0005$; Fig $2, A)$.

Median baseline serum peanut-specific $\mathrm{IgG}$ was $9.7 \mathrm{mg} / \mathrm{L}$ (range, $2.5-56.0 \mathrm{mg} / \mathrm{L})$. A significant increase $(P<.0005)$ in specific IgG levels also started at 3 months (Fig 2, B). Specific IgG levels remained high until 24 months and slowly returned to baseline by 33 months.

The peanut-specific $\mathrm{IgG}_{4}$ followed a slightly different trend (Fig 2,C). Initial concentrations were low, with a median of 0.3 $\mathrm{mg} / \mathrm{L}$ (range, 0.1-1.4 mg/L). Peanut-specific $\mathrm{IgG}_{4}$ concentrations increased initially, reaching statistical significance at 3 months $(2.0 \mathrm{mg} / \mathrm{L}$ vs $0.3 \mathrm{mg} / \mathrm{L} ; P<.0005)$, and continued elevated at the end of the study $(P<.0005)$.

\section{FAB assay}

FAB inhibition by serum factors was tested in 20 patients at baseline and after 12 months of treatment. A decrease in percent relative binding after 12 months of OIT was measured in 18 of the 20 subjects (Fig 3). Subjects with peanut allergy from our egg OIT study ${ }^{16}$ currently avoiding peanuts were used as controls and showed no change in relative binding (data not shown). For the peanut OIT subjects, the percent mean relative binding decreased from $87.6 \% \pm 23.4 \%$ at baseline to $69.3 \% \pm 23.3 \%$ by 12 months $(P<.001)$.

\section{Secreted cytokines}

A panel of 14 cytokines was measured in the supernatants of PBMCs incubated for 24, 48, and 96 hours with peanut, Ara h 2, ConA, or medium alone (RPMI) for the first 5 subjects every 6 months for a period of 2 years on OIT. As expected, a more robust secretion of cytokines was measured after ConA stimulation, enabling measurement of otherwise undetectable cytokines (Fig 4). Cytokines including IL-5, IL-10, IFN- $\gamma$, and TNF- $\alpha$ significantly increased, as did the growth factor G-CSF, whereas IL-2 declined. IL-4 and IL-17 were undetectable at baseline and remained so, whereas many inflammatory mediators (IL-1 $\beta$, IL-6, IL-8, macrophage inflammatory protein [MIP] $1 \beta$, and GM-CSF) were found at saturating levels (data not shown).

After peanut stimulation, a number of inflammatory cytokines/ chemokines were significantly increased over time, including IL$1 \beta$, IL-5, TNF- $\alpha$, and MIP-1 $\beta$, as well as the growth factors GCSF and GM-CSF (Fig 5). Saturating levels of IL-6 and IL-8 prevented the delineation of a trend, and no significant change in monocyte chemotactic protein 1 was observed during immunotherapy (data not shown). After peanut stimulation, no detectable levels of secreted IL-2, IL-4, IL-10, IL-17, or IFN- $\gamma$ were measured (data not shown). Cytokine levels detected after stimulation with a single allergen, Ara h 2, were not different from those with medium alone (data not shown).

\section{FoxP3 $^{+}$regulatory $\mathrm{T}$ cells}

In 10 subjects who received peanut OIT for as long as 36 months, a subpopulation of $\mathrm{FoxP}^{+}{ }^{+} \mathrm{T}$ cells were investigated by flow cytometry in the lymphocyte gates of PBMCs incubated for 6 days with medium alone (RPMI), peanut, or Ara h 2 (Fig 6). During OIT, the number of FoxP3 T cells increased approximately 1.5 -fold in peanut-stimulated cells at 6 and 12 months $(P<.05)$ and decreased thereafter, returning to baseline levels by 20 months. Ara h 2 stimulation created a similar yet less pronounced increase.

\section{Microarray and quantitative real-time PCR analysis of patient $T$ cells}

Genome-wide oligonucleotide microarray analyses compared transcription patterns in T cells obtained from 6 unrelated subjects before starting OIT and 6 months after uncomplicated OIT. Differential expression of genes in subject samples before and 


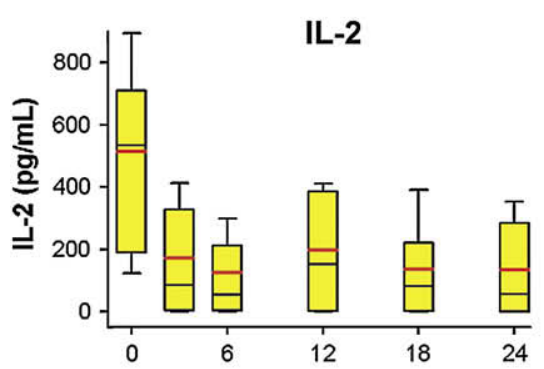

Time on immunotherapy (Month)

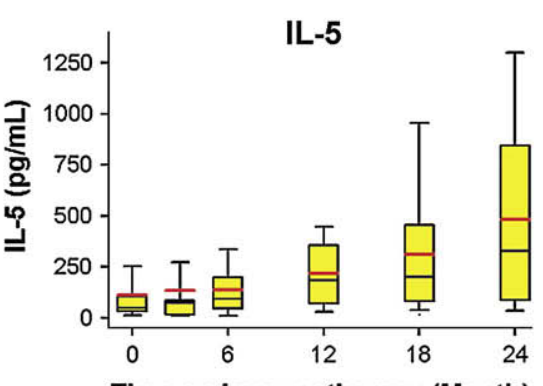

Time on immunotherapy (Month)

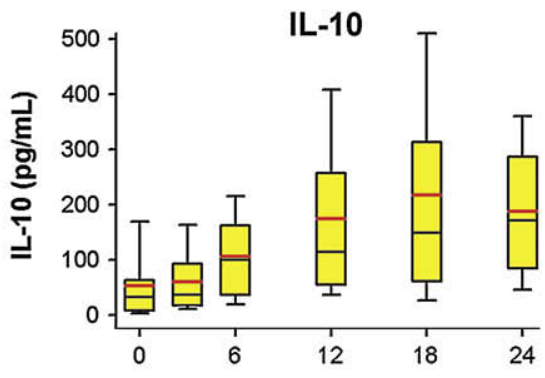

Time on immunotherapy (Month)

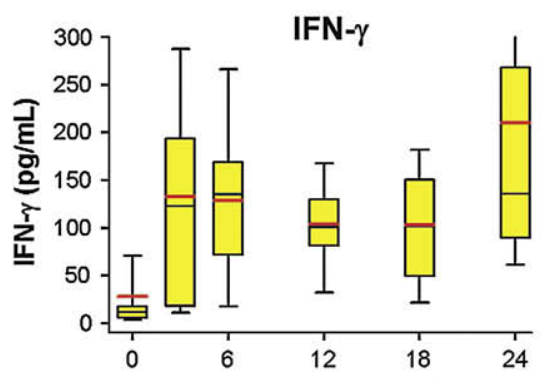

Time on immunotherapy (Month)

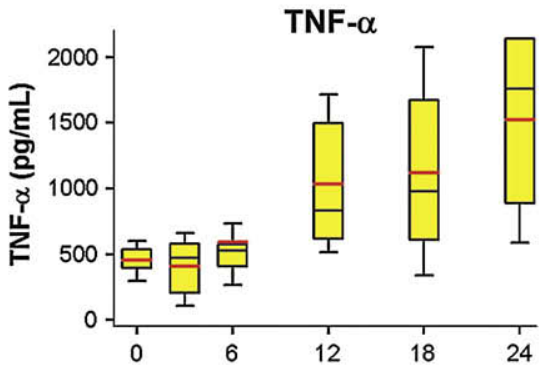

Time on immunotherapy (Month)

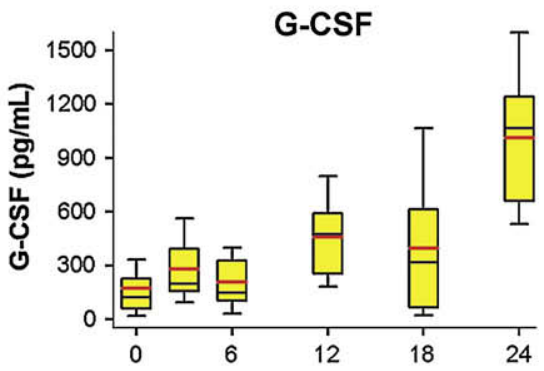

Time on immunotherapy (Month)

FIG 4. Cytokines secreted from PBMCs after ConA stimulation. The plotted 6 cytokines/chemokines all had statistically significant changes versus medium alone $(P<.05)$. Black lines are median values; red lines are means.

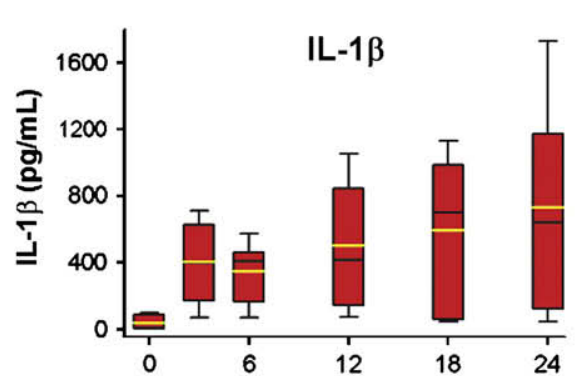

Time on immunotherapy (Month)

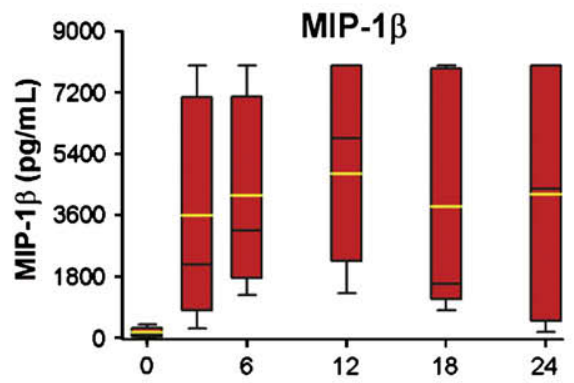

Time on immunotherapy (Month)

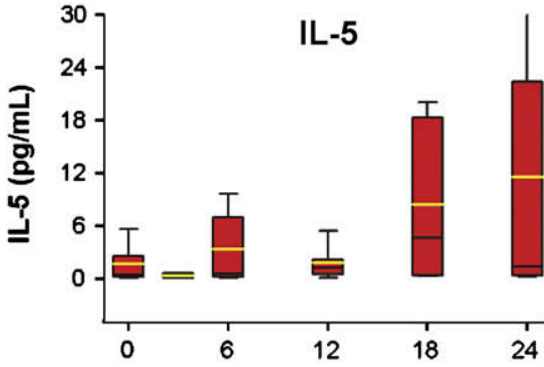

Time on immunotherapy (Month)

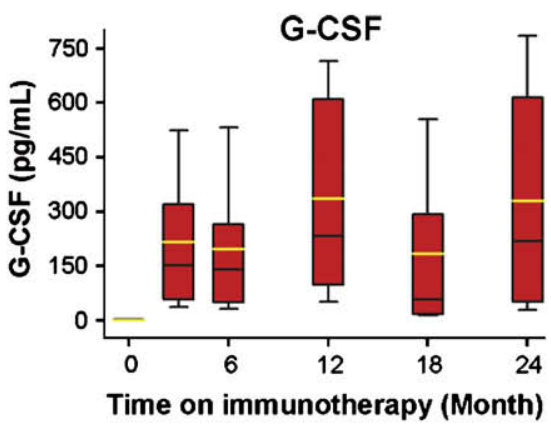

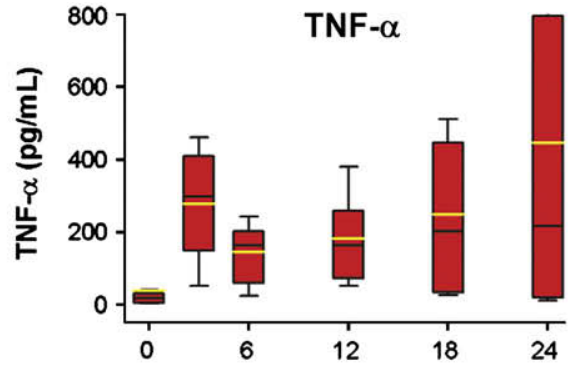

Time on immunotherapy (Month)

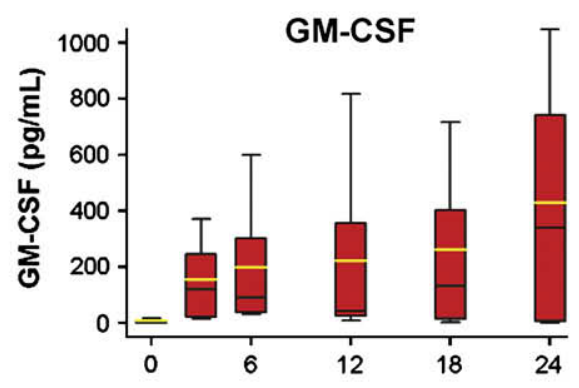

Time on immunotherapy (Month)

FIG 5. Cytokines secreted from PBMCs stimulated with crude peanut extract. The plotted 6 cytokines/chemokines all had statistically significant changes versus medium alone $(P<.05)$. Black lines are median values; yellow lines are means.

after OIT was determined by repeated-measures analysis and yielded 450 transcripts with a false discovery rate of $<7 \%$. A reduced, nonrepetitive subset of 334 genes having a well described Entrez GeneID (see this article's Table E1 in the Online Repository at www.jacionline.org) was then submitted to GeneGo, Inc, for enrichment analysis. The 3 canonical signaling and metabolic pathways most affected by OIT were all involved in apoptosis, and all differentially expressed transcripts in these pathways were downregulated after 6 months of OIT (Table II). Quantitative real-time PCR of selected samples confirmed the observed downregulation of BCL2L11, GADD45A, TNFSF8, and RELA gene expression in 3 subjects after OIT (data not shown). Further enrichment analysis of 110 cellular and molecular processes whose content is defined and mapped by GeneGo, Inc, 


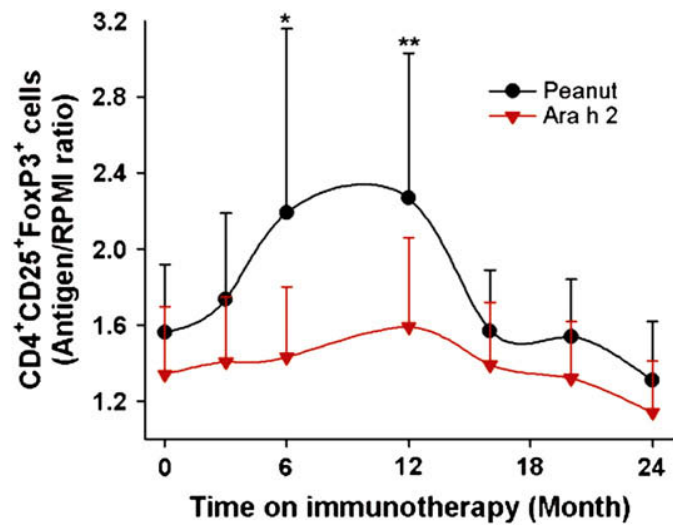

FIG 6. Changes of FoxP3 ${ }^{+}$Treg cells during peanut oral immunotherapy. PBMCs from 10 subjects were cultured in presence of peanut proteins, Ara h 2, or medium alone (RPMI). Paired $t$ tests were used to determine statistical differences between baseline and later time points $(P<.05,6$ months; $P<.01,12$ months).

with each process representing a preset network of protein interactions characteristic for the process, also demonstrated a statistically significant alteration of apoptosis networks after OIT.

\section{DISCUSSION}

In this clinical and mechanistic study, peanut OIT induced clinical desensitization in the 29 subjects with peanut allergy who completed the study. Ninety-three percent successfully completed an OFC to $3.9 \mathrm{~g}$ peanut protein, and all subjects had a significant increase in the amount of peanut they tolerated during food challenge. Peanut OIT was also safe; mild symptoms were relieved with diphenhydramine or albuterol. Our results are consistent with previous studies in which OIT led to clinical desensitization to foods such as egg and cow's milk. ${ }^{14-16,22}$ Furthermore, the humoral and cellular responses associated with peanut OIT suggest that OIT also induces the transition from short-term desensitization to longterm tolerance. For this analysis, we did not perform OFCs after cessation of therapy, when sensitivity could return. Per the protocol, these definitive challenges are planned for subjects who complete 3 years of maintenance therapy and have a significant drop in serum IgE. However, compared with previous OIT studies, our study had a longer duration of maintenance therapy, which we hypothesize has a significant impact on the immunologic parameters indicative of long-term tolerance.

In our study, titrated SPTs showed a significant decrease at 6 months and remained decreased throughout the study. Similarly, basophil activation, a measure of IgE-dependent response, decreased significantly within 4 months, and the decline continued beyond 6 months. IgE-mediated hypersensitivity responses are known to be downregulated during drug desensitization, ${ }^{23}$ and chronic FceRI signaling induces a downregulation of Syk-dependent signal transduction in vitro. ${ }^{24}$

With peanut OIT, peanut-specific $\mathrm{IgE}, \mathrm{IgG}$, and $\mathrm{IgG}_{4}$ increased by approximately 3 months, and then the IgE declined by 18 months. IgG began to decrease by the end of the study, whereas $\mathrm{IgG}_{4}$ remained elevated. Increased levels of specific $\mathrm{IgG}_{4}$ with or without decreased $\mathrm{IgE}$ have been associated with successful venom immunotherapy ${ }^{25}$ lower levels of atopy in the presence of parasite infection, ${ }^{26}$ transient rather than persistent milk allergy, ${ }^{27}$ and the apparent protective effect of high levels of cat allergen
TABLE II. Log decrease in expression of apoptosis-related genes with peanut OIT

\begin{tabular}{|c|c|c|c|}
\hline Pathway* & Gene symbol $†$ & Entrez ID $\ddagger$ & Log ratio§ \\
\hline \multirow{4}{*}{$\begin{array}{l}\text { Regulation of apoptosis } \\
\text { by mitochondrial proteins }\end{array}$} & CASP9 & 842 & -0.5298 \\
\hline & VDAC1 & 7,416 & -0.9541 \\
\hline & $B A K 1$ & 578 & -0.4894 \\
\hline & BCL2L11 & 10,018 & -1.3777 \\
\hline \multirow[t]{4}{*}{ p53-Dependent apoptosis } & $G A D D 45 A$ & 1,647 & -1.1790 \\
\hline & TP73 & 7,161 & -0.3054 \\
\hline & CASP9 & 842 & -0.5298 \\
\hline & BCL2L11 & 10,018 & -1.3777 \\
\hline \multirow{3}{*}{$\begin{array}{l}\text { Antiapoptotic } \\
\text { TNFs/NF-кB/IAP pathway }\end{array}$} & TNFSF8 & 944 & -1.0622 \\
\hline & $R E L$ & 5,966 & -1.4996 \\
\hline & RELA & 5,970 & -0.7671 \\
\hline
\end{tabular}

*Canonical apoptosis and survival signaling and metabolic pathways as defined by GeneGo, Inc.

$†$ HUGO Gene Nomenclature Database, European Molecular Biology Laboratory, European Bioinformatics Institute.

\$Entrez Gene Database, National Center for Biotechnology Information, National Institutes of Health.

$\S \log _{2}$ (expression after 6 months OIT/expression before OIT), calculated from microarray data.

exposure. ${ }^{28,29}$ Previous reports have demonstrated that fractionated $\mathrm{IgG}_{4}$ antibodies from serum of patients who received grass pollen immunotherapy inhibit IgE-FAB binding to B cells, ${ }^{30-33}$ suggesting a functional role of $\mathrm{IgG}_{4}$ in inhibiting $\mathrm{IgE}-\mathrm{FAB}$.

Traditional allergen-injection immunotherapy appears to act through downregulation of allergen-specific $\mathrm{T}_{\mathrm{H}} 2$ responses or increased $\mathrm{T}_{\mathrm{H}} 1$ responses or through the induction of Treg cells. Populations of both thymus-derived $\mathrm{CD} 25^{+}$natural $\mathrm{T}$ cells and antigen-specific $\mathrm{T}$ cells become $\mathrm{CD} 25^{+}$, express FoxP3, secrete $\mathrm{IL}-10$, and have suppressive function. $\mathrm{IL}-10^{+} \mathrm{T}$ cells are induced during venom, dust mite, birch, and grass pollen immunotherapy. ${ }^{34-36}$ In our study, FoxP3 regulatory $\mathrm{T}$ cells increased after the induction of OIT and then eventually decreased. IL-10 was significantly increased over a period of 6 to 12 months, as were a number of inflammatory cytokines/chemokines, such as IL-1 $\beta$, IL-5, TNF- $\alpha$, and MIP-1 $\beta$, and the growth factors G-CSF and GMCSF. These changes did not reflect the typical transition toward a $\mathrm{T}_{\mathrm{H}} 1$ profile that we expected. However, the early induction of regulatory $\mathrm{T}$ cells expressing FoxP3 and the associated increase in IL-10 indicate an immunologic change induced by OIT, with transition away from a $\mathrm{T}_{\mathrm{H}} 2$-type profile that was seen with both nonspecific (ConA) and antigen-specific (peanut) stimulation over time.

Our microarray data demonstrating downregulation of genes in several apoptosis pathways in patient T cells after 6 months of OIT are intriguing and may reflect involvement of programmed cell death in peanut OIT. However, it is unclear from these results whether the observed changes in total peripheral blood T-cell transcription patterns include altered apoptosis of antigen-specific $\mathrm{T}$ cells. To help clarify this point, studies are underway to compare transcript patterns before and after OIT in peanutspecific $\mathrm{T}$ cells isolated by using MHC class II/Ara h 2 peptide tetramers. The lack of treatment-related changes in expression of Treg-specific, $\mathrm{T}_{\mathrm{H}} 1$-specific, or $\mathrm{T}_{\mathrm{H}} 2$-specific genes by microarray versus by protein assays likely reflects the small number of FoxP3-producing cells and low cytokine transcription levels in unstimulated $\mathrm{CD}^{+} \mathrm{T}$ cells analyzed in microarrays. 
To our knowledge, no other oligonucleotide microarray analyses of patient T-cell transcription patterns pretreatment and posttreatment of food allergy have been reported. In 1 microarray study of PBMC transcripts in 8 subjects with allergic rhinitis, several apoptosis-related genes were underexpressed compared with control PBMCs before allergen immunotherapy. ${ }^{37} \mathrm{~A}$ small number of studies have noted increased in vitro apoptosis of stimulated peripheral blood $\mathrm{T}_{\mathrm{H}} 2$ cells after standard allergen immunotherapy in subjects with either grass pollen allergy ${ }^{38,39}$ or dust mite-sensitive asthma. ${ }^{40}$ We plan similar flow-cytometric analyses of apoptosis in patient $\mathrm{T}$ cells after in vitro stimulation with peanut antigen.

Taken together, our results suggest that OIT induces a progression toward tolerance starting with desensitization at approximately 3 months. During this time, the threshold of antigen needed to induce an allergic response changes drastically, as reflected by diminished reaction to SPTs and activation of basophils. Subsequent immunologic changes over a period of 6 to 12 months reflect a proinflammatory, rather than $\mathrm{T}_{\mathrm{H}} 2$, profile.

In our study, results of titrated SPTs; levels of allergen-specific $\mathrm{IgE}, \mathrm{IgG}$, and $\mathrm{IgG}_{4}$ over time; and $\mathrm{FAB}$ data are similar to those reported from studies of traditional subcutaneous immunotherapy. ${ }^{25,30-36}$ Our cytokine data, with a significant increase in IL10 and a number of inflammatory cytokines/chemokines, are not reflective of the typical transition toward a $\mathrm{T}_{\mathrm{H}} 1$ profile. The increase in IL-10 could support an initial increase in Treg cells, leading to tolerance, but the overall increase in the inflammatory cytokines/chemokines is not really suggestive of this expected change. The inflammatory response may result from the oral versus subcutaneous route of exposure, although exactly how is unclear. No similar studies comparing OIT and traditional subcutaneous allergy immunotherapy have been performed that might provide a context for our basophil and microarray data.

Clinical desensitization, which we defined as raising the threshold of food antigen needed to cause allergic symptoms, can provide an improved margin of safety in case of accidental food ingestion. This is an important therapeutic benefit to patients and their families. Blind, placebo-controlled studies with peanut OIT are underway now, as are studies to determine the ability of OIT to induce long-term clinical tolerance after discontinuing OIT.

We acknowledge discussions about this project with the late Larry Katz, $\mathrm{PhD}$ (formerly J. B. Duke Professor of Neurobiology and Investigator, Howard Hughes Medical Institute).

\section{Key messages}

- Peanut OIT resulted in clinical desensitization for the vast majority (27/29) of children with peanut allergy who completed more than 8 months of therapy.

- Evaluation of immunologic changes throughout peanut OIT suggests that desensitization develops by 6 months and is followed by the downregulation of the $T_{H} 2$ response to peanut. By 6 months, diminished reaction to SPTs and activation of basophils occurred. Over 6 to 12 months, secretion of IL-10, IL-5, IFN- $\gamma$, and TNF- $\alpha$ from PBMCs increased. Peanut-specific FoxP3 T cells increased until 12 months and then decreased thereafter. By 12 to 18 months, peanut-specific IgE decreased, whereas $\mathrm{IgG}_{4}$ increased.
- During peanut OIT, T-cell microarrays showed downregulation of genes in apoptotic pathways. This finding is novel and may provide insight into the mechanism of oral immunotherapy.

\section{REFERENCES}

1. Sicherer SH, Munoz-Furlong A, Sampson HA. Prevalence of peanut and tree nut allergy in the United States determined by means of a random digit dial telephone survey: a 5-year follow-up study. J Allergy Clin Immunol 2003;112:1203-7.

2. Emmett SE, Angus FJ, Fry JS, Lee PN. Perceived prevalence of peanut allergy in Great Britain and its association with other atopic conditions and with peanut allergy in other household members. Allergy 1999;54:380-5.

3. Kanny G, Moneret-Vautrin DA, Flabbee J, Beaudouin E, Morisset M, Thevenin F. Population study of food allergy in France. J Allergy Clin Immunol 2001;108:133-40.

4. Bock SA, Munoz-Furlong A, Sampson HA. Fatalities due to anaphylactic reactions to foods. J Allergy Clin Immunol 2001;107:191-3.

5. Bock SA, Munoz-Furlong A, Sampson HA. Further fatalities caused by anaphylactic reactions to food, 2001-2006. J Allergy Clin Immunol 2007;119:1016-8.

6. Sampson HA. Update on food allergy. J Allergy Clin Immunol 2004;113:805-19.

7. Joshi P, Mofidi S, Sicherer SH. Interpretation of commercial food ingredient labels by parents of food-allergic children. J Allergy Clin Immunol 2002;109:1019-21.

8. Vierk K, Falci K, Wolyniak C, Klontz KC. Recalls of foods containing undeclared allergens reported to the US Food and Drug Administration, fiscal year 1999. J Allergy Clin Immunol 2002;109:1022-6.

9. Altschul AS, Scherrer DL, Munoz-Furlong A, Sicherer SH. Manufacturing and labeling issues for commercial products: relevance to food allergy. J Allergy Clin Immunol 2001;108:468.

10. Sicherer SH, Burks AW, Sampson HA. Clinical features of acute allergic reactions to peanut and tree nuts in children. Pediatrics 1998;102:e6.

11. Till SJ, Francis JN, Nouri-Aria K, Durham SR. Mechanisms of immunotherapy. J Allergy Clin Immunol 2004;113:1025-34

12. Oppenheimer JJ, Nelson HS, Bock SA, Christensen F, Leung DY. Treatment of peanut allergy with rush immunotherapy. J Allergy Clin Immunol 1992;90:256-62.

13. Nelson HS, Lahr J, Rule R, Bock A, Leung D. Treatment of anaphylactic sensitivity to peanuts by immunotherapy with injections of aqueous peanut extract. J Allergy Clin Immunol 1997;99:744-51.

14. Patriarca G, Nucera E, Roncallo C, Pollastrini E, Bartolozzi F, De Pasquale T, et al. Oral desensitizing treatment in food allergy: clinical and immunological results. Aliment Pharmacol Ther 2003;17:459-65

15. Meglio P, Bartone E, Plantamura M, Arabito E, Giampietro PG. A protocol for oral desensitization in children with IgE-mediated cow's milk allergy. Allergy 2004;59:980-7.

16. Buchanan AD, Green TD, Jones SM, Scurlock AM, Christie L, Althage KA, et al. Egg oral immunotherapy in nonanaphylactic children with egg allergy. J Allergy Clin Immunol 2007;119:199-205.

17. United States Department of Agriculture. USDA National Nutrient Database for Standard Reference, release 21 (2002). Available at: http://ars.usda.gov/Services/ docs.htm?docid=17477. Accessed January 20, 2009.

18. McDermott RA, Porterfield HS, El Mezayen R, Burks AW, Pons L, Schlichting DG, et al. Contribution of Ara h 2 to peanut-specific, immunoglobulin E-mediated, cell activation. Clin Exp Allergy 2007;37:752-63.

19. Wanich N, Nowak-Wegrzyn A, Sampson HA, Shreffler WG. Allergen-specific basophil activation associated with clinical tolerance in patients with milk allergy. J Allergy Clin Immunol 2009;123:789-94.

20. Wilcock LK, Francis JN, Durham SR. IgE-facilitated antigen presentation: role in allergy and the influence of allergen immunotherapy. Immunol Allergy Clin North Am 2006;26:333-9.

21. Tusher VG, Tibshirani R, Chu G. Significance analysis of microarrays applied to the ionizing radiation response. Proc Natl Acad Sci U S A 2001;98:5116-21.

22. Longo G, Barbi E, Berti I, Meneghetti R, Pittalis A, Ronfani L, et al. Specific oral tolerance induction in children with very severe cow's milk-induced reactions. J Allergy Clin Immunol 2008;121:343-7.

23. Sullivan TJ. Antigen-specific desensitization of patients allergic to penicillin. J Allergy Clin Immunol 1982;69:500-8

24. MacGlashan D, Miura K. Loss of syk kinase during IgE-mediated stimulation of human basophils. J Allergy Clin Immunol 2004;114:1317-24.

25. Clements JL, Yang B, Ross-Barta SE, Eliason SL, Hrstka RF, Williamson RA, et al. Requirement for the leukocyte-specific adapter protein SLP-76 for normal T cell development. Science 1998;281:416-9.

26. Yazdanbakhsh M, van den Biggelaar A, Maizels RM. Th2 responses without atopy: immunoregulation in chronic helminth infections and reduced allergic disease. Trends Immunol 2001;22:372-7. 
27. James JA, Sampson HA. Immunologic changes associated with the development of tolerance in children with cow milk allergy. J Pediatr 1992;121:371-3.

28. Platts-Mills T, Vaughan J, Squillace S, Woodfolk J, Sporik R. Sensitisation, asthma, and a modified Th2 response in children exposed to cat allergen: a population-based cross-sectional study. Lancet 2001;357:752-6.

29. Platts-Mills TA, Vaughan JW, Blumenthal K, Pollart SS, Sporik RB. Serum IgG and IgG4 antibodies to Fel d 1 among children exposed to 20 microg Fel d 1 at home: relevance of a nonallergic modified Th2 response. Int Arch Allergy Immunol 2001;124:126-9.

30. Francis JN. The facilitated antigen binding (FAB) assay-a protocol to measure allergen-specific inhibitory antibody activity. Methods Mol Med 2008;138:255-61.

31. Klunker S, Saggar LR, Seyfert-Margolis V, Asare AL, Casale TB, Durham SR, et al. Combination treatment with omalizumab and rush immunotherapy for ragweed-induced allergic rhinitis: Inhibition of IgE-facilitated allergen binding. J Allergy Clin Immunol 2007;120:688-95.

32. Nouri-Aria KT, Wachholz PA, Francis JN, Jacobson MR, Walker SM, Wilcock LK, et al. Grass pollen immunotherapy induces mucosal and peripheral IL-10 responses and blocking IgG activity. J Immunol 2004;172:3252-9.

33. Wachholz PA, Soni NK, Till SJ, Durham SR. Inhibition of allergen-IgE binding to B cells by $\operatorname{IgG}$ antibodies after grass pollen immunotherapy. J Allergy Clin Immunol 2003;112:915-22.
34. Tighe H, Takabayashi K, Schwartz D, Van Nest G, Tuck S, Eiden JJ, et al. Conjugation of immunostimulatory DNA to the short ragweed allergen amb a 1 enhances its immunogenicity and reduces its allergenicity. J Allergy Clin Immunol 2000; 106:124-34

35. Karlsson MR, Rugtveit J, Brandtzaeg P. Allergen-responsive CD4+CD25+ regulatory T cells in children who have outgrown cow's milk allergy. J Exp Med 2004;199:1679-88.

36. Chatila TA, Blaeser F, Ho N, Lederman HM, Voulgaropoulos C, Helms C, et al. JM2, encoding a fork head-related protein, is mutated in X-linked autoimmunity-allergic disregulation syndrome. J Clin Invest 2000;106:R75-81.

37. Liu Z, Yelverton RW, Kraft B, Tanner SB, Olsen NJ, Aune TM. Highly conserved gene expression profiles in humans with allergic rhinitis altered by immunotherapy. Clin Exp Allergy 2005;35:1581-90.

38. Guerra F, Carracedo J, Madueno JA, Sanchez-Guijo P, Ramirez R. Allergens induce apoptosis in lymphocytes from atopic patients. Hum Immunol 1999;60:840-7.

39. Guerra F, Carracedo J, Solana-Lara R, Sanchez-Guijo P, Ramirez R. TH2 lymphocytes from atopic patients treated with immunotherapy undergo rapid apoptosis after culture with specific allergens. J Allergy Clin Immunol 2001;107: 647-53.

40. Tsai YG, Chien JW, Chen WL, Shieh JJ, Lin CY. Induced apoptosis of TH2 lymphocytes in asthmatic children treated with Dermatophagoides pteronyssinus immunotherapy. Pediatr Allergy Immunol 2005;16:602-8. 
$6350 / /$ transcription // inferred from electronic annotation /II 6355 // regulation of transcription, DNA-dependent // inferred from electronic annotation nucleus // inferred from electronic annotation /// 5634 // nucleus // non-traceable author statement
$6350 / /$ transcription // inferred from electronic annotation /// $6355 / /$ regulation of

transcription, DNA-dependent // non-traceable author statement /// 6355 // regulation of transcription, DNA-

dependent // inferred from electronic annotation
5622 // intracellular // inferred from electronic annotation /I/ 5634 // nucleus // non-traceable author statement /// 5634 // nucleus // inferred from electronic annotation
$3700 / /$ transcription factor activity // inferred from electronic annotation /// 3707 // steroid hormone receptor activity // inferred from electronic annotation /// 3707 // steroid hormone receptor activity // traceable author statement /// 4879 // liganddependent nuclear receptor activity // inferred from electronic annotation /// 4887 // thyroid hormone receptor activity // traceable author statement /// 5488 // binding // traceable author statement ///

8270 // zinc ion binding // inferred from electronic annotation /// 43565 // sequence-specific DNA binding // inferred from electronic annotation /// 46872 // metal ion binding // inferred from electronic annotation /// 3677 // DNA binding // inferred from electronic annotation /// 4872 // receptor activity // inferred from electronic annotation /// 3677 // DNA binding // non-traceable author statement

3677 // DNA binding // nontraceable author statement /// 8270 // zinc ion binding // nontraceable author statement /// 46872 // metal ion binding // inferred from electronic annotation /// 3676 // nucleic acid binding // inferred from electronic annotation /// $8270 / /$ zinc ion binding // inferred from electronic annotation /// 3677 // DNA binding // inferred from electronic annotation

son


$6350 / /$ transcription // inferred from electronic annotation //I 6355 // regulation of

transcription, DNA-dependent // inferred from direct assay /// $6355 / /$ regulation of

transcription, DNA-dependent

// inferred from electronic

annotation /// 6355 //

regulation of transcription,

DNA-dependent // non-

traceable author statement /I/

7165 // signal transduction //

traceable author statement

6357 // regulation of transcription 5634 // nucleus // traceable from RNA polymerase II

promoter // traceable author

statement /// 8219 // cell death

// traceable author statement //

$6355 / /$ regulation of

transcription, DNA-dependent

// inferred from electronic

annotation author statement /// 5634

nucleus // inferred from

electronic annotation
3700 // transcription factor

activity // inferred from

electronic annotation /// $5515 / /$

protein binding // inferred from

electronic annotation /// 8140 //

cAMP response element

binding protein binding // nontraceable author statement /// 43565 // sequence-specific

DNA binding // inferred from electronic annotation /// 46983 // protein dimerization activity

$/ /$ inferred from electronic annotation /// 3677 // DNA binding // inferred from

electronic annotation /// 3677 // DNA binding // non-traceable author statement

$3700 / /$ transcription factor activity // traceable author statement /// 43565 // sequence-specific DNA binding // inferred from

electronic annotation /// 46983 $/ /$ protein dimerization activity // inferred from electronic annotation /// 3677 // DNA binding // inferred from electronic annotation /// $3700 / /$ transcription factor activity // inferred from electronic annotation

D


Transducin-like enhancer of split $6355 / /$ regulation of

(E(sp1) homolog,

$$
\text { Drosophila) }
$$
204141_at
$-1.975228333$
7280
TUBB2A
tubulin, beta $2 \mathrm{~A}$

annotation
Cellular Component

Molecular Function

5634 // nucleus // traceable

transcription, DNA-dependent

// inferred from electronic

author statement /// 5634 //

$8134 / /$ transcription factor

annotation /// 7165 // signal

nucleus // inferred from

binding // inferred from direct

transduction // traceable author

statement /// 7222 // frizzled

signaling pathway // inferred

from electronic annotation /I/

7275 // development //

traceable author statement ///

9887 // organ morphogenesis //

traceable author statement /I/

16481 // negative regulation of

transcription // inferred from

direct assay /// 30178 //

negative regulation of $\mathrm{Wn}$

receptor signaling pathway //

non-traceable author statement

/// 6350 // transcription //

inferred from electronic

annotation /// 16055 // Wnt

receptor signaling pathway //

inferred from electronic

annotation /// 45449 //

regulation of transcription //

inferred from electronic

7018 // microtubule-based movement // inferred from

electronic annotation /// 51258

// protein polymerization //

inferred from electronic

annotation assay /// 5515 // protein

binding // inferred from

physical interaction activity // inferred from
5737 // cytoplasm // inferred from electronic annotation /// 5856 // cytoskeleton // not recorded /// 5874 // microtubule // inferred from electronic annotation //

$43234 / /$ protein complex // inferred from electronic annotation
166 // nucleotide binding // inferred from electronic annotation /// 3924 // GTPase electronic annotation /// 5198 // structural molecule activity // inferred from electronic annotation /// 5200 // structural constituent of cytoskeleton /I not recorded /// 5525 // GTP binding // inferred from

electronic annotation 
6629 // lipid metabolism // traceable author statement /II 8152 // metabolism // inferred from electronic annotation /I/ 16126 // sterol biosynthesis // inferred from electronic annotation /// 6694 // steroid biosynthesis // inferred from electronic annotation /// $8610 / /$

lipid biosynthesis // inferred from electronic annotation

$\begin{array}{llccc}\text { 224836_at } & -1.8171125 & 58476 & \text { TP53INP2 } & \begin{array}{c}\text { tumor protein p53 inducible } \\ \text { nuclear protein } 2\end{array} \\ \text { 200730_s_at } & -1.794823667 & 7803 & \text { PTP4A1 } & \begin{array}{c}\text { protein tyrosine phosphatase type } \\ \text { IVA, member } 1\end{array}\end{array}$

$6470 / /$ protein amino acid dephosphorylation // inferred from electronic annotation /I/ 7049 // cell cycle // inferred from electronic annotation /// 7275 // development // inferred from electronic annotation

$6350 / /$ transcription // inferred from electronic annotation /I/ $6355 / /$ regulation of transcription, DNA-dependent // inferred from electronic annotation
5783 // endoplasmic reticulum // 248 // C-5 sterol desaturase inferred from electronic annotation /I/ 16020 // membrane // inferred from electronic annotation /// 16021 // integral to membrane // inferred from electronic annotation

5634 // nucleus // inferred from electronic annotation

5783 // endoplasmic reticulum // 4725 // protein tyrosine inferred from electronic annotation /// 16020 // membrane // inferred from electronic annotation

5622 // intracellular // inferred from electronic annotation /// 5634 // nucleus // inferred from electronic annotation ctivity // traceable author statement /// 3824 // catalytic activity // inferred from electronic annotation /// $5506 / /$ ron ion binding // inferred from electronic annotation /II $16491 / /$ oxidoreductase activity // inferred from electronic annotation

phosphatase activity // inferred from electronic annotation III 16787 // hydrolase activity // inferred from electronic annotation /// 4721 // phosphoprotein phosphatase activity // inferred from electronic annotation

3677 // DNA binding // inferred from electronic annotation /II 8270 // zinc ion binding // inferred from electronic annotation /// 46872 // metal ion binding // inferred from electronic annotation /// $3676 / /$ nucleic acid binding // inferred from electronic annotation 
statement /// 8643 //

carbohydrate transport

inferred from electronic

annotation /// 15758 // glucose

transport // traceable author

statement /// 6810 // transport //

inferred from electronic

annotation /// 7275 //

development // inferred from

electronic annotation /// $7283 / /$

spermatogenesis // inferred

from electronic annotation /II

30154 // cell differentiation //

inferred from electronic

annotation

210837_s_at $\quad-1.738381167 \quad 5144 \quad$ PDE4D

Phosphodiesterase 4D, cAMPspecific (phosphodiesterase E dunce homolog, Drosophila)
7165 // signal transduction // inferred from electronic annotation
$5625 / /$ soluble fraction // traceable author statement /// $5626 / /$ insoluble fraction //

traceable author statement to membrane // inferred from

electronic annotation /// 16021

// integral to membrane // not

recorded
4114 // 3',5'-cyclic-nucleotide phosphodiesterase activity // non-traceable author statement /// 4115 // 3',5'-cyclic-AMP phosphodiesterase activity // traceable author statement // 16787 // hydrolase activity // inferred from electronic annotation /// 46872 // metal ion binding // inferred from electronic annotation /// $4114 / /$ 3',5'-cyclic-nucleotide phosphodiesterase activity // inferred from electronic annotation /// 3824 // catalytic activity // inferred from electronic annotation 3998 // acylphosphatase activity $/ /$ inferred from electronic annotation 
metabolism // inferred from

electronic annotation /// 6003 //

ructose 2,6-bisphosphate

metabolism // non-traceable

author statement /// 8152 //

metabolism // inferred from

electronic annotation

\begin{abstract}
221140_s_at $\quad-1.718265667$
\end{abstract}
29933

GPR132

G protein-coupled receptor 132

inferred from electronic

coupled receptor protein

signaling pathway // inferred

from electronic annotation
16020 // membrane // inferred from electronic annotation $/ I /$ $16021 / /$ integral to membrane // inferred from electronic annotation
166 // nucleotide binding //

inferred from electronic

annotation /// 3824 // catalytic

activity // inferred from

electronic annotation /// $3873 / /$

6-phosphofructo-2-kinase

activity // inferred from

electronic annotation /// $3873 / /$

6-phosphofructo-2-kinase

activity // non-traceable author

statement /// 4331 // fructose-

2,6-bisphosphate 2-

phosphatase activity // inferred

from electronic annotation III

$4331 / /$ fructose-2,6-

bisphosphate 2-phosphatase

activity // non-traceable author

statement /// 5524 // ATP

binding // inferred from

electronic annotation /// 1630

// kinase activity // inferred

from electronic annotation //I

16740 // transferase activity //

inferred from electronic

annotation /// 16787 //

hydrolase activity // inferred

from electronic annotation III

42802 // identical protein

binding // inferred from

physical interaction

1584 // rhodopsin-like receptor activity // inferred from

electronic annotation /// $4872 / /$

receptor activity // inferred

from electronic annotation /II

$4871 / /$ signal transducer

activity // inferred from

electronic annotation /// 4930 //

G-protein coupled receptor

activity // inferred from

electronic annotation 
Gene Ontology

dunce homolog, Drosophila)

7165 // signal transduction //

inferred from electronic

annotation

$\begin{array}{clccc}\text { 221704_s_at } & -1.601305 & 79720 & \text { VPS37B } & \begin{array}{l}\text { vacuolar protein sorting 37 } \\ \text { homolog B (S. cerevisiae) I/I } \\ \end{array} \\ & & & \begin{array}{l}\text { vacuolar protein sorting 37 } \\ \text { homolog B (S. cerevisiae) }\end{array} \\ \text { 213452_at } & -1.599954833 & 7738 & \text { ZNF184 } & \text { zinc finger protein 184 }\end{array}$

$6355 / /$ regulation of transcription, DNA-dependent

// inferred from electronic annotation /// 6350 // transcription // inferred from electronic annotation /// 6355 // regulation of transcription,

DNA-dependent // non-

traceable author statement
5625 // soluble fraction //

traceable author statement //I

5626 // insoluble fraction //

traceable author statement

Molecular Function

3824 // catalytic activity //

inferred from electronic

annotation /// 4114 // 3, 5'

cyclic-nucleotide

phosphodiesterase activity //

inferred from electronic

annotation /// 4115 // 3', 5' -

cyclic-AMP phosphodiesterase activity // traceable author

statement /// 16787 // hydrolase activity // inferred from

electronic annotation

$$
\text { - }
$$

5622 // intracellular // inferred from electronic annotation /II

5634 // nucleus // inferred from electronic annotation /// 5634 // nucleus // non-traceable author statement

(2)

\section{6 // nucleic acid binding //} inferred from electronic annotation /// 8270 // zinc ion binding // inferred from electronic annotation /// 46872 // metal ion binding // inferred from electronic annotation /// 3677 // DNA binding //

inferred from electronic annotation /// 3677 // DNA binding // non-traceable author statement /// 8270 // zinc ion binding // non-traceable author statement 
regulatory protein

promoter // inferred from

equence or structural

similarity

similarity /// 6917 // induction

or structural similarity ///

or structural similarity /I/

inferred from sequence 
nuclear factor, interleukin 3 regulated

$6355 / /$ regulation of transcription, DNA-dependent // inferred from electronic annotation /// 6366 //

transcription from RNA polymerase II promoter // traceable author statement /// 6955 // immune response // traceable author statement

6350_s_at $\quad-1.567034667 \quad 7556$

ZNF10

zinc finger protein 10

$\begin{array}{cccc}\text { 208868_s_at } & -1.533629833 \quad 23710 \quad \text { GABARAPL1 } & \begin{array}{c}\text { GABA(A) receptor-associated } \\ \text { protein like } 1\end{array}\end{array}$

//

\section{6}

$6605 / /$ protein targeting // inferred from sequence or structural similarity /// 7268 // synaptic transmission // inferred from sequence or structural similarity
6350 // transcription // inferred from electronic annotation // 6355 // regulation of

transcription, DNA-dependent // inferred from electronic annotation

(in
uthor statement /// 5634 nucleus // inferred from electronic annotation
5776 // autophagic vacuole // inferred from direct assay /I/ 5874 // microtubule // inferred from electronic annotation /II 5886 // plasma membrane // inferred from sequence or structural similarity

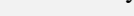

Molecular Function

3700 // transcription factor activity // traceable author statement /// 3714 // transcription corepressor activity // traceable author statement /// 43565 // sequence-specific DNA binding // inferred from electronic annotation /// 46983 // protein dimerization activity // inferred from electronic annotation /// 3677 // DNA binding // inferred from electronic annotation /// $3700 / /$ transcription factor activity // inferred from electronic annotation /// 3677 // DNA binding // traceable author statement

5622 // intracellular // inferred from electronic annotation /// electronic annotation
3677 // DNA binding // inferred from electronic annotation /// 8270 // zinc ion binding // inferred from electronic annotation /// 46872 // metal ion binding // inferred from electronic annotation /// $3676 / /$ nucleic acid binding // inferred from electronic annotation

$5515 / /$ protein binding // inferred from physical interaction /// inferred from sequence or structural similarity /// 48487 // beta-tubulin binding // inferred from sequence or structural similarity /// 50811 // GABA receptor binding // inferred from sequence or structural similarity 5515 // protein binding // 
1501 // skeletal development // traceable author statement // 6817 // phosphate transport // inferred from electronic annotation /// 7605 // sensory perception of sound // inferred from electronic annotation //I 8544 // epidermis development // traceable author statement

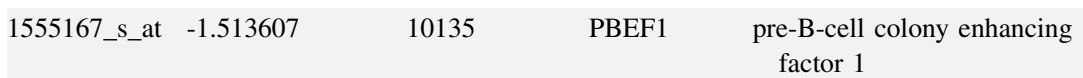

factor 1

// signal transduction //

traceable author statement /II 7267 // cell-cell signaling // 8284 // positive regulation of cell proliferation // traceable author statement /// 19363 // pyridine nucleotide biosynthesis // inferred from electronic annotation

\section{$6355 / /$ regulation of}

-rel reticuloendotheliosis viral oncogene homolog (avian) traceable author statement /// transcription, DNA-dependent

// inferred from electronic

annotation /// 6366 //

transcription from RNA

polymerase II promoter // not recorded /// 43123 // positive regulation of I-kappaB kinase/ NF-kappaB cascade // inferred from expression pattern //I $6350 / /$ transcription // inferred from electronic annotation /II 45449 // regulation of transcription // inferred from electronic annotation
$5581 / /$ collagen // inferred from 5201// extracellular matrix lectronic annotation /// $5584 / /$ collagen type I // not recorded // 5737 // cytoplasm // inferre from electronic annotation /I/ $5578 / /$ extracellular matrix (sensu Metazoa) // inferred from electronic annotation inferred from electronic annotation /// 8147 // structural constituent of bone // not recorded /// 5198 // structural molecule activity // inferred from electronic annotation

$4516 / /$ nicotinate phosphoribosyltransferase activity // inferred from electronic annotation /// 5125 // cytokine activity // traceable author statement /// 16757 // transferase activity,

ransferring glycosyl groups // inferred from electronic annotation /// 47280 // nicotinamide phosphoribosyltransferase activity // inferred from electronic annotation /// 16740 // transferase activity // inferred from electronic annotation

5634 // nucleus // inferred from electronic annotation $3700 / /$ transcription factor activity // non-traceable author statement /// 4871 // signal transducer activity // inferred from expression pattern /// 3677 // DNA binding // inferred from electronic annotation /// 3700 // transcription factor activity /I inferred from electronic annotation 
222846 at

$-1.454860833$

RAB8B

RAB8

RAB8B,
family

1553267_a_at -1.421095833

246175

CNOT6L

CCR4-NOT transcription complex, subunit 6-like

218273_s_at $-1.3857885 \quad 54704 \quad$ PPM2C protein phosphatase 2C,

magnesium-dependent,

catalytic subunit

Biological Process

Cellular Component

Molecular Function

transcription, DNA-dependen

// inferred from electronic

annotation /// 7264 // small

GTPase mediated signal

transduction // inferred from

electronic annotation /// 15031

// protein transport // non-

traceable author statement ///

$15031 / /$ protein transport //

inferred from electronic

annotation /// 6810 // transport

// inferred from electronic

annotation

16311 // dephosphorylation // inferred from sequence or structural similarity /// 6470 // protein amino acid

dephosphorylation // inferred from electronic annotation
5622 // intracellular // inferred

from electronic annotation /II

16020 // membrane // inferred

from electronic annotation

166 // nucleotide binding //

inferred from electronic

annotation /// 3924 // GTPase activity // non-traceable author statement /// 5524 // ATP binding // inferred from electronic annotation /// $5525 / /$ GTP binding // inferred from electronic annotation /// 8134 // transcription factor binding // inferred from electronic annotation

5739 // mitochondrion // inferred 287 // magnesium ion binding // from sequence or structural similarity /// 8287 // protein serine/threonine phosphatase complex // inferred from electronic annotation /// 5739 // mitochondrion // inferred from electronic annotation inferred from sequence or

structural similarity /// 5509 // calcium ion binding // inferred from sequence or structural similarity /// 3824 // catalytic activity // inferred from

electronic annotation /// $4722 / /$ protein serine/threonine phosphatase activity // inferred from electronic annotation /II 287 // magnesium ion binding // inferred from electronic annotation /// $4721 / /$ phosphoprotein phosphatase activity // inferred from

electronic annotation /// 4741 // [pyruvate dehydrogenase (lipoamide)] phosphatase activity // inferred from electronic annotation /// $5509 / /$ calcium ion binding // inferred from electronic annotation III 16787 // hydrolase activity // inferred from electronic annotation /// 46872 // metal ion binding // inferred from electronic annotation 
$6511 / /$ ubiquitin-dependent protein catabolism // inferred from electronic annotation /// 6512 // ubiquitin cycle inferred from electronic annotation

\section{BCL2-like 11 (apoptosis} facilitator)

\section{0_s_at $\quad-1.371434333$}

8507

ENC1

ectodermal-neural cortex

(with BTB-like domain)

219312_s_at $-1.365253167 \quad 65986 \quad$ ZBTB10 $\begin{gathered}\text { zinc finger and BTB domain } \\ \text { containing } 10\end{gathered}$

$6350 / /$ transcription // inferred
6915 // apoptosis // inferred from 5624 // membrane fraction // electronic annotation /// 6917 // induction of apoptosis // traceable author statement //I 43065 // positive regulation of apoptosis // inferred from electronic annotation

7275 // development // traceable author statement /// 7399 // nervous system development // traceable author statement /// 7275 // development // inferred from electronic annotation from electronic annotation //I $6355 / /$ regulation of

transcription, DNA-dependent // inferred from electronic annotation
5634 // nucleus // inferred from electronic annotation

traceable author statement // 16020 // membrane // inferred from electronic annotation

5634 // nucleus // traceable author statement /// 5856 // cytoskeleton // inferred from electronic annotation

5622 // intracellular // inferred from electronic annotation /II 5634 // nucleus // inferred from electronic annotation

\section{7 // cysteine-type}

endopeptidase activity // inferred from electronic annotation /// 4221 // ubiquitin thiolesterase activity // inferred from electronic annotation /// 16787 // hydrolase activity // inferred from electronic annotation /// 8233 // peptidase activity // inferred from electronic annotation /// 8234 // cysteine-type peptidase activity // inferred from electronic annotation

$5515 / /$ protein binding // inferred from physical interaction

3779 // actin binding // inferred from electronic annotation /// 5515 // protein binding // inferred from electronic annotation

3677 // DNA binding // inferred from electronic annotation /II 5515 // protein binding // inferred from electronic annotation /// 8270 // zinc ion binding // inferred from electronic annotation /// 46872 // metal ion binding // inferred from electronic annotation III 3676 // nucleic acid binding // inferred from electronic annotation 


\section{6-pyruvoyltetrahydropterin} synthase
6559 // L-phenylalanine

catabolism // inferred from

electronic annotation /// 6729 //

tetrahydrobiopterin

biosynthesis // traceable author statement /// 7417 // central

nervous system development // traceable author statement /II $6729 / /$ tetrahydrobiopterin biosynthesis // inferred from

$\begin{array}{lllll}\text { 225539_at } & -1.347026 & 49854 & \text { ZNF295 } & \text { zinc finger protein } 295 \\ & & & \\ & & & & \\ \text { 202684_s_at } & -1.341559167 & 8731 & \text { RNMT } & \begin{array}{r}\text { RNA (guanine-7-) } \\ \text { methyltransferase }\end{array}\end{array}$

electronic annotation

$6350 / /$ transcription // inferred from electronic annotation /I/ 6355 // regulation of transcription, DNA-dependent // inferred from electronic annotation

6370 // mRNA capping // inferred 5634 // nucleus // traceable from electronic annotation //I 6370 // mRNA capping //

traceable author statement electronic annotation
Molecular Function

3874 // 6

pyruvoyltetrahydropterin synthase activity // traceable author statement /// $8270 / /$ zinc ion binding // inferred

from electronic annotation /II 16829 // lyase activity // inferred from electronic annotation /// 42802 // identical protein binding // inferred from physical interaction /// $46872 / /$ metal ion binding // inferred from electronic annotation /II 3874 // 6-

pyruvoyltetrahydropterin synthase activity // inferred from electronic annotation

5622 // intracellular // inferred from electronic annotation /II 5634 // nucleus // inferred from

NA binding // inferred from electronic annotation /II 5515 // protein binding // inferred from electronic annotation /// 8270 // zinc ion binding // inferred from electronic annotation /// 46872 // metal ion binding // inferred from electronic annotation /// 3676 // nucleic acid binding // inferred from electronic annotation

3723 // RNA binding // traceable author statement /// 4482 // mRNA (guanine-N7-

)-methyltransferase activity // traceable author statement /II 8168 // methyltransferase activity // inferred from electronic annotation /// 16740 // transferase activity // inferred from electronic annotation 


\begin{tabular}{|c|c|c|c|c|c|c|c|}
\hline Probe Set ID & Log Ratio & Entrez Gene & Gene Symbol & Gene Descriptor & Biological Process & Cellular Component & Molecular Function \\
\hline 210001_s_at & -1.340937 & 8651 & SOCS1 & $\begin{array}{l}\text { suppressor of cytokine } \\
\text { signaling } 1\end{array}$ & $\begin{array}{l}1558 \text { // regulation of cell growth } \\
\text { // inferred from electronic } \\
\text { annotation /// } 1932 \text { // } \\
\text { regulation of protein amino } \\
\text { acid phosphorylation // } \\
\text { inferred from sequence or } \\
\text { structural similarity /// } 6512 \text { // } \\
\text { ubiquitin cycle // inferred from } \\
\text { electronic annotation /// } 7242 \text { // } \\
\text { intracellular signaling cascade } \\
\text { // inferred from electronic } \\
\text { annotation /// 7259 // JAK- } \\
\text { STAT cascade // traceable } \\
\text { author statement /// 19221 // } \\
\text { cytokine and chemokine } \\
\text { mediated signaling pathway // } \\
\text { inferred from sequence or } \\
\text { structural similarity /// 42518 // } \\
\text { negative regulation of tyrosine } \\
\text { phosphorylation of Stat3 } \\
\text { protein // inferred from } \\
\text { sequence or structural } \\
\text { similarity /// 46426 // negative } \\
\text { regulation of JAK-STAT } \\
\text { cascade // inferred from } \\
\text { sequence or structural } \\
\text { similarity /// } 46426 \text { // negative } \\
\text { regulation of JAK-STAT } \\
\text { cascade // non-traceable author } \\
\text { statement /// } 46627 / / \text { negative } \\
\text { regulation of insulin receptor } \\
\text { signaling pathway // inferred } \\
\text { from sequence or structural } \\
\text { similarity /// 9968 // negative } \\
\text { regulation of signal } \\
\text { transduction // inferred from el }\end{array}$ & $\begin{array}{l}5737 / / \text { cytoplasm // traceable } \\
\text { author statement }\end{array}$ & $\begin{array}{l}4860 \text { // protein kinase inhibitor } \\
\text { activity // traceable author } \\
\text { statement /// } 5159 \text { // insulin- } \\
\text { like growth factor receptor } \\
\text { binding // inferred from } \\
\text { physical interaction /// } 19901 / / \\
\text { protein kinase binding // } \\
\text { inferred from physical } \\
\text { interaction /// } 19210 / / \text { kinase } \\
\text { inhibitor activity // inferred } \\
\text { from sequence or structural } \\
\text { similarity }\end{array}$ \\
\hline
\end{tabular}


6631 // fatty acid metabolism // 5622 // intracellular // inferred inferred from sequence or from sequence or structural structural similarity /// $6631 / /$ fatty acid metabolism // inferred from direct assay /// 6629 // lipid metabolism // inferred from electronic annotation similarity /// 5624 // membrane fraction // inferred from sequence or structural similarity /// 5778 // peroxisomal membrane // inferred from sequence or structural similarity /// 5622 // intra

$\begin{array}{ccccc}\text { 228536_at } & -1.328323 & 90826 & \text { LOC90826 } & \text { hypothetical protein BC004337 } \\ \text { 208881_x_at } & -1.326290667 & 3422 & \text { IDI1 } & \begin{array}{c}\text { isopentenyl-diphosphate delta } \\ \text { isomerase } 1\end{array}\end{array}$

213138_at $-1.325532333 \quad 10865 \quad$ ARID5A $\quad \begin{gathered}\text { AT rich interactive domain 5A } \\ \text { (MRF1-like) }\end{gathered}$
isomerase 1

\section{$6695 / /$ cholesterol biosynthesi $/ /$ inferred from electronic} annotation /// 8299 // isoprenoid biosynthesis // traceable author statement /I/ 16117 // carotenoid

biosynthesis // inferred from electronic annotation /// 6694 // steroid biosynthesis // inferred from electronic annotation /// 8299 // isoprenoid biosynthesis // inferred from electronic annotation /// 8610 // lipid

biosynthesis // inferred from electronic annotation /// 16126 // sterol biosynthesis // inferred from electronic annotation

45892 // negative regulation of transcription, DNA-dependent // traceable author statement
5777 // peroxisome // traceable author statement /// 5777 // electronic annotation

5622 // intracellular // inferred from electronic annotation /// 5634 // nucleus // Unknown peroxisome // inferred from
5524 // ATP binding // inferred from sequence or structural similarity /// 47499 // calciumindependent phospholipase A2 activity // inferred from sequence or structural similarity /// 47499 // calciumindependent phospholipase A2 activity // inferred from direct assay /// 5488 // binding // inferred from electronic annotation /// 5524 // ATP

binding // non-traceable author statement

$8168 / /$ methyltransferase activity // inferred from electronic annotation /// 16740 // transferase activity // inferred from electronic annotation

287 // magnesium ion binding // inferred from electronic annotation /// 4452 // isopentenyl-diphosphate deltaisomerase activity // traceable author statement /// 16853 // isomerase activity // inferred from electronic annotation /// 4452 // isopentenyldiphosphate delta-isomerase activity // inferred from electronic annotation

3677 // DNA binding // inferred from electronic annotation /II 3677 // DNA binding //

traceable author statement /// 16564 // transcriptional repressor activity // traceable author statement 
Probe Set ID Log Ratio Entrez Gene Gene Symbol

219015 s at $\quad-1.324439667 \quad 55849$

GLT28D1

Gene Descriptor

glycosyltransferase 28 domain containing 1

\section{$218013 x$ at -1.301145167}

DCTN4

dynactin 4 (p62)

217127_at $\quad-1.297697167$

1491

$\mathrm{CTH}$

cystathionase (cystathionine gamma-lyase)
Biological Process

Cellular Component

5975 // carbohydrate metabolism

$/ /$ inferred from electronic

annotation /// 30259 // lipid

glycosylation // inferred from

electronic annotation

Molecular Function

16740 // transferase activity //

inferred from electronic

annotation /// 16758 //

ransferase activity,

transferring hexosyl groups //

inferred from electronic

annotation /// 30246 //

carbohydrate binding //

inferred from electronic

annotation

534 // nucleus // traceable

author statement /// 5737 //

cytoplasm // traceable author

statement /// 5813 //

centrosome // traceable author statement /// 5856 //

cytoskeleton // inferred from

electronic annotation /// 5869 //

dynactin complex // not reco

652 // amino acid biosynthesis //

inferred from electronic

annotation /// 19344 // cysteine

biosynthesis // inferred from

electronic annotation /// 6520 //

amino acid metabolism //

inferred from electronic

annotation /// 6534 // cysteine

metabolism // traceable author

statement \begin{tabular}{l} 
/23 // cystathionine gamma- \\
lyase activity // inferred from \\
electronic annotation /// 16829 \\
// lyase activity // inferred from \\
electronic annotation \\
\hline
\end{tabular}

(Continued)

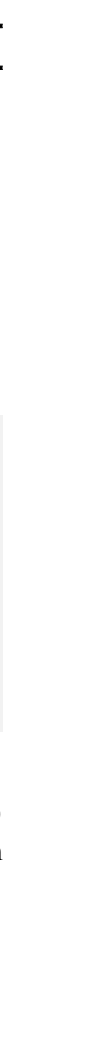


$6468 / /$ protein amino acid

phosphorylation // inferre

from electronic annotation /I/

7242 // intracellular signaling

cascade // inferred from

electronic annotation /// 6464 //

protein modification //

traceable author statement
166 // nucleotide binding // inferred from electronic annotation /// 4713 // proteintyrosine kinase activity // traceable author statement /II $5515 / /$ protein binding // inferred from physical

interaction /// 5524 // ATP binding // inferred from electronic annotation /// 16740 // transferase activity // inferred from electronic annotation /II 4672 // protein kinase activity $/ /$ inferred from electronic annotation /// 4713 // proteintyrosine kinase activity // inferred from electronic annotation /// 16301 // kinase activity // inferred from electronic annotation 
(sensu Mammalia) // inferred from sequence or structural similarity /// 1709 // cell fate determination // non-traceable author statement /// 7154 // cell communication // inferred from electronic annotation /I/ 7219 // Notch signaling pathway // non-traceable author statement /// 7399 // nervous system development // inferred from sequence or structural similarity /// $9887 / /$ organ morphogenesis // inferred from sequence or structural similarity /// 9912 // auditory receptor cell fate commitment // inferred from sequence or structural similarity /// 30097 // hemopoiesis // non-traceable author statement /// 30154 // cell differentiation // traceable author statement /// 30155 // regulation of cell adhesion // traceable author statement /II 42472 // inner ear morphogenesis // inferred from sequence or structural similarity /// 42475 // odontogenesis (sensu Vertebrata) // inferred from sequence or structural similarity /// 7219 // Notch signaling pathway // inferred from electroni
SRY (sex determining region Y)box 4 non-traceable author statemen // 5887 // integral to plasma membrane // non-traceable author statement //I 160 membrane // inferred from electronic annotation /// 1602

// integral to membrane // inferred from electr from physical interaction // 5509 // calcium ion binding // inferred from electronic annotation

$$
\text { (n) }
$$

5634 // nucleus // inferred from electronic annotation

from electrc $6355 / /$ regulation of transcription, DNA-dependent // inferred from electronic annotation

$$
\text { - }
$$

(1)

$3700 / /$ transcription factor activity // traceable author statement /// 3677 // DNA binding // inferred from electronic annotation

1784 // phosphotyrosine binding // inferred from direct assay 
solute carrier family 5 (sodiumdependent vitamin transporter), member 6

\section{2_at $-1.252561833 \quad 27076 \quad$ LYPD3 LY6/PLAUR domain containing}

204093_at $\quad-1.229745$

$\mathrm{CCNH}$

cyclin $\mathrm{H}$
81689
HBLD2

\section{Biological Process}

$6811 / /$ ion transport // inferred from electronic annotation /I/ 6814 // sodium ion transport // inferred from electronic annotation /// 6810 // transport $/ /$ inferred from electronic annotation /// 6810 // transport // traceable author statement

\section{9 // regulation of cyclin-} dependent protein kinase activity // not recorded /// 628 // DNA repair // not recorded /// 6350 // transcription // inferred from electronic annotation /// 6355 // regulation of transcription, DNA-dependent // inferred from electronic annotation /II 7049 // cell cycle // inferred from electronic annotation /II 74 // regulation of progression through cell cycle // inferred from electronic annotation

EESB like domain containing 2 /// HESB like domain containing 2
5624 // membrane fraction // traceable author statement /I/ 5887 // integral to plasma membrane // traceable author statement /// 16020 // membrane // inferred from electronic annotation /// 16021 // integral to membrane // inferred from electronic annota

16020 // membrane // inferred from electronic annotation /I/ 46658 // anchored to plasma membrane // traceable autho statement

5634 // nucleus // traceable author statement /// 5634 // nucleus // inferred from electronic annotation
5634 // nucleus // inferred from electronic annotation
5215 // transporter activity // inferred from electronic annotation /// 8523 // sodiumdependent multivitamin

transporter activity // traceable author statement /// 15293 // symporter activity // inferred from electronic annotation /II 31402 // sodium ion binding // inferred from electronic

annotation

48503 // GPI anchor binding // inferred from electronic annotation 221712_s_at $-1.224328167 \quad 54663 \quad$ WDR74 $\quad$ WD repeat domain 74 /// WD repeat domain 74 inferred from electronic annotation /// 46872 // metal ion binding // inferred from electronic annotation /// 51536 // iron-sulfur cluster binding // inferred from electronic annotation $-$ 
inferred from electronic

annotation /// 5792 //

microsome // traceable author annotation /// 5524 // ATP

statement /// $5792 / /$

binding // inferred from

microsome // inferred from

electronic annotation

$\begin{array}{lllll}\text { 206976_s_at } & -1.222607 & 10808 & \text { HSPH1 } & \begin{array}{l}\text { heat shock } 105 \mathrm{kDa} / 110 \mathrm{kDa} \\ \text { protein } 1\end{array} \\ \text { 204472_at } & -1.218162667 & 2669 & \text { GEM } & \begin{array}{l}\text { GTP binding protein } \\ \text { overexpressed in skeletal } \\ \text { muscle }\end{array}\end{array}$
author statement
6457 // protein folding // inferred from electronic annotation /// $6986 / /$ response to unfolded

protein // traceable author

statement /// 6986 // response

to unfolded protein // inferred

from electronic annotation

6955 // immune response //

traceable author statement ///

$7166 / /$ cell surface receptor

linked signal transduction //

traceable author statement ///

7264 // small GTPase mediated

signal transduction // inferred

from electronic annotation //

7165 // signal transduction //

traceable author statement
(I cytoplasm // traceable

16020 // membrane // inferred

from electronic annotation

166 // nucleotide binding // inferred from electronic annotation /// 5516 //

calmodulin binding // inferred from electronic annotation /// 5525 // GTP binding //

traceable author statement // 5515 // protein binding // inferred from physical interaction /// 5525 // GTP binding // inferred from electronic annotation 

cell cycle // traceable author statement /// 184 // mRNA catabolism, nonsense-mediated decay // traceable author statement /// 6412 // protein biosynthesis // inferred from electronic annotation /// 82 G1/S transition of mitotic cell cycle // inferred from sequence or structural similarity /// 184 // mRNA catabolism, nonsensemediated decay // inferred

from sequence or structural similarity

serum/glucocorticoid regulated kinase
$6468 / /$ protein amino acid phosphorylation // inferred from electronic annotation /II $6468 / /$ protein amino acid phosphorylation // traceable author statement /// 6814 // sodium ion transport // traceable author statement /// 6915 // apoptosis // inferred from electronic annotation /I/ 6950 // response to stress // traceable author statement
5622 // intracellular // nontraceable author statement //I

166 // nucleotide binding // 5622 // intracellular // inferred from sequence or structural similarity

\section{4 // nucleus // inferred from} electronic annotation

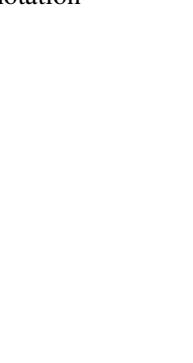
// inferred from electronic inferred from electronic annotation /// 3747 // translation release factor activity // inferred from mutan phenotype /// 3924 // GTPase activity // traceable author statement /// 5515 // protein binding // inferred from physical interaction /// 5525 //

GTP binding // inferred from electronic annotation /// 3747 // translation release factor activity // inferred from sequence or structural similarity /// 3924 // GTPase activity // inferred from sequence or structural similarity /// $5515 / /$ protein binding // inferred from sequence or structural similarity

166 // nucleotide binding // inferred from electronic annotation /// 4674 // protein serine/threonine kinase activity annotation /// 4674 // protein serine/threonine kinase activity // traceable author statement /// 5524 // ATP binding // inferred from electronic annotation /II 16740 // transferase activity // inferred from electronic annotation /// 4672 // protein kinase activity // inferred from electronic annotation /// 1630

// kinase activity // inferred from electronic annotation 3676 // nucleic acid binding // inferred from electronic annotation
(Continued) 


$\begin{array}{ll} & \text { dependent protein kinase } \\ & \text { activity // traceable author } \\ & \text { statement /// } 6281 / / \text { DNA } \\ & \text { repair // traceable author } \\ & \text { statement /// } 6915 / / \text { apoptosis } \\ & \text { // traceable author statement /// } \\ & 7049 / / \text { cell cycle // inferred } \\ \text { from electronic annotation /// } & 7050 / / \text { cell cycle arrest // } \\ \text { traceable author statement /// } & 6974 / / \text { response to DNA } \\ \text { damage stimulus // inferred } \\ \text { from electronic annotation /// } \\ \text { ing // cell cycle arrest // } \\ \text { inferred from electronic } \\ \text { annotation /// } 74 / / \text { regulation } \\ \text { of progression through cell } \\ \text { cycle // traceable author } \\ \text { statement }\end{array}$




\begin{tabular}{|c|c|c|c|c|c|c|c|}
\hline \multirow{2}{*}{ Probe Set ID } & \multirow{2}{*}{ Log Ratio } & \multirow[b]{2}{*}{ Entrez Gene } & \multirow[b]{2}{*}{ Gene Symbol } & \multirow{2}{*}{ Gene Descriptor } & & & \\
\hline & & & & & Biological Process & Cellular Component & Molecular Function \\
\hline 208810_at & -1.177939167 & 10049 & DNAJB6 & $\begin{array}{l}\text { DnaJ (Hsp40) homolog, } \\
\text { subfamily B, member } 6\end{array}$ & $\begin{array}{l}6457 / / \text { protein folding // inferred } \\
\text { from electronic annotation /// } \\
6986 / / \text { response to unfolded } \\
\text { protein // non-traceable author } \\
\text { statement }\end{array}$ & - & $\begin{array}{l}31072 \text { // heat shock protein } \\
\text { binding // inferred from } \\
\text { electronic annotation /// } 51082 \\
\text { // unfolded protein binding // } \\
\text { inferred from electronic } \\
\text { annotation }\end{array}$ \\
\hline 207001_x_at & -1.159597833 & 1831 & TSC22D3 & TSC22 domain family, member 3 & $\begin{array}{l}6355 \text { // regulation of } \\
\text { transcription, DNA-dependent } \\
\text { // inferred from electronic } \\
\text { annotation /// } 6355 \text { // } \\
\text { regulation of transcription, } \\
\text { DNA-dependent // traceable } \\
\text { author statement }\end{array}$ & 一 & $\begin{array}{l}3700 / / \text { transcription factor } \\
\text { activity // inferred from } \\
\text { electronic annotation /// } 3700 / / \\
\text { transcription factor activity // } \\
\text { traceable author statement }\end{array}$ \\
\hline 225582_at & -1.156030667 & 85450 & KIAA1754 & KIAA1754 & - & - & - \\
\hline 1555281_x_at & -1.149420667 & 25852 & ARMC8 & armadillo repeat containing 8 & $\begin{array}{l}7155 / / \text { cell adhesion // inferred } \\
\text { from electronic annotation }\end{array}$ & $\begin{array}{l}5856 / / \text { cytoskeleton // inferred } \\
\text { from electronic annotation }\end{array}$ & $\begin{array}{l}5198 \text { // structural molecule } \\
\text { activity // inferred from } \\
\text { electronic annotation /// } 5488 / / \\
\text { binding // inferred from } \\
\text { electronic annotation /// } 5515 / / \\
\text { protein binding // inferred from } \\
\text { electronic annotation }\end{array}$ \\
\hline 219343_at & -1.145858 & 55664 & CDC37L1 & $\begin{array}{l}\text { CDC37 cell division cycle } 37 \\
\text { homolog }(\mathrm{S} \text {. cerevisiae)-like } 1\end{array}$ & $\begin{array}{l}74 / / \text { regulation of progression } \\
\text { through cell cycle // inferred } \\
\text { from electronic annotation /// } \\
51301 / / \text { cell division // } \\
\text { inferred from electronic } \\
\text { annotation }\end{array}$ & - & - \\
\hline 209362_at & -1.13266 & 9412 & SURB7 & $\begin{array}{l}\text { SRB7 suppressor of RNA } \\
\text { polymerase B homolog (yeast) }\end{array}$ & $\begin{array}{l}6350 / / \text { transcription // inferred } \\
\text { from electronic annotation /// } \\
45944 \text { // positive regulation of } \\
\text { transcription from RNA } \\
\text { polymerase II promoter // } \\
\text { inferred from direct assay /// } \\
6355 / / \text { regulation of } \\
\text { transcription, DNA-dependent } \\
\text { // inferred from electronic } \\
\text { annotation /// 6357 // } \\
\text { regulation of transcription } \\
\text { from RNA polymerase II } \\
\text { promoter // traceable author } \\
\text { statement }\end{array}$ & $\begin{array}{l}119 \text { // mediator complex // } \\
\text { inferred from direct assay /// } \\
5634 \text { // nucleus // inferred from } \\
\text { electronic annotation /// } 5665 / / \\
\text { DNA-directed RNA } \\
\text { polymerase II, core complex // } \\
\text { traceable author statement }\end{array}$ & $\begin{array}{l}3702 \text { // RNA polymerase II } \\
\text { transcription factor activity // } \\
\text { traceable author statement /// } \\
3713 \text { // transcription } \\
\text { coactivator activity // inferred } \\
\text { from direct assay /// } 3899 \text { // } \\
\text { DNA-directed RNA } \\
\text { polymerase activity // traceable } \\
\text { author statement }\end{array}$ \\
\hline
\end{tabular}


inferred from electronic

annotation /// 5975 //

carbohydrate metabolism //

inferred from electronic

annotation

\begin{tabular}{|c|c|c|c|c|c|}
\hline 222874_s_at & -1.116975 & 2055 & CLN8 & $\begin{array}{l}\text { ceroid-lipofuscinosis, neuronal } 8 \\
\text { (epilepsy, progressive with } \\
\text { mental retardation) }\end{array}$ & $\begin{array}{l}7399 \text { // nervous system } \\
\text { development // traceable } \\
\text { author statement }\end{array}$ \\
\hline
\end{tabular}
222815 at
$-1.103659667$
51132
RNF12
ring finger protein 12

6350 // transcription // inferred from electronic annotation /I/ 6355 // regulation of transcription, DNA-dependent // inferred from electronic annotation /// 16481 // negative regulation of transcription // non-traceable author statemen /// 6512 // ubiquitin cycle // inferred from electronic annotation

\begin{tabular}{|c|c|c|c|c|}
\hline 219347_at & -1.10166583 & 55270 & NUDT15 & nudix (nucleoside diphosphate \\
\hline
\end{tabular}


interferon-related developmental regulator 1

7518 // myoblast cell fate

author statement /// 30154 //

from electronic annotation //I

7275 // development // inferred

from electronic annotation

227960_s_at $\quad-1.096905$

81889

FAHD1

fumarylacetoacetate hydrolase

domain containing 1

frot/ metabolism // inferred

from electronic annotation determination // traceable

cell differentiation // inferred

Molecular Function

5488 // binding // inferred from

electronic annotation

-

neuroepithelial cell transforming gene 1
1558 // regulation of cell growth // non-traceable author statement /// 7165 // signal transduction // traceable author statement /// 35023 //

regulation of Rho protein

signal transduction // inferred

from electronic annotation
5622 // intracellular // inferred from electronic annotation /II 5634 // nucleus // inferred from electronic annotation

(Continued) 


\section{$-1.084398667$ 1595 \\ CYP51A1 \\ cytochrome P450, family 51 , subfamily A, polypeptide 1}

AXUD1
6118 // electron transport // inferred from electronic annotation /// 6695 //

cholesterol biosynthesis // inferred from electronic annotation /// 6694 // steroid biosynthesis // inferred from lipid biosynthesis // inferred from electronic annotation /// 16126 // sterol biosynthesis // inferred from electronic annotation
6915 // apoptosis // non-traceable 5634 // nucleus // inferred from
4 // regulation of progression through cell cycle // traceable author statement /// 6468 // protein amino acid

phosphorylation // traceable author statement /// 6468 // protein amino acid

phosphorylation // inferred from electronic annotation electronic annotation /// $8610 / /$
16020 // membrane // inferred from electronic annotation //I $16021 / /$ integral to membrane

// inferred from electronic annotation author statement /// 6915 // electronic annotation

$166 / /$ nucleotide binding // inferred from electronic annotation /// 4674 // protein serine/threonine kinase activity // traceable author statement // 5515 // protein binding // inferred from electronic annotation /// 5524 // ATP binding // inferred from

electronic annotation /// 16740 // transferase activity // inferred from electronic annotation /II 4672 // protein kinase activity // inferred from electronic annotation /// 4674 // protein serine/threonine kinase activity // inferred from electronic annotation /// 16301 // kinase activity // inferred from electronic annotation

4497 // monooxygenase activity // inferred from electronic annotation /// 5506 // iron ion binding // inferred from

electronic annotation /// 8398 // sterol 14-demethylase activity // inferred from electronic annotation /// 20037 // heme binding // inferred from electronic annotation /// 46872 // metal ion binding // inferred from electronic annotation /II 16491 // oxidoreductase activity // inferred from electronic annotation /// 8398 // sterol 14-demethylase activity // not recorded apoptosis // inferred from electronic annotation 
traceable author statement /I/ 7264 // small GTPase mediated signal transduction // inferred from electronic annotation

235735_at $\quad-1.066199833 \quad 944 \quad$ TNFSF8 $\quad \begin{gathered}\text { Tumor necrosis factor (ligand) } \\ \text { superfamily, member } 8\end{gathered}$ \\ WD repeat domain 33}

MASTL

microtubule associated serine/ threonine kinase-like

\section{$6917 / /$ induction of apoptosis}

traceable author statement /// 6955 // immune response // inferred from electronic annotation /// 7165 // signal transduction // traceable author statement /I/ 7267 // cell-cell signaling // traceable author statement /// 8283 // cell proliferation // traceable author statement

$6301 / /$ postreplication repair // non-traceable author statement /// 6817 // phosphate transport // inferred from electronic annotation /// 7283 // spermatogenesis // nontraceable author statement $6468 / /$ protein amino acid phosphorylation // inferred from electronic annotation mic annotation /// 6020 // membrane // inferred from electronic annotation

5615 // extracellular space // inferred from electronic annotation /// 5887 // integra to plasma membrane // traceable author statement /// 16020 // membrane // inferred from electronic annotation /II 16021 // integral to membrane // inferred from electr

5634 // nucleus // inferred from direct assay /// 5737 //

cytoplasm // inferred from electronic annotation /// 5634 // nucleus // inferred from electronic annotation nferred from electronic annotation /// 3924 // GTPase activity // not recorded /// 5525 // GTP binding // inferred from electronic annotation

$5164 / /$ tumor necrosis factor receptor binding // inferred from electronic annotation /// 5125 // cytokine activity // inferred from electronic annotation /// 5102 // receptor binding // traceable author statement
166 // nucleotide binding // inferred from electronic annotation /// 4674 // protein serine/threonine kinase activity // inferred from electronic annotation /// 5524 // ATP binding // inferred from electronic annotation /// 16740 // transferase activity // inferred from electronic annotation //I 4672 // protein kinase activity // inferred from electronic annotation /// 16301 // kinase activity // inferred from electronic annotation 
$6350 / /$ transcription // inferred from electronic annotation /I/ $6810 / /$ transport // inferred from electronic annotation //I 45540 // regulation of

cholesterol biosynthesis // nontraceable author statement /II 45893 // positive regulation of transcription, DNA-dependent // non-traceable author statement /// 6355 // regulation dependent // inferred from electronic annotation /// 6915 // apoptosis // inferred from electronic annotation

208622_s_at $-1.027501167 \quad 7430 \quad$ VIL2 villin 2 (ezrin)

villin 2 (ezrin)

7016 // cytoskeletal anchoring // non-traceable author statement /// 8360 // regulation of cell shape // inferred from electronic annotation /// 51017 // actin filament bundle formation // inferred from direct assay of transcription, DNA
5622 // intracellular // inferred from electronic annotation /// 5634 // nucleus // non-traceable author statement /// 5737 // cytoplasm // non-traceable author statement /// $16021 / /$ integral to membrane // inferred from electronic annotation /// 5634 //

5737 // cytoplasm // inferred from electronic annotation /// $5856 / /$
cytoskeleton // inferred from electronic annotation /// 5884 // actin filament // inferred from direct assay /// 5902 // microvillus // non-traceable author statement /// $16020 / /$ membra
5386 // carrier activity // nontraceable author statement /I/ 5543 // phospholipid binding // non-traceable author statemen /// 8431 // vitamin E binding // non-traceable author statement // 16563 // transcriptional activator activity // nontraceable author statement /// 5215 // transporter activity // inferred from electronic annotation /// 8289 // lipid binding // inferred from

electronic annotation

5198 // structural molecule activity // inferred from electronic annotation /// 5488 // binding // inferred from

electronic annotation /// 8092 // cytoskeletal protein binding // inferred from electronic annotation /// 51015 // actin filament binding // inferred from direct assay /// 5515 // protein binding // inferred from physical interaction

\section{Josephin domain containing 1}

yippee-like 5 (Drosophila)

salvador homolog 1 (Drosophila) $7165 / /$ signal transduction //

inferred from electronic annotation
$5515 / /$ protein binding // inferred from electronic annotation 
Probe Set ID Log Ratio Entrez Gene Gene Symbol

Gene Descriptor

$5500 \quad$ PPP1CB

protein phosphatase 1 , catalytic
subunit, beta isoform

subunit, beta isoform
212749_s_at $\quad-1.005041$
25898
RCHY1
ring finger and $\mathrm{CHY}$ zinc finger domain containing 1

$\begin{array}{lllll}\text { 224281_s_at } & -0.994716333 & 51335 & \text { NGRN } & \begin{array}{c}\text { neugrin, neurite outgrowth } \\ \text { associated }\end{array} \\ \text { 1562255_at } & -0.989167 & 94120 & \text { SYTL3 } & \text { synaptotagmin-like 3 }\end{array}$
6512 // ubiquitin cycle // inferred from electronic annotation

5975 // carbohydrate metabolism

// inferred from electronic

annotation /// 5977 // glycogen

metabolism // inferred from

electronic annotation /// 7049 //

cell cycle // inferred from

electronic annotation /// 51301

// cell division // inferred from

electronic annotation

Cellular Component

Molecular Function

$4721 / /$ phosphoprotein

phosphatase activity // inferred from electronic annotation //I $5506 / /$ iron ion binding //

inferred from electrc

annotation /// 16787 //

hydrolase activity // inferred

from electronic annotation ///

30145 // manganese ion

binding // inferred from

electronic annotation /// 46872

// metal ion binding // inferred

from electronic annotation

$5515 / /$ protein binding // inferred from electronic annotation /// $5515 / /$ protein binding //

inferred from physical interaction /// 8270 // zinc ion binding // inferred from

electronic annotation /// 46872 // metal ion binding // inferred from electronic annotation

30182 // neuron differentiation // non-traceable author statement /// 6464 // protein modification

// inferred from electronic annotation

634 // nucleus // inferred from electronic annotation /// 5634 // nucleus // non-traceable author statement

$6886 / /$ intracellular protein transport // inferred from electronic annotation
3677 // DNA binding // inferred from electronic annotation /// 4835 // tubulin-tyrosine ligase activity // inferred from electronic annotation

$5515 / /$ protein binding // inferred from electronic annotation /// 8270 // zinc ion binding // inferred from electronic annotation /// 17137 // Rab GTPase binding // inferred from electronic annotation 
6412 // protein biosynthesis // inferred from electronic annotation /// 6415 // translational termination // inferred from electronic annotation

6958 // complement activation, classical pathway // inferred from electronic annotation /I/ electronic annotation /// $6955 / /$ immune response // inferred from electronic annotation 45087 // innate imm response // inferred from

accelerating factor

complement (Cromer blood

group)

chemokine (C-X-C motif) ligand $6898 / /$ receptor mediated

5737 // cytoplasm // inferred from 5515 // protein binding // inferred electronic annotation

from physical interaction ///

16149 // translation release

factor activity, codon specific // inferred from electronic annotation /// $43022 / /$

ribosome binding // traceable author statement /// 3747 // translation release factor activity // traceable author statement

5625 // soluble fraction // traceable author statement /// $5887 / /$ integral to plasma membrane // traceable author statement /// $16020 / /$ membrane // inferred from electronic annotation

$-$


Probe Set ID

209161_at

$-0.978153333$

9128

PRPF4

Gene Descriptor

PRP4 pre-mRNA processing

factor 4 homolog (yeast)

\section{6_at}

$-0.97345$

8462

KLF11

Kruppel-like factor 11

212644_s_at

$-0.968791333$

93487

C14orf32

\section{Biological Process}

398 // nuclear mRNA splicing, via spliceosome // inferred from electronic annotation // 8380 // RNA splicing // nontraceable author statement // 6397 // mRNA processing // inferred from electronic annotation /// 8380 // RNA splicing // inferred from electronic annotation /// 6396 //

RNA processing // traceable author statement /// 8380 // RNA splicing // traceable author statement

122 // negative regulation of transcription from RNA polymerase II promoter // traceable author statement /// $6350 / /$ transcription // inferred from electronic annotation //I 6355 // regulation of transcription, DNA-dependent // inferred from electronic annotation /// 6366 // transcription from RNA polymerase II promoter // traceable author statement //I $8285 / /$ negative regulation of cell proliferation // traceable author statement
Molecular Function

31202 // RNA splicing factor activity, transesterification mechanism // non-traceable author statement author statement /// 5681 spliceosome complex // nontraceable author statement /II 5634 // nucleus // inferred from electronic annotation /// $5681 / /$ spliceosome complex // inferred from electronic annotation

5622 // intracellular // inferred from electronic annotation // 5634 // nucleus // traceable author statement /// 5634 // nucleus // inferred from electronic annotation
3700 // transcription factor activity // traceable author statement /// 8270 // zinc ion binding // inferred from electronic annotation /// 46872 // metal ion binding // inferred from electronic annotation /II 3676 // nucleic acid binding // inferred from electronic annotation /// 3677 // DNA binding // inferred from electronic annotation 
$6612 / /$ protein targeting to membrane // non-traceable author statement /// 6930 // substrate-bound cell migration, cell extension // non-traceable author statement /// $7242 / /$ intracellular signaling cascade // non-traceable author statement /// 7268 // synaptic transmission // non-traceable author statement /// 30036 // actin cytoskeleton organization and biogenesis // non-traceable author statement
HAP domain containing, apoptosis associated protein 2

228749_at $-0.9638685 \quad 57683 \quad$ KIAA1571 KIAA1571 protein

218189_s_at $\quad-0.959609 \quad 54187 \quad$ NANS $\begin{aligned} & \text { N-acetylneuraminic acid } \\ & \text { synthase (sialic acid synthase) }\end{aligned}$

9103 // lipopolysaccharide biosynthesis // non-traceable author statement /// 16051 // carbohydrate biosynthesis // inferred from electronic annotation
5737 // cytoplasm // nontraceable author statement
5634 // nucleus // non-traceable author statement /// 5783 // endoplasmic reticulum // inferred from electronic annotation /// 5856 // cytoskeleton // non-traceable author statement /// 5895 // interleukin-5 receptor complex // inferred from sequence or $\mathrm{s}$

ar

5137 // interleukin-5 receptor

binding // inferred from

sequence or structura similarity /// 5515 // protein binding // inferred from

electronic annotation /// 8093 // cytoskeletal adaptor activity // non-traceable author statement // 42043 // neurexin binding // inferred from sequence or tructural similarity /// $45545 / /$ syndecan binding // nontraceable author statement /// 46982 // protein

heterodimerization activity // inferred from physical

interaction

3677 // DNA binding // inferred from electronic annotation /II 8270 // zinc ion binding // inferred from electronic annotation /// 46872 // metal ion binding // inferred from electronic annotation /// $3676 / /$ nucleic acid binding // inferred from electronic annotation

3676 // nucleic acid binding // inferred from electronic annotation /// 8270 // zinc ion binding // inferred from electronic annotation

8781 // N-acylneuraminate cytidylyltransferase activity // non-traceable author statement III 16740 // transferase activity // inferred from electronic annotation /// 47444 // Nacylneuraminate-9-phosphate synthase activity // inferred from electronic annotation /// 50462 // N-acetylneuraminate synthase activity // inferred from electronic annotation 
5737 // cytoplasm // inferred from 166 // nucleotide binding //

208078 s_at $\quad-0.95652$

150094

SNF1LK

SNF1-like kinase /// SNF1-like kinase sequence or structural similarity /// 5622 // intracellular // inferred from electronic annotation /// 5634 // nucleus // inferred from electronic annotation /l infe annotation /// 7243 // protei kinase cascade // inferred from sequence or structural similarity /// 7346 // regulation of progression through mitotic cell cycle // inferred from sequence or structural similarity /// 45595 // regulation of cell differentiation // inferred from sequence or structural similarity /// 6350 // transcription // inferred from electronic annotation /// 6355 // regulation of transcription,

DNA-dependent // inferred from electronic annotation /// 45449 // regulation of transcription // inferred from electronic annotation /// 6468 // protein amino acid

phosphorylation // inferred from electronic annotation /// 7275 // development // inferred from electronic annotation //I 30154 // cell differentiation // inferred from electronic annotation /// 122 // negative regulation of transcription from RNA polymerase II promoter // traceable author statem inferred from electronic annotation /// 287 // magnesium ion binding // inferred from sequence or structural similarity /// 4674 // protein serine/threonine kinase activity // inferred from sequence or structural similarity /// 5524 // ATP binding // inferred from sequence or structural similarity /// 16740 // transferase activity // inferred from electronic annotation I/I 3676 // nucleic acid binding // inferred from electronic annotation /// 3677 // DNA binding // inferred from electronic annotation /// $3700 / /$ transcription factor activity // inferred from electronic annotation /// 8270 // zinc ion binding // inferred from electronic annotation /// 43565 // sequence-specific DNA binding // inferred from electronic annotation /// 46872 // metal ion binding // inferred from electronic annotation III 287 // magnesium ion binding // inferred from electronic annotation /// 4672 // protein kinase activity // inferred from electronic annotation /// 4674 // protein serine/threonine kin$$
\text { - }
$$ 


\section{Probe Set ID \\ Log Ratio \\ Gene Descriptor}

$-0.954184333$ voltage-dependent anion channel 6820 // anion transport //

traceable author statement ///

8632 // apoptotic program //

traceable author statement ///

$6810 / /$ transport // inferred

from electronic annotation ///

$6811 / /$ ion transport // inferred

from electronic annotation /II

6820 // anion transport //

inferred from electronic

annotation /// 6915 // apoptosis

// inferred from electronic

$226321 \_$at $\quad-0.952975833 \quad 116068$
LYSMD3 annotation

LysM, putative peptidoglycanbinding, domain containing 3
16998 // cell wall catabolism //

inferred from electronic

annotation
Cellular Component
5739 // mitochondrion //

traceable author statement ///

$5741 / /$ mitochondrial outer membrane // traceable author

statement /// 16020 //

membrane // inferred from

electronic annotation /// 16021

// integral to membrane //

inferred from electronic

annotatio

\section{Molecular Function}

8308 // voltage-gated ion-

selective channel activity //

inferred from electronic

annotation /// 15283 //

apoptogenic cytochrome c

release channel activity //

traceable author statement ///

15482 // voltage-gated anion

channel porin activity //

traceable author statement /I/

15288 // porin activity //

inferred from electronic

annotation

4518 // nuclease activity //

inferred from electronic

annotation /// 16787 //

hydrolase activity // inferred

from electronic annotation

-
-


6826 // iron ion transport // inferred from electronic annotation /// 6879 // iron ion homeostasis // inferred from electronic annotation /// 6880 // intracellular sequestering of iron ion // traceable author statement /// 6955 // immune response // inferred from direct assay /// 6955 // immune response // inferred from sequence or structural similarity /// 8283 // cell proliferation // traceable author statement /// 8285 // negative regulation of cell proliferation // inferred from direct assay /// $8285 / /$ negative regulation of cell proliferation // inferred from sequence or structural similarity /// 6879 // iron ion homeostasis // traceable author statement /// 6928 // cell motility // traceable author statement /// 30041 // actin filament polymerization // traceable author statement III $6461 / /$ protein complex assembly // non-traceable author statement

\begin{tabular}{|c|c|c|c|c|}
\hline 1554786_at & -0.937690667 & 57091 & C20orf32 & $\begin{array}{l}\text { chromosome } 20 \text { open reading } \\
\text { frame } 32\end{array}$ \\
\hline
\end{tabular}

7165 // signal transduction // inferred from electronic annotation

1503 // ossification // inferred from electronic annotation /II 30154 // cell differentiation // inferred from sequence or structural similarity /// 30198 // extracellular matrix organization and biogenesis // inferred from sequence or structural similarity /// 45045 // secretory pathway // inferred from sequence or structural similarity
(I inferred from sequence or structural similarity /// 5886 // plasma membrane // nontraceable author statement /// 8043 // ferritin complex // traceable author statement //I 5856 // cytoskeleton // inferred from electronic annota

6020 // membrane // inferred from electronic annotation

5622 // intracellular // inferred from sequence or structural similarity /// 5634 // nucleus // inferred from electronic annotation /// 5622 // intracellular // inferred from electronic annotation
4322 // ferroxidase activity // inferred from electronic annotation /// 5488 // binding // inferred from electronic annotation /// 5515 // protein binding // inferred from physical interaction /// 8199 // ferric iron binding // inferred from electronic annotation /I/ 16491 // oxidoreductase activity // inferred from electronic annotation /// 19900 // kinase binding // inferred from sequence or structural similarity /// 19900 // kinase binding // non-traceable author statement /// 46872 // metal ion binding // inferred from electronic annotation /// $5506 / /$ iron ion binding // inferred from electronic annotation /II 3779 // actin binding // inferred from electronic annotation /// 5506 // iron ion binding // traceable author statemen

155 // two-component sensor activity // inferred from electronic annotation

3676 // nucleic acid binding // inferred from electronic nnotation /I/ 5515 // protein binding // inferred from sequence or structural similarity 
$6350 / /$ transcription // inferred from electronic annotation /I/ 6355 // regulation of

transcription, DNA-dependent

// traceable author statement // $6355 / /$ regulation of

transcription, DNA-dependent

$/ /$ inferred from electronic

annotation

\begin{tabular}{|c|c|c|c|c|c|}
\hline 219357_at & -0.923290333 & 9567 & GTPBP1 & GTP binding protein 1 & $\begin{array}{l}6412 \text { // protein biosynthesis // } \\
\text { inferred from electronic } \\
\text { annotation /// } 6955 \text { // immune } \\
\text { response // traceable author } \\
\text { statement /// } 7165 \text { // signal } \\
\text { transduction // traceable author } \\
\text { statement }\end{array}$ \\
\hline
\end{tabular}

5634 // nucleus // traceable author statement /// 5634 // nucleus // inferred from electronic annotation
$3700 / /$ transcription factor activity // inferred from electronic annotation /// 3707 // steroid hormone receptor activity // inferred from electronic annotation /// $8270 / /$ zinc ion binding // inferred from electronic annotation /II 43565 // sequence-specific DNA binding // inferred from electronic annotation /// 46872 // metal ion binding // inferred from electronic annotation /II 3677 // DNA binding // inferred from electronic annotation /// 4872 // receptor activity // inferred from electronic annotation /// 4879 // ligand-dependent nuclear receptor activity // inferred from electronic annotation /II 4879 // ligand-dependent nuclear receptor activity // traceable author statement 166 // nucleotide binding // inferred from electronic annotation /// 5525 // GTP binding // inferred from electronic annotation /// 5525 // GTP binding // traceable author statement /// 9055 // electron carrier activity // inferred from electronic annotation /// 15035 // protein disulfide oxidoreductase activity // inferred from electronic annotation 


\section{TCDD-inducible poly(ADP-}

ribose) polymerase $6471 / /$ protein amino acid ADP- 5634 // nucleus // inferred from ribosylation // inferred from electronic annotation

electronic annotation

1556698_a_at $-0.917641167 \quad 285513$

GRIN3

201303 at

$-0.916190167$

9775

DDX48
$\mathrm{G}$ protein-regulated inducer of neurite outgrowth 3

DEAD (Asp-Glu-Ala-Asp) box polypeptide 48

x

6364 // rRNA processing // inferred from electronic annotation
Molecular Function

$5515 / /$ protein binding // inferred from physical interaction ///

$3676 / /$ nucleic acid binding // inferred from electronic annotation /// 3950 // NAD+

ADP-ribosyltransferase activity // inferred from electronic annotation /// 8270 // zinc ion binding // inferred from electronic annotation /// 16740 // transferase activity // inferred from electronic annotation /// 16757 // transferase activity, transferring glycosyl groups // inferred from electronic annotation /// 46872 // metal ion binding // inferred from electronic annotation

$$
\text { - }
$$

166 // nucleotide binding // inferred from electronic annotation /// 3677 // DNA

binding // inferred from

electronic annotation /// 3723 // RNA binding // inferred from electronic annotation /// $5515 / /$ protein binding // inferred from physical interaction /// $5524 / /$ ATP binding // inferred from electronic annotation /// 8026 // ATP-dependent helicase activity // inferred from electronic annotation /// 16787 // hydrolase activity // inferred from electronic annotation /// $3676 / /$ nucleic acid binding // inferred from electronic annotation /// 4386 // helicase activity // inferred from electronic annotation$$
\text { - }
$$ 
traceable author statement /I/

$7155 / /$ cell adhesion // inferred

from direct assay /// $7157 / /$

heterophilic cell adhesion //

inferred from direct assay /II

7162 // negative regulation of

cell adhesion // non-traceable

author statement /// $7165 / /$

signal transduction // traceable

author statement /// 7275

development // traceable

author statement /// 8285 //

negative regulation of cell

proliferation // non-traceable

author statement /// 8285 //

negative regulation of cell

proliferation // traceable author statement /// 30097 //

hemopoiesis // non-traceable author statement /// 7155 // cell adhesion // traceable author statement

\begin{tabular}{|c|c|c|c|c|}
\hline 235615_at & -0.900246833 & 5229 & PGGT1B & $\begin{array}{l}\text { Protein geranylgeranyltransferase } \\
\text { type I, beta subunit }\end{array}$ \\
\hline
\end{tabular}

$8348 / /$ protein amino acid

geranylgeranylation //

traceable author statement

5953 // CAAX-protein geranylgeranyltransferase complex // traceable author statement

218033_s_at $\quad-0.899702167 \quad 8303 \quad$ SNN stannin

// endosome // non-traceable author statement /I/ 5886 // plasma membrane // inferred from direct assay /// 5887 // integral to plasma membrane // non-traceabl
6950 // response to stress // traceable author statement /I/ $9628 / /$ response to abiotic
16020 // membrane // inferred

from electronic annotation /I/ $16021 / /$ integral to membrane // inferred from electronic annotation
4659 // prenyltransferase activity // inferred from electronic annotation /// 4662 // CAAXprotein geranylgeranyltransferase activity // traceable author statement /// 8270 // zinc ion binding // inferred from electronic annotation /// 16740 // transferase activity // inferred from electronic annotation /I/ 46872 // metal ion binding // inferred from electronic annotation /// 3824 // catalytic activity // inferred from electronic annotation 
matrix metallopeptidase 9 (gelatinase $\mathrm{B}, 92 \mathrm{kDa}$ gelatinase, $92 \mathrm{kDa}$ type IV collagenase)

\begin{tabular}{|c|c|c|c|c|}
\hline 227368_at & -0.890388833 & 55122 & C6orf166 & $\begin{array}{l}\text { Chromosome } 6 \text { open reading } \\
\text { frame } 166\end{array}$ \\
\hline 230129_at & -0.886411833 & 118672 & C10orf89 & $\begin{array}{l}\text { chromosome } 10 \text { open reading } \\
\text { frame } 89\end{array}$ \\
\hline
\end{tabular}

219253_at
79134
FAM11B frame 89

\section{family with sequence similarity 11 , member B}

270 // peptidoglycan metabolism 5578 // extracellular matrix // inferred from electronic annotation /// 6508 // proteolysis // inferred from direct assay /// 30225 // traceable author statement //

30574 // collagen catabolism // inferred from electronic annotation /// 6508 //

proteolysis // inferred from electronic annotation

(sensu Metazoa) // inferred

inferred from direct assay macrophage differentiation //

from electronic annotation ///

5615 // extracellular space //
16020 // membrane // inferred
from electronic annotation ///
$16021 / /$ integral to membrane
// inferred from electronic
annotation

4229 // gelatinase B activity // inferred from direct assay /II 5509 // calcium ion binding // inferred from electronic

annotation /// 5518 // collagen binding // traceable author statement /// 8133 //

collagenase activity // inferred from direct assay /// 8270 // zinc ion binding // traceable author statement /// 5515 // protein binding // inferred from physical interaction /// 4222 // metalloendopeptidase activity // inferred from electronic annotation /// 4229 // gelatinase B activity // inferred from electronic annotation /II 8233 // peptidase activity // inferred from electronic annotation /// 8237 // metallopeptidase activity // inferred from electronic annotation /// 8270 // zinc ion binding // inferred from electronic annotation /// 16787 // hydrolase activity // inferred from electronic annotation //I 46872 // metal ion binding // inferred from electronic annotation

287 // magnesium ion binding // inferred from electronic annotation /// 16301 // kinase activity // inferred from

electronic annotation /// 16740 // transferase activity // inferred from electronic annotation

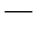


$6350 / /$ transcription // inferred from electronic annotation /II 6355 // regulation of

transcription, DNA-dependent // inferred from electronic annotation /// 6366 //

transcription from RNA

polymerase II promoter //

traceable author statement

\section{7_at \\ $-0.871392$}

57132

CHMP1B

chromatin modifying protein $1 \mathrm{~B}$

$15031 / /$ protein transport //

inferred from electronic

annotation /// $6810 / /$ transport

$/ /$ inferred from electronic annotation

$\begin{array}{rll}\text { 205281_s_at } & -0.870478167 \quad 5277 \quad \text { PIGA } & \text { phosphatidylinositol glycan } \\ & \text { anchor biosynthesis, class A } \\ & \text { (paroxysmal nocturnal } \\ & \text { hemoglobinuria) //I } \\ & \text { phosphatidylinositol glycan } \\ & \text { anchor biosynthesis, class A } \\ & \text { (paroxysmal nocturnal } \\ & \text { hemoglobinuria) }\end{array}$

$\begin{array}{ccccc}\text { 220285_at } & -0.86751 & 51104 & \text { C9orf77 } & \begin{array}{c}\text { chromosome 9 open reading } \\ \text { frame 77 }\end{array} \\ \text { 235230_at } & -0.865278333 & 257068 & \text { PLCXD2 } & \begin{array}{c}\text { Phosphatidylinositol-specific } \\ \text { phospholipase C, X domain } \\ \text { containing 2 }\end{array}\end{array}$

6506 // GPI anchor biosynthesis $506 / /$

// traceable author statement /// glycosylphosphatidylinositol9058 // biosynthesis // inferred N-

from electronic annotation //I 9893 // positive regulation of metabolism // traceable author statement /// 6506 // GPI anchor biosynthesis // inferred from electronic annotation

acetylglucosaminyltransferase (GPI-GnT) complex // inferred from direct assay /// 5783 //

endoplasmic reticulum // inferred from electronic annotation /// 5789 //

endoplasmic reticulum membrane // inferred from direct
5515 // protein binding // inferred from physical interaction //I 16757 // transferase activity, transferring glycosyl groups // inferred from electronic annotation /// 17176 // phosphatidylinositol Nacetylglucosaminyltransferase activity // traceable author statement /// $16740 / /$

transferase activity // inferred from electronic annotation /II 17176 // phosphatidylinositol

acetylglucosaminyltransferase activity // inferred from electronic annotation

7165 // signal transduction // inferred from electronic

annotation /// 7242 //

intracellular signaling cascade

// inferred from electronic

annotation 
$6355 / /$ regulation of

transcription, DNA-dependent

// inferred from electronic

annotation /// 7165 // signal

transduction // inferred from

electronic annotation /// $9649 / /$

entrainment of circadian clock

// traceable author statement ///

$16481 / /$ negative regulation of

transcription // inferred from

sequence or structural

similarity /// $48511 / /$ rhythmic

process // inferred from

electronic annotation /// $7623 / /$

circadian rhythm // traceable

author statement

204071_s_at $-0.85936316710210 \quad$ TOPORS $\begin{gathered}\text { topoisomerase I binding, } \\ \text { arginine/serine-rich }\end{gathered}$

200673_at

$-0.856153333$

9741

LAPTM4A

lysosomal-associated protein transmembrane 4 alpha

$6810 / /$ transport // inferred from electronic annotation
RGS1 regulator of G-protein signalling
6955 // immune response //

traceable author statement /II

7165 // signal transduction //

non-traceable author statement

/// 7193 // G-protein signaling.

adenylate cyclase inhibiting

pathway // traceable author

statement /// 9968 // negative

regulation of signal

transduction // inferred from

electronic annotation annotation /// 4871 // signal

transducer activity // inferred from electronic annotation /II 5515 // protein binding // inferred from sequence or structural similarity

$5515 / /$ protein binding // inferred from electronic annotation /// 8270 // zinc ion binding //

inferred from electronic annotation /// 16874 // ligase activity // inferred from

electronic annotation /// 46872 // metal ion binding // inferred from electronic annotation

-

inferred from direct assay III

16020 // membrane // inferred from electronic annotation //I $16021 / /$ integral to membrane // inferred from electronic annotation

5886 // plasma membrane // traceable author statement

4871 // signal transducer activity // inferred from electronic annotation /// 5096 // GTPase activator activity // traceable author statement /// $5516 / /$ calmodulin binding // traceable author statement
苗

$\stackrel{m}{\rightarrow}$ 
$122 / /$ negative regulation of transcription from RNA

polymerase II promoter // not recorded /// 6350 //

transcription // inferred from

electronic annotation /// 6355 //

regulation of transcription,

DNA-dependent // inferre

from electronic annotation /II

7275 // development //

traceable author statement

$\begin{array}{llccl}\text { 226370_at } & -0.842846333 & 80311 & \text { KLHL15 } & \text { kelch-like 15 (Drosophila) } \\ & & & & \\ \text { 1564027_a_at } & -0.8388195 & 285966 & \text { FLJ40722 } & \text { hypothetical protein FLJ40722 } \\ \text { 207735_at } & -0.838808167 & 54941 & \text { RNF125 } & \text { ring finger protein 125 }\end{array}$

guanine nucleotide binding protein ( $\mathrm{G}$ protein), alpha inhibiting activity polypeptide
$6810 / /$ transport // non-traceable author statement /// 7165 //

signal transduction // inferred from electronic annotation /II 7186 // G-protein coupled receptor protein signaling pathway // inferred from electronic annotation /// 7194 // negative regulation of adenylate cyclase activity // traceable author statement

$\begin{array}{lcccc}\text { 227337_at } & -0.832628667 & 353322 & \text { ANKRD37 } & \text { ankyrin repeat domain } 37 \\ & & & & \\ 220368 \text { s_at } & -0.827011833 & 55671 & \text { KIAA2010 } & \text { KIAA2010 }\end{array}$

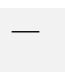

-
$5634 / /$ nucleus // inferred from electronic annotation

\section{scription factor} 5634 // nucleus // inferred from electronic annotation

(ain
binding // inferred from

electronic annotation /// 46872

// metal ion binding // inferred from electronic annotation /II

3676 // nucleic acid binding // inferred from electronic annotation /// 3677 // DNA

binding // inferred from electronic annotation 5515 // protein binding // inferred from electronic annotation -

3676 // nucleic acid binding // inferred from electronic annotation /// 5515 // protein binding // inferred from electronic annotation /// $8270 / /$ zinc ion binding // inferred from electronic annotation /// 16874 // ligase activity // inferred from electronic annotation /// 46872 // metal ion binding // inferred from electronic annotation

166 // nucleotide binding // inferred from electronic annotation /// 3924 // GTPase activity // traceable author statement /// $4871 / /$ signal transducer activity // inferred from electronic annotation //I 5525 // GTP binding // inferred from electronic annotation /// $19001 / /$ guanyl nucleotide binding // inferred from electronic annotation

5488 // binding // inferred from electronic annotation

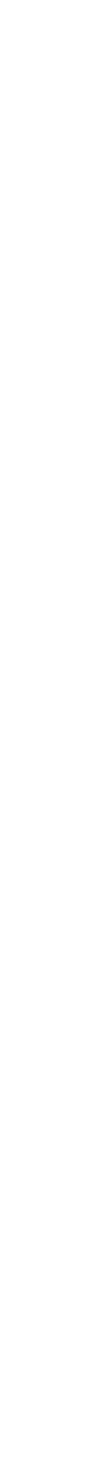


stimulus // inferred from

expression pattern /// 30433 // ER-associated protein catabolism // inferred from direct assay /// 30503 // regulation of cell redox homeostasis // inferred from direct assay /// 30968 // unfolded protein response // inferred from direct assay III 30970 // retrograde protein transport, ER to cytosol // inferred from direct assay /II 45184 // establishment of protein localization // traceable author statement /// 6886 // intracellular protein transport // inferred from electronic annotation /// 6412 // protein biosynthesis // inferred from electronic annotation electronic annotation /// 1602

// integral to membrane // inferred from electronic annotation /// 30176 // integral to endoplasmic reticulum membr annotation /II $16209 / /$

antioxidant activity // inferred from direct assay /// 19899 // enzyme binding // inferred from physical interaction /// 5515 // protein binding // inferred from physical interaction /// 3735 // structural constituent of ribosome // inferred from electronic annotation
166 // nucleotide binding // inferred from electronic annotation /// 3723 // RNA binding // inferred from electronic annotation /// $3676 / /$ nucleic acid binding // inferred from electronic annotation 


\begin{tabular}{|c|c|c|c|c|c|c|c|}
\hline \multirow[b]{2}{*}{ Probe Set ID } & \multirow{2}{*}{ Log Ratio } & \multirow[b]{2}{*}{ Entrez Gene } & \multirow[b]{2}{*}{ Gene Symbol } & \multirow[b]{2}{*}{ Gene Descriptor } & \multirow{2}{*}{\multicolumn{2}{|c|}{ Cellular Component }} & \multirow[b]{2}{*}{ Molecular Function } \\
\hline & & & & & & & \\
\hline 207445_s_at & -0.820649 & 10803 & CCR9 & $\begin{array}{l}\text { chemokine (C-C motif) receptor } \\
9\end{array}$ & $\begin{array}{l}6935 \text { // chemotaxis // traceable } \\
\text { author statement /// } 6968 / / \\
\text { cellular defense response // } \\
\text { traceable author statement /// } \\
7165 / / \text { signal transduction // } \\
\text { inferred from electronic } \\
\text { annotation /// } 7186 \text { // G-protein } \\
\text { coupled receptor protein } \\
\text { signaling pathway // traceable } \\
\text { author statement /// } 7204 / / \\
\text { elevation of cytosolic calcium } \\
\text { ion concentration // traceable } \\
\text { author statement /// } 7186 / / \text { G- } \\
\text { protein coupled receptor } \\
\text { protein signaling pathway // } \\
\text { inferred from electronic } \\
\text { annotation }\end{array}$ & $\begin{array}{l}5886 \text { // plasma membrane // } \\
\text { traceable author statement /// } \\
5887 / / \text { integral to plasma } \\
\text { membrane // traceable author } \\
\text { statement /// } 16020 \text { // } \\
\text { membrane // inferred from } \\
\text { electronic annotation /// } 16021 \\
\text { // integral to membrane // } \\
\text { inferred from electronic } \\
\text { annotati }\end{array}$ & $\begin{array}{l}1584 \text { // rhodopsin-like receptor } \\
\text { activity // inferred from } \\
\text { electronic annotation /// } 4872 \text { // } \\
\text { receptor activity // inferred } \\
\text { from electronic annotation /// } \\
16493 \text { // C-C chemokine } \\
\text { receptor activity // inferred } \\
\text { from electronic annotation /// } \\
4871 / / \text { signal transducer } \\
\text { activity // inferred from } \\
\text { electronic annotation /// } 4930 \text { // } \\
\text { G-protein coupled receptor } \\
\text { activity // inferred from } \\
\text { electronic annotation }\end{array}$ \\
\hline 212430_at & -0.819566 & 55544 & RBM38 & $\begin{array}{l}\text { RNA binding motif protein } 38 / / / \\
\text { RNA binding motif protein } 38\end{array}$ & - & - & $\begin{array}{l}166 \text { // nucleotide binding // } \\
\text { inferred from electronic } \\
\text { annotation /// } 3676 \text { // nucleic } \\
\text { acid binding // inferred from } \\
\text { electronic annotation /// } 3723 \text { // } \\
\text { RNA binding // inferred from } \\
\text { electronic annotation }\end{array}$ \\
\hline 204335_at & -0.8186395 & 55702 & CCDC94 & coiled-coil domain containing 94 & - & - & - \\
\hline 1555274_a_at & -0.805795 & 85465 & SELI & selenoprotein I & $\begin{array}{l}8654 / / \text { phospholipid biosynthesis } \\
\text { // inferred from electronic } \\
\text { annotation }\end{array}$ & $\begin{array}{l}16020 / / \text { membrane // inferred } \\
\text { from electronic annotation /// } \\
16021 / / \text { integral to membrane } \\
\text { // inferred from electronic } \\
\text { annotation }\end{array}$ & $\begin{array}{l}8430 / / \text { selenium binding // } \\
\text { inferred from electronic } \\
\text { annotation /// } 16740 / / \\
\text { transferase activity // inferred } \\
\text { from electronic annotation }\end{array}$ \\
\hline 208093_s_at & -0.804331833 & 81565 & NDEL1 & $\begin{array}{l}\text { nudE nuclear distribution gene } \mathrm{E} \\
\text { homolog like } 1 \text { (A. nidulans) } \\
\text { /// nudE nuclear distribution } \\
\text { gene E homolog like } 1 \\
\text { (A. nidulans) }\end{array}$ & $\begin{array}{l}6810 \text { // transport // inferred from } \\
\text { electronic annotation /// } 7399 / / \\
\text { nervous system development // } \\
\text { inferred from electronic } \\
\text { annotation /// } 30154 / / \text { cell } \\
\text { differentiation // inferred from } \\
\text { electronic annotation /// } 7275 \text { // } \\
\text { development // inferred from } \\
\text { electronic annotation }\end{array}$ & $\begin{array}{l}5856 / / \text { cytoskeleton // inferred } \\
\text { from electronic annotation /// } \\
5874 / / \text { microtubule // inferred } \\
\text { from electronic annotation }\end{array}$ & $\begin{array}{l}5515 / / \text { protein binding // inferred } \\
\text { from physical interaction }\end{array}$ \\
\hline
\end{tabular}


inferred from electronic

annotation

\begin{tabular}{|c|c|c|c|c|c|c|}
\hline 226328_at & -0.801374333 & 83855 & KLF16 & Kruppel-like factor 16 & $\begin{array}{l}6350 / / \text { transcription // inferred } \\
\text { from electronic annotation /// } \\
6355 \text { // regulation of } \\
\text { transcription, DNA-dependent } \\
\text { // inferred from electronic } \\
\text { annotation }\end{array}$ & $\begin{array}{l}5622 / / \text { intracellular // inferred } \\
\text { from electronic annotation /// } \\
5634 \text { // nucleus // inferred from } \\
\text { electronic annotation }\end{array}$ \\
\hline 225282_at & -0.800108 & 64744 & SMAP1L & $\begin{array}{l}\text { stromal membrane-associated } \\
\text { protein 1-like }\end{array}$ & $\begin{array}{l}43087 \text { // regulation of GTPase } \\
\text { activity // inferred from } \\
\text { electronic annotation }\end{array}$ & - \\
\hline
\end{tabular}

electronic annotation /// 46870

// cadmium ion binding //

inferred from electronic

annotation /// 46872 // meta

ion binding // inferred from

electronic annotation /// 46872

// metal ion binding // traceable author statement /// $5506 / /$

iron ion binding // inferred

from electronic annotation //I

9055 // electron carrier activity

$/ /$ inferred from electronic

annotation

3677 // DNA binding // inferred from electronic annotation /II 8270 // zinc ion binding // inferred from electronic annotation /// 46872 // meta ion binding // inferred from electronic annotation /// $3676 / /$ nucleic acid binding // inferred from electronic annotation

5096 // GTPase activator activity $/ /$ inferred from electronic annotation /// 8270 // zinc ion binding // inferred from

electronic annotation /// 46872 // metal ion binding // inferred from electronic annotation 


\begin{tabular}{|c|c|c|c|c|c|c|c|}
\hline \multirow[b]{2}{*}{ Probe Set ID } & \multirow[b]{2}{*}{ Log Ratio } & \multirow[b]{2}{*}{ Entrez Gene } & \multirow[b]{2}{*}{ Gene Symbol } & \multirow[b]{2}{*}{ Gene Descriptor } & \\
\hline & & & & & Biological Process & Cellular Component & Molecular Function \\
\hline 202236_s_at & -0.795418167 & 6566 & SLC16A1 & $\begin{array}{l}\text { solute carrier family } 16, \text { member } \\
1 \text { (monocarboxylic acid } \\
\text { transporter } 1 \text { ) }\end{array}$ & $\begin{array}{l}6810 / / \text { transport // inferred from } \\
\text { electronic annotation /// } 15711 \\
\text { // organic anion transport // } \\
\text { inferred from electronic } \\
\text { annotation /// } 15728 / / \\
\text { mevalonate transport // } \\
\text { traceable author statement /// } \\
15718 / / \text { monocarboxylic acid } \\
\text { transport // traceable author } \\
\text { statement }\end{array}$ & $\begin{array}{l}5624 \text { // membrane fraction // } \\
\text { traceable author statement /// } \\
16020 / / \text { membrane // inferred } \\
\text { from electronic annotation /// } \\
16021 / / \text { integral to membrane } \\
\text { // inferred from electronic } \\
\text { annotation /// } 16021 \text { // integral } \\
\text { to membrane // traceable } \\
\text { author statement }\end{array}$ & $\begin{array}{l}5215 \text { // transporter activity // } \\
\text { inferred from electronic } \\
\text { annotation /// } 15130 \text { // } \\
\text { mevalonate transporter activity } \\
\text { // traceable author statement /// } \\
15293 / / \text { symporter activity // } \\
\text { inferred from electronic } \\
\text { annotation /// } 15355 / / \\
\text { monocarboxylate porter } \\
\text { activity // inferred from } \\
\text { electronic annotation /// } 8028 \text { // } \\
\text { monocarboxylic acid } \\
\text { transporter activity // traceable } \\
\text { author statement }\end{array}$ \\
\hline 221596_s_at & -0.793717167 & 84060 & DKFZP564O0523 & $\begin{array}{r}\text { hypothetical protein } \\
\text { DKFZp56400523 }\end{array}$ & - & - & $\begin{array}{l}166 / / \text { nucleotide binding // } \\
\text { inferred from electronic } \\
\text { annotation }\end{array}$ \\
\hline 224206_x_at & -0.791450833 & 55892 & MYNN & myoneurin & $\begin{array}{l}6351 / / \text { transcription, DNA- } \\
\text { dependent // traceable author } \\
\text { statement }\end{array}$ & $\begin{array}{l}5622 / / \text { intracellular // inferred } \\
\text { from electronic annotation /// } \\
5634 / / \text { nucleus // inferred from } \\
\text { electronic annotation }\end{array}$ & $\begin{array}{l}5515 \text { // protein binding // inferred } \\
\text { from electronic annotation /// } \\
3676 / / \text { nucleic acid binding // } \\
\text { inferred from electronic } \\
\text { annotation /// } 8270 \text { // zinc ion } \\
\text { binding // inferred from } \\
\text { electronic annotation /// } 46872 \\
\text { // metal ion binding // inferred } \\
\text { from electronic annotation /// } \\
3700 / / \text { transcription factor } \\
\text { activity // traceable author } \\
\text { statement /// 8270 // zinc ion } \\
\text { binding // traceable author } \\
\text { statement }\end{array}$ \\
\hline
\end{tabular}




\section{Biological Process \\ 6878 // copper ion homeostasis // 5737 // cytoplasm // non-}

traceable author statement

\section{3_at \\ $-0.789475333$ $-0.789208167$ \\ 51026}

hypothetical protein LOC144438

golgi transport 1 homolog B (S.

cerevisiae)

$\begin{array}{cccc}\text { 221020_s_at } & -0.774771333 \quad 81034 \quad \text { SLC25A32 } & \text { solute carrier family } 25, \text { member } 6810 \\ & & 32 / / / \text { solute carrier family } 25, \\ & \text { member } 32\end{array}$

member 32
GOLT1B
Molecular Function

$5507 / /$ copper ion binding // not recorded /// 8270 // zinc ion binding // inferred from

electronic annotation /// 46872 // metal ion binding // inferred from electronic annotation /// 5507 // copper ion binding // inferred from electronic annotation /// 46870 // cadmium ion binding // inferred from electronic annotation /// 5507 // copper ion binding // non-traceable author statement /// 8270 // zinc ion binding // nontraceable author statement /II 46870 // cadmium ion binding // non-traceable author statement
$15031 / /$ protein transport // inferred from electronic annotation /// 16192 // vesiclemediated transport // inferred

from electronic annotation /I/ 43123 // positive regulation of I-kappaB kinase/NF-kappaB cascade // inferred from mutant phenotype /// 6810 // transport // inferred from electronic annotation

6810 // transport // inferred from // folic acid transport // nontraceable author statement
16020 // membrane // inferred $4871 / /$ signal transducer activity from electronic annotation /I/ 16021 // integral to membrane // inferred from electronic annotation

5739 // mitochondrion // inferred $5743 / /$ mitochondrial inner membrane // non-traceable author statement /// 16020 // membrane // inferred from electronic annotation /// 16021 // integral to membrane // inferred from electro inferred from mutant phenotype

\section{5 // transporter activity //} inferred from electronic nnotation /// 5488 // binding // inferred from electronic annotation /// 8517 // folic acid transporter activity // nontraceable author statement - 
eukaryotic translation initiation factor 5
6412 // protein biosynthesis //

inferred from electronic

annotation /// 6446 //

regulation of translational

initiation // traceable author

statement /// 6413 //

translational initiation //

inferred from electronic

annotation /// 6446 //

regulation of translational

initiation // inferred from

electronic annotation /// 6413 //

translational initiation // non-

traceable author statement
5737 // cytoplasm // traceable

author statement /// 5829 //

166 // nucleotide binding // inferred from electronic annotation /// 3743 // translation initiation factor activity // non-traceable author statement /// 3924 // GTPase activity // traceable author statement /// 5525 // GTP binding // inferred from

electronic annotation /// 3743 // translation initiation facto activity // inferred from

electronic annotation /// 8135//

translation factor activity,

nucleic acid binding //

traceable author statement

.




\section{5 // regulation of}

factor of kappa light

polypeptide gene enhancer in

B-cells 3, p65 (avian)

\begin{tabular}{|c|c|c|c|c|}
\hline 216902_s_at & -0.765497 & 54700 & RRN3 & $\begin{array}{l}\text { RRN3 RNA polymerase I } \\
\text { transcription factor homolog } \\
\text { (S. cerevisiae) }\end{array}$ \\
\hline
\end{tabular}
-

$/ /$ inferred from electronic annotation /// 6916 // antiapoptosis // inferred from direct assay /// 6954 // inflammatory response // inferred from direct assay III 6968 // cellular defense response // non-traceable author statement /// 10033 // response to organic substance // inferred from direct assay //I 10224 // response to UV-B // inferred from direct assay /II $19221 / /$ cytokine and chemokine mediated signaling pathway // inferred from direct assay /// 43123 // positive regulation of I-kappaB kinase/ NF-kappaB cascade // inferred from expression pattern /II 51092 // activation of NFkappaB transcription factor // inferred from direct assay /II $51607 / /$ defense response to virus // non-traceable author statement /// 6350 // transcription // inferred from electronic annotation /// 45449 // regulation of transcription // inferred from electronic annotation

$6350 / /$ transcription // inferred from electronic annotation /II $6355 / /$ regulation of transcription, DNA-dependent // inferred from electronic annotation /// 6360 //

transcription from RNA polymerase I promoter // traceable author statement
5634 // nucleus // inferred from direct assay /// 5634 // nucleus inferred from electronic annotation /// 5667 // transcription factor complex // inferred from direct as 5737 // cytoplasm // inferred

from direct assay $5634 / /$ nucleus // inferred from
electronic annotation
$3700 / /$ transcription factor activity // inferred from electronic annotation /// 3705 // RNA polymerase II transcription factor activity, enhancer binding // inferred from direct assay /// $4871 / /$ signal transducer activity // inferred from expression pattern /// 19901 // protein kinase binding // inferred from physical interaction /// $42301 / /$ phosphate binding // inferred from direct assay /// 42802 // identical protein binding $/ /$ inferred from direct assay /I/ 47485 // protein N-terminus binding // inferred from physical interaction /// 51059 // NF-kappaB binding // inferred from physical interaction //I

5515 // protein binding // inferred from physical interaction /// 8134 //

transcription factor binding // inferred from physical interaction /// 42802 //

identical protein binding // inferred from physical interaction /// 3677 // DNA

binding // inferred from direct assay /// 3700 // transcription factor activity // inferred from direct assay /// $5515 / /$ protein binding // inferred from direct assay /// 367

3701 // RNA polymerase I

transcription factor activity // traceable author statement 

author statement /// 45893 //

$\begin{array}{llccc}\text { 226008_at } & -0.762606 & 56160 & \text { NDNL2 } & \text { necdin-like 2 } \\ \text { 232048_at } & -0.761400167 & 143684 & \text { FAM76B } & \begin{array}{c}\text { family with sequence similarity } \\ 76, \text { member B }\end{array} \\ \text { 209149_s_at } & -0.757001833 & 10548 & \text { TM9SF1 } & \begin{array}{c}\text { transmembrane 9 superfamily } \\ \text { member } 1\end{array}\end{array}$

$/ /$ inferred from electronic annotation /// 6302 // doublestrand break repair // inferred from mutant phenotype /I/ $6333 / /$ chromatin assembly or disassembly // inferred from electronic annotation /// $6350 / /$ transcription // inferred from electronic annotation /// $6366 / /$

transcription from RNA

polymerase II promoter // raceable author statement //

16568 // chromatin

modification // inferred from electronic annotation /// 16573

// histone acetylation // inferred from direct assay /// $30521 / /$ androgen receptor signaling

pathway // non-traceable positive regulation of transcription, DNA-dependent // non-traceable author statement /// 6355 // regulation of transcription, DNAdependent // inferred from electronic annotation

$1558 / /$ regulation of cell growth // inferred from electronic 5634 // nucleus // inferred from annotation electronic annotation nucleus // traceable author statement /// 35267 // TIP60 histone acetyltransferase complex // inferred from direct assay /// 5634 // nucleus // inferred from electronic annotation

$6810 / /$ transport // inferred from electronic annotation

binding //

inferred from electronic annotation /// 3713 // transcription coactivato activity // non-traceable autho statement /// 4402 // histone acetyltransferase activity /I inferred from electronic annotation /// 5515 // protein binding // inferred from physical interaction /// $8270 / /$ zinc ion binding // inferred from electronic annotation /// 8415 // acyltransferase activity $/ /$ inferred from electronic annotation /// 16740 //

transferase activity // inferred from electronic annotation //I 46872 // metal ion binding // inferred from electronic annotation /// 50681 // androgen receptor binding // non-traceable author statement // 3713 // transcription coactivator activity // traceable author statement

-
member 1 


\section{0 // DNA replication //}

inferred from electronic

annotation /// 7049 // cell cycle

// inferred from electronic

annotation /// 7067 // mitosis //

inferred from electronic

annotation /// $51301 / /$ cell

division // inferred from

electronic annotation

$\begin{array}{llrll}\text { 208673_s_at } & -0.755549667 & 6428 & \text { SFRS3 } & \begin{array}{c}\text { splicing factor, arginine/serine- } \\ \text { rich } 3\end{array} \\ & & & \\ & & & \\ & & & & \\ \text { 222706_at } & -0.753962333 & 54883 & \text { CCDC49 } & \begin{array}{l}\text { coiled-coil domain containing 49 } \\ \text { pleckstrin homology, Sec7 and } \\ \text { coiled-coil domains } \\ 1 \text { (cytohesin 1) }\end{array}\end{array}$

5634 // nucleus // inferred from electronic annotation

-
from electronic annotation /II 5737 // cytoplasm // inferred from direct assay /// 5886 // plasma membrane // inferred from direct assay
5622 // intracellular // inferred
398 // nuclear mRNA splicing, via spliceosome // inferred from electronic annotation /// 6397 // mRNA processing // inferred from electronic annotation

16192 // vesicle-mediated transport // traceable author statement /// 30155 // regulation of cell adhesion // inferred from direct assay /I/ 32012 // regulation of ARF protein signal transduction // inferred from electronic annotation

367
3677 // DNA binding // inferred rom electronic annotation /// 3887 // DNA-directed DNA polymerase activity // inferred from electronic annotation /// 16740 // transferase activity // inferred from electronic annotation /// 16779 // nucleotidyltransferase activity // inferred from electronic annotation

166 // nucleotide binding // inferred from electronic annotation /// 3723 // RNA binding // inferred from electronic annotation /// 3723 // RNA binding // traceable author statement /// 3676 // nucleic acid binding // inferred from electronic annotation

5086 // ARF guanyl-nucleotide exchange factor activity // traceable author statement /II 5515 // protein binding // inferred from direct assay //I 5085 // guanyl-nucleotide exchange factor activity // inferred from electronic annotation /// 5086 // ARF guanyl-nucleotide exchange factor activity // inferred from electronic annotation 
$82 / /$ G1/S transition of mitotic cell cycle // traceable author statement /// 6512 // ubiquitin cycle // inferred from electronic annotation /// 7049 // cell cycle // inferred from electronic annotation /// $7050 / /$ cell cycle arrest // traceable author statement /// 8285 // negative regulation of cell proliferation // traceable autho statement /// 8629 // induction of apoptosis by intracellular signals // traceable author statement

211797_s_at $\quad-0.7486355 \quad 4802 \quad$ NFYC nuclear transcription factor $Y$,
gamma
$74 / /$ regulation of progression through cell cycle // traceable author statement /// 6350 // transcription // inferred from electronic annotation /// 6355 // regulation of transcription, DNA-dependent // traceable author statement /// 6357 // regulation of transcription from RNA polymerase II promoter // traceable author statement /// 6457 // protein folding // traceable author statement /// 6355 // regulation of transcription, DNA dependent // inferred from direct assay /// 6355

regulation of transcription, DNA-dependent // inferre from electronic annotation
5622 // intracellular // inferred from electronic annotation /I/ 5634 // nucleus // inferred from expression pattern /// 5634 // nucleus // non-traceable author statement /// 16602 // CCAATbinding factor complex // inferred from direct assay /I/ $5634 / 1$
$5515 / /$ protein binding // inferred from physical interaction

$3700 / /$ transcription factor activity // traceable author statement /// 3702 // RNA polymerase II transcription factor activity // traceable author statement /// 3713 // transcription coactivator activity // traceable author statement /// 3887 // DNAdirected DNA polymerase activity // inferred from

electronic annotation /// 5515 // protein binding // inferred from direct assay /// 16740

transferase activity // inferred from electronic annotation /// 43565 // sequence-specific

DNA binding // inferred from electronic annotation /// 3677 // DNA binding // inferred from direct assay /// 3677 // DNA binding // inferred from electronic annotation 
$6355 / /$ regulation of

transcription, DNA-dependent

// inferred from electronic

annotation electronic annotation /// 5730 // nucleolus // traceable author statement /// 5622 // intracellular // inferred from electronic annotation

\section{eotide binding $/ /$} inferred from electronic annotation /// 3723 // RNA binding // inferred from electronic annotation /// 4004 // ATP-dependent RNA helicase activity // traceable author statement /// 5524 // ATP binding // inferred from electronic annotation /// 16787 // hydrolase activity // inferred from electronic annotation /// 4386 // helicase activity // inferred from electronic annotation /// 3676 // nucleic acid binding // inferred from electronic annotation /// $3677 / /$ DNA binding // inferred from electronic annotation /// $8270 / /$ zinc ion binding // inferred from electronic annotation /// 46872 // metal ion binding // inferred from electronic annotation /// 8026 // ATP-

dependent helicase activity // inferred from electronic annotation

(Continued) 
Burkitt lymphoma receptor 1 , GTP binding protein

(chemokine (C-X-C motif) receptor 5)

202543 s at

244828_x_at -0.743475833

231771_

$-0.7422205$

92345

10804
GMFB

LOC92345

GJB6 hypothetical protein $\mathrm{BC} 008207$

gap junction protein, beta 6

$$
\text { (connexin 30) }
$$

5887 // integral to plasma membrane // traceable author statement /// 16020 // membrane // inferred from electronic annotation /// 16021 // integral to membrane // inferred from electronic annotation pathway // traceable author statement /// 42113 // B cell activation // inferred from electronic annotation /// $7186 / /$ G-protein coupled receptor protein signaling pathway // inferred from electronic annotation

\section{Molecular Function}

1584 // rhodopsin-like receptor activity // inferred from electronic annotation /// 4872 // receptor activity // inferred from electronic annotation /// 4945 // angiotensin type II receptor activity // inferred from electronic annotation /// 16494 // C-X-C chemokine receptor activity // inferred from electronic annotation /// 4871 // signal transducer activity // inferred from electronic annotation /// 4930 // G-protein coupled receptor activity // inferred from electronic annotation /// 4930 // G-protein coupled receptor activity // traceable author statement

3779 // actin binding // inferred from electronic annotation /// 8083 // growth factor activity // inferred from electronic annotation

3823 // antigen binding // non-

6955 // immune response // non- 5576 // extracellular region // traceable author statement /// 7154 // cell communication // inferred from electronic annotation /// 7605 // sensory perception of sound // traceable author statement /// 7605 // sensory perception of sound // inferred from electronic 622 // intracellular // inferred from electronic annotation // 5922 // connexon complex // annotation

6396 // RNA processing // inferred from electronic annotation non-traceable author statement inferred from electronic annotation /// 16020 // membrane // inferred from electronic annotation /// 1602

traceable author statement II/ 15285 // connexon channel activity // inferred from electronic annotation

// integral to membrane // inferred from electronic a

175 // 3'-5'-exoribonuclease activity // inferred from electronic annotation /// 3723 // RNA binding // inferred from electronic annotation 


\begin{abstract}
232612_s_at $\quad-0.740365167 \quad 55054$
\end{abstract}
ATG16L1

ATG16 autophagy related 16-like

1 (S. cerevisiae)

208841 s at -0.739521833

9908

G3BP2

203622 st -0.7391365

56902

putatative $28 \mathrm{kDa}$ protein

Ras-GTPase activating protein SH3 domain-binding protein 2
6914 // autophagy // inferred

from electronic annotation ///

$15031 / /$ protein transport //

inferred from electronic

annotation /// 6810 // transport

// inferred from electronic

annotation

6397 // mRNA processing // inferred from electronic annotation /// 6406 // mRNA export from nucleus // inferred

from electronic annotation /// $6810 / /$ transport // inferred from electronic annotation //I 7253 // cytoplasmic sequestering of NF-kappaB // non-traceable author statement /// 7265 // Ras protein signal transduction // non-traceable author statement

5622 // intracellular // inferred from electronic annotation $/ / /$ 5737 // cytoplasm // nontraceable author statement

6020 // membrane // inferred from electronic annotation

inferred fron

annotation

166 // nucleotide binding // inferred from electronic annotation /// 3723 // RNA binding // non-traceable author statement /// 30159 // receptor signaling complex scaffold activity // non-traceable author statement /// 3676 // nucleic acid binding // inferred from electronic annotation /// 3723 //

RNA binding // inferred from electronic annotation

3676 // nucleic acid binding // inferred from electronic annotation /// 3723 // RNA binding // inferred from electronic annotation

223787_s_at $\quad-0.734289 \quad 51244 \quad$ C3orf19 $\begin{gathered}\text { chromosome } 3 \text { open reading } \\ \text { frame } 19\end{gathered}$
frame 19 
L27 /// mitochondrial

ribosomal protein $\mathrm{L} 27$

201083_s_at $\quad-0.7325775 \quad 9774 \quad$ BCLAF

\section{3_at}

$-0.729714333$

55853

C10orf110

206360_s_at

$-0.727941333$
9021
SOCS3 factor 1

\section{chromosome 10 open reading}

frame 110

suppressor of cytokine signaling
BCL2-associated transcription
6412 // protein biosynthesis // inferred from electronic annotation /// 6412 // protein biosynthesis // non-traceable author statement

5622 // intracellular // inferred from electronic annotation ///

5739 // mitochondrion //

inferred from electronic

annotation /// 5762 //

mitochondrial large ribosomal

subunit // non-traceable author

statement /// 5840 // ribosome

// inferred from electro

5634 // nucleus // non-traceable author statement /// 5634 // nucleus // inferred from direct assay /// 5634 // nucleus // inferred from electronic

transcription, DNA-dependent // inferred from electronic annotation /// 6917 // induction of apoptosis // traceable author statement /// 16481 // negative regulation of transcription // inferred from direct assay //I 43065 // positive regulation of apoptosis // inferred from direct assay

1558 // regulation of cell growth $/ /$ inferred from electronic annotation /// 6916 // antiapoptosis // traceable author statement /// 7242 //

intracellular signaling cascade // inferred from electronic annotation /// 7259 // JAKSTAT cascade // traceable author statement /// 9968 // negative regulation of signal transduction // inferred from electronic annotation
3735 // structural constituent of ribosome // inferred from electronic annotation /// 3735 // structural constituent of ribosome // non-traceable author statement

3677 // DNA binding // inferred from direct assay /// $5515 / /$ protein binding // inferred from physical interaction /// 16564 // transcriptional repressor activity // traceable author statement /// 16564 // transcriptional repressor activity // inferred from direct assay /// 3677 // DNA binding // inferred from electronic annotation

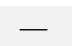

$860 / /$ protein kinase inhibito activity // traceable author statement 
218172_s_at $-0.725955833 \quad 79139 \quad$ DERL1 Der1-like domain family, member 1

\section{9}

$-0.725638333$

10988
Biological Process

$15031 / /$ protein transport //

inferred from electronic annotation /// 19060 // intracellular transport of viral proteins in host cell // traceable author statement /// 30433 // ER-associated protein catabolism // inferred from direct assay /// $30968 / /$ unfolded protein response // inferred from direct assay /II 30970 // retrograde protein transport, ER to cytosol // inferred from direct assay // $6810 / /$ transport // inferred from electronic annotation // 45184 // establishment of protein localization // traceable author statement

6445 // regulation of translation // traceable author statement /// 6464 // protein modification // traceable author statement $/ I$ 6508 // proteolysis // inferred from electronic annotation // 18206 // peptidyl-methionine modification // traceable author statement /// $31365 / / \mathrm{N}$ terminal protein amino acid modification // traceable author statement /// 6417 // regulation of protein biosynthesis //

traceable author statement

5783 // endoplasmic reticulum // 4872 // receptor activity // noninferred from direct assay //I 5783 // endoplasmic reticulum $/ /$ inferred from mutant phenotype /// $16020 / /$ membrane // inferred from electronic annotation /// 1602

// integral to membrane //

inferred from electronic anno raceable 5515 // protein binding // inferred from physical interaction /// 42288 // MHC class I protein binding // inferred from direct assay

5737 // cytoplasm // traceable

\section{author statement}

\section{9 // methionyl}

aminopeptidase activity // inferred from electronic annotation /// 4239 //

methionyl aminopeptidase activity // traceable author statement /// 8233 // peptidase activity // inferred from electronic annotation /// 46872 // metal ion binding // inferred from electronic annotation /// 50897 // cobalt ion binding // inferred from electronic annotation /// 4177 // aminopeptidase activity // inferred from electronic annotation /// 8235 // metalloexopeptidase activity // inferred from electronic annotation /// 16787 // hydrolase activity // inferred from electronic annotation $\sum_{\substack{\mathrm{m} \\ \mathrm{N}}}^{\circ}$

\section{m}

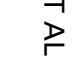


122 // negative regulation of transcription from RNA polymerase II promoter // traceable author statement /II $6350 / /$ transcription // inferred from electronic annotation /II 6355 // regulation of transcription, DNA-dependent // inferred from electronic annotation /// 6810 // transport // traceable author statement /I/ $7001 / /$ chromosome organization and biogenesis (sensu Eukaryota) // not recorded
206108 s at $\quad-0.717038667$
SFRS6 splicing factor, arginine/serinerich 6

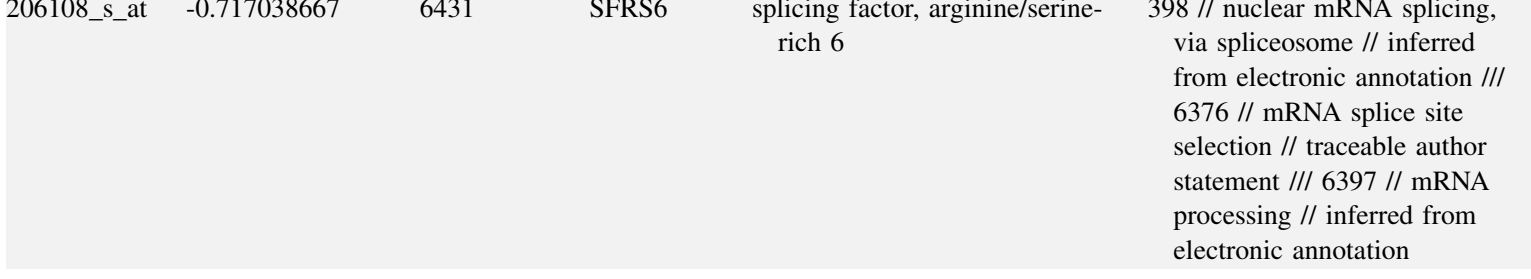

398 // nuclear mRNA splicing, via spliceosome // inferred 6376 // mRNA splice site electronic annotation 5622 // intracellular // inferred rom electronic annotation

5634 // nucleus // traceable nucleus // inferred from

electronic annotation

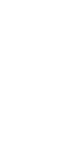

228 // nuclear chromosome // author statement /// 5634 //

\section{$3676 / /$ nucleic acid binding //}

inferred from electronic

annotation /// 3700 //

transcription factor activity // traceable author statement /II 3704 // specific RNA polymerase II transcription factor activity // not recorded /// 5515 // protein binding // inferred from electronic annotation /// 5515 // protein binding // traceable author statement /// 8270 // zinc ion binding // inferred from

electronic annotation /// 46872 // metal ion binding // inferred from electronic annotation /II 3677 // DNA binding // inferred from electronic annotation /// 3677 // DNA binding // traceable author statement

5634 // nucleus // inferred from electronic annotation /// 5634 // nucleus // not recorded

166 // nucleotide binding // inferred from electronic annotation /// 3723 // RNA binding // inferred from

electronic annotation /// 3676 // nucleic acid binding // inferred from electronic annotation

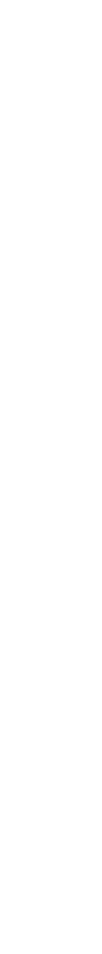


annotation /// 8152 //

metabolism // inferred from

electronic annotation /// $8610 / /$

lipid biosynthesis // inferred

from electronic annotation /II

9058 // biosynthesis // inferred

from electronic annotation //I

$6631 / /$ fatty acid metabolism // traceable author statement

Cellular Component

inferred from electronic

annotation /// 4313 // [acyl-

carrier protein]

S-acetyltransferase activity //

inferred from electronic

annotation /// 4314 // [acyl-

carrier protein]

S-malonyltransferase activity //

inferred from electronic

annotation /// 4315 //

3-oxoacyl-[acyl-carrier

protein] synthase activity //

inferred from electronic

annotation /// 4316 //

3-oxoacyl-[acyl-carrier

protein] reductase activity //

inferred from electronic

annotation /II 4317 //

3-hydroxypalmitoyl-[acyl-

carrier protein] dehydratase

activity // inferred from

electronic annotation /// 4319 //

enoyl-[acyl-carrier protein]

reductase (NADPH, B-

specific) activity // inferred

from electronic annotation ///

4320 // oleoyl-[acyl-carrier

protein] hydrolase activity //

inferred from electronic

annotation /// 5515 // protein

binding // inferred from

physical interaction /// $16491 / /$

oxidoreductase activity //

inferred from electronic

annotation /// 16740 //

transferase activity // inferred

from electronic annotatio

\section{DNA-damage-inducible}

transcript 4

202776 at $-0.713180333 \quad 30836 \quad$ DNTTIP2

deoxynucleotidyltransferase,

terminal, interacting protein 2

(1)

?
annotation 
interferon stimulated exonuclease gene 20kDa-like 2 /I/ interferon stimulated exonuclease gene 20kDa-like 2

$\begin{array}{ccccc}\text { 221766_s_at } & -0.708867667 & 55603 & \text { FAM46A } & \begin{array}{c}\text { family with sequence similarity } \\ 46, \text { member A }\end{array} \\ \text { 244868_at } & -0.708648333 & 22882 & \text { ZHX2 } & \text { Zinc fingers and homeoboxes 2 }\end{array}$

$219798 \_$s_at -0.7066985

56257

BCDIN3

bin3, bicoid-interacting 3, homolog (Drosophila)
5622 /I int electronic annotation /// 5634 // nucleus // inferred from electronic annotation
45892 // negative regulation of transcription, DNA-dependent // inferred from direct assay /// $6350 / /$ transcription // inferred from electronic annotation /II $6355 / /$ regulation of transcription, DNA-dependent

// inferred from electronic annotation /// 45449 // regulation of transcription // inferred from electronic annotation
5622 // intracellular // inferred from electronic annotation /II 5634 // nucleus // inferred from direct assay /// 5634 // nucleus $/ /$ inferred from electronic annotation
4527 // exonuclease activity // inferred from electronic annotation /// 16787 // hydrolase activity // inferred from electronic annotation /// 4518 // nuclease activity // inferred from electronic annotation

$3700 / /$ transcription factor activity // inferred from direct assay /// 5515 // protein binding // inferred from physical interaction /// $8270 / /$ zinc ion binding // inferred from electronic annotation //I 43565 // sequence-specific

DNA binding // inferred from electronic annotation /// 46872 // metal ion binding // inferred from electronic annotation /// 3676 // nucleic acid binding // inferred from electronic annotation /// 3677 // DNA binding // inferred from electronic annotation /// $3700 / /$ transcription factor activity // inferred from electronic annotation

$8168 / /$ methyltransferase activity $/ /$ inferred from electronic annotation /// 16740 // transferase activity // inferred from electronic annotation

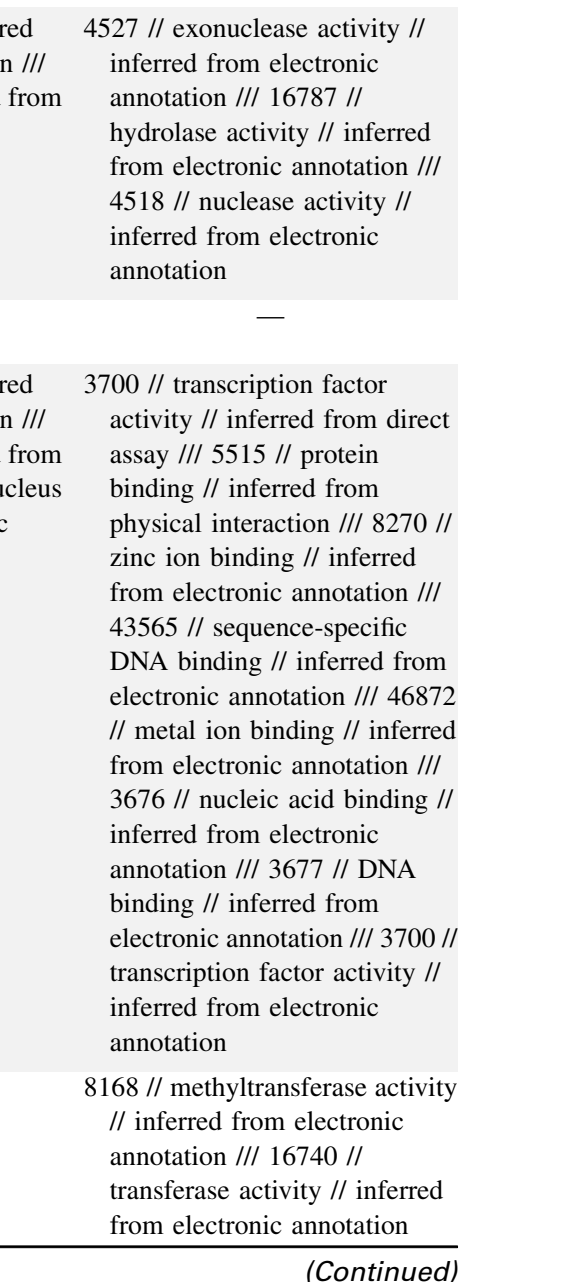


6364 // rRNA processing // inferred from electronic annotation /// 6888 // ER to Golgi vesicle-mediated

transport // inferred from electronic annotation /// $7264 / /$ small GTPase mediated signal transduction // inferred from electronic annotation /// 15031 // protein transport // inferred from electronic annotation III 6810 // transport // inferred from electronic annotation /II 7046 // ribosome biogenesis // inferred from electronic annotation

hromosome 8 open reading frame 61

$\begin{array}{lllll}\text { 229958_at } & -0.705591333 & 619435 & \text { C8orf61 } & \begin{array}{c}\text { chromosome } 8 \text { open reading } \\ \text { frame } 61\end{array} \\ \text { 230764_at } & -0.7044995 & 23731 & \text { C9orf5 } & \begin{array}{c}\text { Chromosome } 9 \text { open reading } \\ \text { frame } 5\end{array}\end{array}$

203013_at $\quad-0.704272333 \quad 11319 \quad$ ECD $\quad \begin{gathered}\text { ecdysoneless homolog } \\ \text { (Drosophila) }\end{gathered}$

$\begin{array}{ccccc}\text { 225699_at } & -0.703454167 & 285958 & \text { C7orf40 } & \begin{array}{c}\text { chromosome 7 open reading } \\ \text { frame 40 }\end{array} \\ \text { 204833_at } & -0.703122667 & 9140 & \text { ATG12 } & \begin{array}{c}\text { ATG12 autophagy related 12 } \\ \text { homolog (S. cerevisiae) }\end{array}\end{array}$

5622 // intracellular // inferred

from electronic annotation

166 // nucleotide binding // inferred from electronic annotation /// 3924 // GTPase activity // traceable author statement /// 5525 // GTP binding // inferred from electronic annotation /// 8047 // enzyme activator activity // no recorded
6110 // regulation of glycolysis // traceable author statement /II $6366 / /$ transcription from RNA polymerase II promoter //

traceable author statement

45 // autophagic vacuole formation // inferred from electronic annotation /// $6512 / /$ ubiquitin cycle // inferred from electronic annotation /// 6914 // autophagy // traceable author statement /// 6915 // apoptosis // traceable author statement /// 6914 // autophagy // inferred from electronic annotation /I/ 6464 // protein modification // traceable author statement

\section{7 // cytoplasm // traceable author statement /// 5737 // \\ $5515 / /$ protein binding // inferred from physical interaction} cytoplasm // inferred from electronic annotation
3713 // transcription coactivator activity // traceable author statement

from electronic annotation

16021 // integral to membrane statement /// 16021 // integral to membrane // inferred from electronic annotation

(n)




\section{4 // mRNA catabolism,} nonsense-mediated decay // inferred from electronic annotation /// 398 // nuclear mRNA splicing, via spliceosome // inferred from electronic annotation /// $6406 / /$ mRNA export from nucleus // inferred from electronic annotation /// 6810 // transport // inferred from electronic annotation /// 6396 // RNA processing // inferred from electronic annotation /// 6397 // mRNA processing // inferred from electronic annotation
6508 // proteolysis // nontraceable author statement /// 6955 // immune response // traceable author statement // 6508 // proteolysis // inferred from electronic annotation
5634 // nucleus // non-traceable 166 // nucleotide binding // athor statement /// 5737 //

cytoplasm // non-traceable author statement /// 5634 // nucleus // inferred from electronic annotation /// 5737 cytoplasm // inferred from electronic annotation

5737 // cytoplasm // nontraceable author statement //I 16020 // membrane // inferred from electronic annotation inferred from electronic inferred from electronic annotation /// 3729 // mRNA binding // non-traceable autho statement /// 5515 // protein binding // inferred from

physical interaction /// $3676 / /$ nucleic acid binding // inferred from electronic annotation //I

3723 // RNA binding // inferred from electronic annotation /// 3723 // RNA

binding // non-traceable author statement

4177 // aminopeptidase activity // inferred from electronic annotation /// 4252 // serinetype endopeptidase activity // inferred from electronic annotation /// 4274 // dipeptidyl-peptidase IV activity // inferred from electronic annotation /// 8233 peptidase activity // inferred from electronic annotation //I $8236 / /$ serine-type peptidase activity // inferred from electronic annotation /// 16787 // hydrolase activity // inferred from electronic annotation /II 8239 // dipeptidyl-peptidase activity // non-traceable author statement 
$5886 / /$ plasma membrane // traceable author statement

\section{6_s_at}

$-0.695251667$

80824

DUSP16

dual specificity phosphatase $16 / / / 188$ // inactivation of MAPK dual specificity phosphatase 16

activity // traceable author statement /// 6470 // protein amino acid dephosphorylation // inferred from electronic annotation /// 45204 // MAPK export from nucleus //

traceable author statement /I/ 45209 // MAPK phosphatase export from nucleus,

leptomycin B sensitive // traceable author statement /// 16311 // dephosphorylation // traceable author statement

\begin{tabular}{|c|c|c|c|c|}
\hline 213376_at & -0.694042833 & 22890 & ZBTB1 & $\begin{array}{l}\text { zinc finger and BTB domain } \\
\text { containing } 1\end{array}$ \\
\hline
\end{tabular}

5634 // nucleus // traceable author statement /// 5737 // cytoplasm // traceable author statement /// 5634 // nucleus // inferred from electronic annotation

622 // intracellular // inferred from electronic annotation /// 5634 // nucleus // inferred from electronic annotation
$6350 / /$ transcription // inferred from electronic annotation /II $6355 / /$ regulation of transcription, DNA-dependen // inferred from electronic annotation

\section{Molecular Function}

16301 // kinase activity // inferred from electronic annotation /I/ 5198 // structural molecule activity // traceable author statement /// 5515 // protein binding // traceable author statement

4725 // protein tyrosine phosphatase activity // inferred from electronic annotation /II 16787 // hydrolase activity // inferred from electronic annotation // 17017 // MAP kinase phosphatase activity // inferred from electronic annotation /// 4721 // phosphoprotein phosphatase activity // inferred from electronic annotation /// 8138 // protein tyrosine/serine/

threonine phosphatase activity // inferred from electronic annotation /// $4721 / /$

phosphoprotein phosphatase activity // traceable author statement

3676 // nucleic acid binding // inferred from electronic annotation /// 3677 // DNA binding // inferred from electronic annotation /// 5515 // protein binding // inferred from electronic annotation /// $8270 / /$ zinc ion binding // inferred from electronic annotation /// 46872 // metal ion binding // inferred from electronic annotation 

(RNA/RNP complex 1interacting) dual specificity phosphatase 11

\section{6 // RNA processing //} traceable author statement /II $6470 / /$ protein amino acid from electronic annotation dephosphorylation // inferred

\begin{tabular}{|c|c|c|c|c|}
\hline 202523_s_at & -0.688867167 & 9806 & SPOCK2 & $\begin{array}{l}\text { sparc/osteonectin, cwcv and } \\
\text { kazal-like domains } \\
\text { proteoglycan (testican) } 2\end{array}$ \\
\hline
\end{tabular}

\section{3 at}

$-0.676218167$

$-0.676017$

11103

203203_s_at

KRR

GRASP

\section{phosphoinositides 1)-}

GRP1 (general receptor for

associated scaffold protein

KRR1, small subunit (SSU)
processome component,

homolog (yeast)
7416 // synaptogenesis // nontraceable author statement // 30198 // extracellular matrix organization and biogenesis // non-traceable author statement /// 45595 // regulation of cell differentiation // non-traceable author statement

6364 // rRNA processing //
inferred from sequence or structural similarity electronic annotation /// 16020 electronic annotation /// 5732 // ribonucleoprotein complex //
$5578 / /$ extracellular matrix (sensu Metazoa) // nontraceable author statement /I/ 5578 // extracellular matrix (sensu Metazoa) // inferred from electronic annotation

5634 // nucleus // inferred from // membrane // inferred from electronic annotation

5634 // nucleus // inferred from small nucleolar inferred from sequence or structural similarity author statement /// 4725 // protein tyrosine phosphatase activity // traceable author statement /// 8138 // protein tyrosine/serine/threonine phosphatase activity // inferred from electronic annotation //I 16787 // hydrolase activity // inferred from electronic annotation /// 3723 // RNA binding // inferred from electronic annotation /// 4721 // phosphoprotein phosphatase activity // inferred from electronic annotation

5509 // calcium ion binding // inferred from direct assay /// 5509 // calcium ion binding // inferred from electronic annotation

$5515 / /$ protein binding // inferred from electronic annotation

5515 // protein binding // inferrec from sequence or structural similarity /// 30515 // snoRNA binding // inferred from sequence or structural similarity /// 3676 // nucleic acid binding // inferred from electronic annotation /// 3723 // RNA binding // inferred from electronic annotation

16020 // membrane // inferred from electronic annotation /// $16021 / /$ integral to membrane // inferred from electronic annotation

2)

223511_at $\quad-0.672153667 \quad 83932 \quad$ Clorf124 $\quad$ frame 124 from electronic annotation

3677 // DNA binding // inferred from electronic annotation 


\begin{tabular}{|c|c|c|c|c|c|c|c|}
\hline \multirow[b]{2}{*}{ Probe Set ID } & \multirow[b]{2}{*}{ Log Ratio } & \multirow[b]{2}{*}{ Entrez Gene } & \multirow[b]{2}{*}{ Gene Symbol } & \multirow[b]{2}{*}{ Gene Descriptor } & \\
\hline & & & & & Biological Process & Cellular Component & Molecular Function \\
\hline 231983_at & -0.671169 & 200205 & C1orf69 & $\begin{array}{l}\text { chromosome } 1 \text { open reading } \\
\text { frame } 69\end{array}$ & $\begin{array}{l}6546 / / \text { glycine catabolism // } \\
\text { inferred from electronic } \\
\text { annotation }\end{array}$ & $\begin{array}{l}5737 \text { // cytoplasm // inferred from } \\
\text { electronic annotation }\end{array}$ & $\begin{array}{l}4047 / / \text { aminomethyltransferase } \\
\text { activity // inferred from } \\
\text { electronic annotation }\end{array}$ \\
\hline 223819_x_at & -0.665328667 & 28991 & COMMD5 & COMM domain containing 5 & - & $\begin{array}{l}5634 / / \text { nucleus // inferred from } \\
\text { electronic annotation }\end{array}$ & - \\
\hline 238476_at & -0.663777833 & 153222 & LOC153222 & adult retina protein & $\begin{array}{l}6355 / / \text { regulation of } \\
\text { transcription, DNA-dependent } \\
\text { // inferred from electronic } \\
\text { annotation }\end{array}$ & $\begin{array}{l}5634 / / \text { nucleus // inferred from } \\
\text { electronic annotation }\end{array}$ & $\begin{array}{l}3700 \text { // transcription factor } \\
\text { activity // inferred from } \\
\text { electronic annotation /// } 43565 \\
\text { // sequence-specific DNA } \\
\text { binding // inferred from } \\
\text { electronic annotation /// } 46983 \\
\text { // protein dimerization activity } \\
\text { // inferred from electronic } \\
\text { annotation }\end{array}$ \\
\hline 230023_at & -0.662249833 & 387338 & NSUN4 & $\begin{array}{l}\text { NOL1/NOP2/Sun domain family, } \\
\text { member } 4\end{array}$ & - & - & - \\
\hline 226612_at & -0.662115 & 134111 & FLJ25076 & similar to CG4502-PA & $\begin{array}{l}6512 / / \text { ubiquitin cycle // inferred } \\
\text { from electronic annotation }\end{array}$ & - & $\begin{array}{l}4842 / / \text { ubiquitin-protein ligase } \\
\text { activity // inferred from } \\
\text { electronic annotation }\end{array}$ \\
\hline 207515_s_at & -0.661354333 & 9533 & POLR1C & $\begin{array}{l}\text { polymerase (RNA) I polypeptide } \\
\text { C, } 30 \mathrm{kDa}\end{array}$ & $\begin{array}{l}6350 / / \text { transcription // inferred } \\
\text { from electronic annotation /// } \\
6360 / / \text { transcription from RNA } \\
\text { polymerase I promoter // } \\
\text { traceable author statement }\end{array}$ & $\begin{array}{l}5634 \text { // nucleus // inferred from } \\
\text { electronic annotation /// } 5736 / / \\
\text { DNA-directed RNA } \\
\text { polymerase I complex // } \\
\text { traceable author statement }\end{array}$ & $\begin{array}{l}3677 \text { // DNA binding // inferred } \\
\text { from electronic annotation /// } \\
3899 \text { // DNA-directed RNA } \\
\text { polymerase activity // inferred } \\
\text { from electronic annotation /// } \\
3899 \text { // DNA-directed RNA } \\
\text { polymerase activity // traceable } \\
\text { author statement /// } 16740 / / \\
\text { transferase activity // inferred } \\
\text { from electronic annotation /// } \\
46983 / / \text { protein dimerization } \\
\text { activity // inferred from } \\
\text { electronic annotation /// 16779 } \\
\text { // nucleotidyltransferase } \\
\text { activity // inferred from } \\
\text { electronic annotation }\end{array}$ \\
\hline
\end{tabular}


398 // nuclear mRNA splicing, via spliceosome // inferred from electronic annotation /// 6364 // rRNA processing // inferred from electronic annotation /// 6810 // transport // inferred from electronic annotation /// $6811 / /$ ion transport // inferred from electronic annotation /// 15986 // ATP synthesis coupled proton transport // inferred from electronic annotation /I/ 15992 // proton transport // inferred from electronic annotation /// 6397 // mRNA processing // inferred from electronic annotation /// $6091 / /$ generation of precursor metabolites and energy // no recorded

\begin{tabular}{|c|c|c|c|c|}
\hline 209339_at & -0.655213333 & 6478 & SIAH2 & $\begin{array}{l}\text { seven in absentia homolog } 2 \\
\text { (Drosophila) /// seven in } \\
\text { absentia homolog } 2 \\
\text { (Drosophila) }\end{array}$ \\
\hline
\end{tabular}

$6511 / /$ ubiquitin-dependent protein catabolism // traceable author statement /// 6915 // apoptosis // inferred from electronic annotation /// 7049 // cell cycle // inferred from electronic annotation /// 7264 // small GTPase mediated signal transduction // traceable author statement /// 7275 //

development // inferred from electronic annotation /// $6511 / /$ ubiquitin-dependent protein catabolism // inferred from electronic annotation /// 6512 // ubiquitin cycle // inferred from electronic annotation
Molecular Function author statement /// 5739 // mitochondrion // inferred from electronic annotation /// 16469 // proton-transporting twosector ATPase complex // inferred from electronic annotation /// 45263 // protontransporting ATP synthase

5634 // nucleus // inferred from electronic annotation /// 5737 // cytoplasm // traceable author statement activity // inferred from binding // traceable author statement /// 5515 // protein binding // inferred from physical interaction /// 15078 // hydrogen ion transporter electronic annotation /// 46933 // hydrogen-transporting ATP synthase activity, rotational mechanism // inferred from electronic annotation /// 46961 // hydrogen-transporting ATPase activity, rotational mechanism // inferred from electronic annotation /// 5215 // transporter activity // nontraceable author statemen

3714 // transcription corepressor activity // traceable author statement /// 5515 // protein binding // inferred from electronic annotation /// $8270 / /$ zinc ion binding // inferred from electronic annotation /II 16874 // ligase activity // inferred from electronic annotation /// 46872 // metal ion binding // inferred from electronic annotation 


\begin{tabular}{|c|c|c|c|c|c|c|c|}
\hline 204448_s_at & -0.653306 & 5082 & PDCL & phosducin-like & $\begin{array}{l}7165 \text { // signal transduction // non- } \\
\text { traceable author statement /// } \\
7601 / / \text { visual perception // } \\
\text { inferred from electronic } \\
\text { annotation /// } 50896 / / \text { response } \\
\text { to stimulus // inferred from } \\
\text { electronic annotation }\end{array}$ & - & $\begin{array}{l}16299 / / \text { regulator of G-protein } \\
\text { signaling activity // non- } \\
\text { traceable author statement }\end{array}$ \\
\hline 226308_at & -0.652660667 & 93323 & NY-SAR-48 & sarcoma antigen NY-SAR-48 & - & - & - \\
\hline 202010_s_at & -0.649903833 & 57862 & ZNF410 & zinc finger protein 410 & $\begin{array}{l}6350 / / \text { transcription // inferred } \\
\text { from electronic annotation /// } \\
6355 / / \text { regulation of } \\
\text { transcription, DNA-dependent } \\
\text { // inferred from electronic } \\
\text { annotation }\end{array}$ & $\begin{array}{l}5622 / / \text { intracellular // inferred } \\
\text { from electronic annotation /// } \\
5634 / / \text { nucleus // inferred from } \\
\text { electronic annotation }\end{array}$ & $\begin{array}{l}3677 \text { // DNA binding // inferred } \\
\text { from electronic annotation /// } \\
8270 \text { // zinc ion binding // } \\
\text { inferred from electronic } \\
\text { annotation /// } 46872 / / \text { metal } \\
\text { ion binding // inferred from } \\
\text { electronic annotation /// } 3676 / / \\
\text { nucleic acid binding // inferred } \\
\text { from electronic annotation }\end{array}$ \\
\hline 224717_s_at & -0.649120167 & 79086 & C19orf42 & $\begin{array}{l}\text { chromosome } 19 \text { open reading } \\
\text { frame } 42\end{array}$ & - & - & - \\
\hline 207332_s_at & -0.646887667 & 7037 & TFRC & transferrin receptor $(\mathrm{p} 90, \mathrm{CD} 71)$ & $\begin{array}{l}6508 \text { // proteolysis // inferred } \\
\text { from electronic annotation /// } \\
6826 \text { // iron ion transport // not } \\
\text { recorded /// } 6879 \text { // iron ion } \\
\text { homeostasis // non-traceable } \\
\text { author statement /// } 6897 / / \\
\text { endocytosis // inferred from } \\
\text { electronic annotation /// } 6879 / / \\
\text { iron ion homeostasis // } \\
\text { traceable author statement }\end{array}$ & $\begin{array}{l}5576 / / \text { extracellular region // } \\
\text { inferred from direct assay /// } \\
5768 / / \text { endosome // inferred } \\
\text { from direct assay /// } 5887 / / \\
\text { integral to plasma membrane // } \\
\text { traceable author statement /// } \\
16020 / / \text { membrane // non- } \\
\text { traceable author statement /// } \\
16023 \text { // cytopl }\end{array}$ & $\begin{array}{l}4872 \text { // receptor activity // } \\
\text { inferred from electronic } \\
\text { annotation /// } 4998 / / \\
\text { transferrin receptor activity // } \\
\text { non-traceable author statement } \\
\text { /// } 8233 \text { // peptidase activity // } \\
\text { inferred from electronic } \\
\text { annotation /// } 4998 / / \\
\text { transferrin receptor activity // } \\
\text { traceable author statement }\end{array}$ \\
\hline
\end{tabular}


5622 // intracellular // inferred from expression pattern

\begin{tabular}{|c|c|c|c|c|}
\hline 201242_s_at & -0.641335833 & 481 & ATP1B1 & $\begin{array}{l}\text { ATPase, } \mathrm{Na}+/ \mathrm{K}+\text { transporting, } \\
\text { beta } 1 \text { polypeptide }\end{array}$ \\
\hline
\end{tabular}

$6811 / /$ ion transport // inferred from electronic annotation /// $6813 / /$ potassium ion transport // inferred from electronic annotation /// 6814 // sodium ion transport // inferred from electronic annotation /// $6810 / /$ transport // inferred from electronic annotation /// $6810 / /$

transport // traceable author statement
5890 // sodium:potassium-

exchanging ATPase complex // traceable author statement /// 16020 // membrane // inferred from electronic annotation //I $16021 / /$ integral to membrane inferred from electronic annotation

chydrolase activity //

inferred from direct assay /II 16787 // hydrolase activity // inferred from electronic annotation /// 4649 // poly(ADP-ribose) glycohydrolase activity // inferred from electronic annotation /// 4649 // poly(ADP-ribose) glycohydrolase activity // traceable author statement

3676 // nucleic acid binding // inferred from electronic annotation /// 5515 // protein binding // inferred from electronic annotation /// $8270 / /$ zinc ion binding // inferred from electronic annotation /// 46872 // metal ion binding // inferred from electronic annotation

5391 // sodium:potassiumexchanging ATPase activity // inferred from electronic annotation /// 5391 // sodium:potassium-exchanging ATPase activity // traceable author statement /// 30955 // potassium ion binding // inferred from electronic annotation /// 31402 // sodium ion binding // inferred from electronic annotation 
splicing factor, arginine/serinerich $7,35 \mathrm{kDa}$

398 // nuclear mRNA splicing, via spliceosome // inferred from electronic annotation // 8380 // RNA splicing // inferred from direct assay /I/ 6397 // mRNA processing // inferred from electronic annotation /// 6397 // mRNA processing // traceable author statement

\section{1 at}

$-0.639138$

10285

SMNDC1 survival motor neuron domain containing $1 / / /$ survival motor neuron domain containing 1
245 // spliceosome assembly // inferred from electronic annotation /// 6915 // apoptosis // inferred from electronic annotation /// 6917 // induction of apoptosis // traceable author statement /// 8380 // RNA splicing // traceable author statement /// 398 // nuclear mRNA splicing, via spliceosome // inferred from electronic annotation /// 6397 // mRNA processing // inferred from electronic annotation /I/ 6397 // mRNA processing // traceable author statement

222748_s_at $\quad-0.638796333 \quad 54957 \quad$ TXNL4B $\quad$ thioredoxin-like 4B

398 // nuclear mRNA splicing, via spliceosome // inferred from electronic annotation /// 7049 // cell cycle // inferred from electronic annotation /// 7067 // mitosis // inferred from electronic annotation /// 6397 // mRNA processing // inferred from electronic annotation // $51301 / /$ cell division // inferred from electronic annotation

Molecular Function

5634 // nucleus // traceable author statement /// $5634 / /$ nucleus // inferred from electronic annotation

5634 // nucleus // inferred from electronic annotation /// $5681 / /$ spliceosome complex // inferred from electronic annotation
534 // nucleus // traceable author statement /// $5681 / /$ spliceosome complex // traceable author statement /II 5737 // cytoplasm // inferred from electronic annotation /// 5634 // nucleus // inferred from electronic annotation /// 5681 // spliceosome com
166 // nucleotide binding // inferred from electronic annotation // 3723 // RNA binding // inferred from electronic annotation /// $5515 / /$ protein binding // inferred from physical interaction /// $8270 / /$ zinc ion binding // inferred from electronic annotation /// 46872 // metal ion binding // inferred from electronic annotation /// 3676 // nucleic acid binding // inferred from electronic annotation

5515 // protein binding // inferred from physical interaction /// 31202 // RNA splicing factor activity, transesterification mechanism // traceable author statement /// 3676 // nucleic acid binding // inferred from electronic annotation /// 3723 // RNA binding // inferred from electronic annotation 
from electronic annotation ///

$16740 / /$ transferase activity // inferred from electronic annotation /// 16779 //

nucleotidyltransferase activity // inferred from electronic

$\begin{array}{lllll}\text { 210275_s_at } & -0.633341667 & 7763 & \text { ZFAND5 } & \text { zinc finger, AN1-type domain } 5 \\ \text { 202643_s_at } & -0.623726667 & 7128 & \text { TNFAIP3 } & \begin{array}{c}\text { tumor necrosis factor, alpha- } \\ \text { induced protein 3 }\end{array}\end{array}$

6512 // ubiquitin cycle // inferred from electronic annotation /I/ $6915 / /$ apoptosis // inferred from electronic annotation /// 6916 // anti-apoptosis // nontraceable author statement /// 43124 // negative regulation of I-kappaB kinase/NF-kappaB cascade // inferred from direct assay annotation

3677 // DNA binding // inferred from electronic annotation /// 8270 // zinc ion binding // inferred from electronic annotation /// 46872 // metal ion binding // inferred from electronic annotation

3677 // DNA binding // inferred from electronic annotation /// 5515 // protein binding // inferred from physical interaction /// 8234 // cysteinetype peptidase activity // inferred from electronic annotation /// 8270 // zinc ion binding // inferred from electronic annotation /// 46872 // metal ion binding // inferred from electronic annotation /// 8233 // peptidase activity //

inferred from electronic annotation /// 16787 // hydrolase activity // inferred from electronic annotation 
fibroblast growth factor 9 (gliaactivating factor)

$74 / /$ regulation of progression $8283 / /$ cell proliferation //

212240_s_at $\quad-0.615695 \quad 5295 \quad$ PIK3R1 $\begin{array}{r}\text { phosphoinositide-3-kinase, } \\ \text { regulatory subunit } 1(\mathrm{p} 85\end{array}$
alpha) through cell cycle // inferred from electronic annotation // 7165 // signal transduction // traceable author statement /// 7267 // cell-cell signaling // traceable author statement /I/ inferred from electronic annotation /// 30154 // cell differentiation // inferred from electronic annotation /// 7275 // development // inferred from electronic annotation 7242 // intracellular signaling cascade // inferred from electronic annotation /// 7242 // intracellular signaling cascade // non-traceable author statement /// $8286 / /$ insulin receptor signaling pathway // inferred from physical interaction /// 46854 // phosphoinositide phosphorylation // inferred from sequence or structural similarity /// 48009 // insulinlike growth factor receptor signaling pathway // inferred from physical interaction //I 7165 // signal transduction // inferred from electronic annotation

\section{$5615 / /$ extracellular space //} traceable author statement

8083 // growth factor activity // traceable author statement /// $8201 / /$ heparin binding // inferred from electronic annotation /// 8083 // growth factor activity // inferred from electronic annotation

5622 // intracellular // inferred from electronic annotation $/ 1 /$ $5942 / /$ phosphoinositide 3-kinase complex // inferred from electronic annotation $35030 / /$ phosphoinositide 3-kinase complex, class IA // inferred from sequence or structural similarity 
241756_at $-0.607308333$
SMARCA2

SWI/SNF related, matrix associated, actin dependent regulator of chromatin subfamily a, member 2
Biological Process

6350 // transcription // inferred from electronic annotation /// 6357 // regulation of ranscription from RNA

polymerase II promoter // traceable author statement // $6355 / /$ regulation of

transcription, DNA-dependent // inferred from electronic annotation /// 6355 //

regulation of transcription, DNA-dependent // traceable author statement
5634 // nucleus // inferred from electronic annotation /// 5654 // nucleoplasm // traceable author statement

// nucleotide binding // inferred from electronic annotation /// 3677 // DNA binding // inferred from

electronic annotation /// $3713 / /$ transcription coactivator activity // traceable author statement /// 5515 // protein binding // inferred from physical interaction /// 5524 // ATP binding // inferred from electronic annotation /// 8026 // ATP-dependent helicase activity // inferred from electronic annotation /// 16787 // hydrolase activity // inferred from electronic annotation /// 3676 // nucleic acid binding // inferred from electronic annotation /// 4386 // helicase activity // inferred from electronic annotation /// $4386 / /$ helicase activity // traceable author statement

5737 // cytoplasm // inferred from

\section{sequence or structural similarity /// 5886 // plasma membrane // inferred from sequence or structural similarity /// 5737 // cytoplasm // traceable author statement /// 5886 // plasma membrane // traceable author statem \\ $186 / /$ G-protein coupled pathway // inferred from sequence or structural similarity /// 7186 // G-protein coupled receptor protein ignaling pathway // traceable author statement}




\section{Probe Set ID \\ Log Ratio Entrez Gene \\ Gene Symbol \\ Gene Descriptor}

MED6 mediator of RNA polymerase II 45944 // positive regulation of

transcription, subunit 6

homolog (S. cerevisiae)

\section{3_at}

54556

ING3

inhibitor of growth family, member 3

// inferred from electronic

regulation of transcription transcription from RNA

polymerase II promoter //

inferred from direct assay /I/

$6350 / /$ transcription // inferred

from electronic annotation //I

$6355 / /$ regulation of

transcription, DNA-dependent

annotation /// 45449 //

regulation of transcription //

inferred from electronic

annotation /// 6357 //

from RNA polymerase II

promoter // traceable author

statement

1558 // regulation of cell growth

// inferred from electronic

annotation /// 6350 //

transcription // inferred from

electronic annotation /// 6355 //

regulation of transcription,

DNA-dependent // inferred

from electronic annotation //

16568 // chromatin

modification // inferred from

electronic annotation

\section{Cellular Component}

$19 / 1$ mediator comp inferred from direct assay /// 5634 // nucleus // traceable author statement /// 5634 //

nucleus // inferred from

electronic annotation /// 119 //

mediator complex // traceable

author statement electronic annotation

-

3702 // RNA polymerase II

transcription factor activity //

traceable author statement /II

3713 // transcription

coactivator activity // inferred

from direct assay /I/ 4872 //

receptor activity // inferred

from electronic annotation /// 30528 // transcription regulator activity // inferred from

electronic annotation

$5515 / /$ protein binding // inferred from electronic annotation /II 8270 // zinc ion binding // inferred from electronic annotation /// 46872 // metal ion binding // inferred from electronic annotation 
ct assay III $6468 / /$

protein amino acid direct assay /// 5634 // nucleu

phosphorylation // inferred

from electronic annotation

\begin{tabular}{|c|c|c|c|c|}
\hline 200597_at & -0.594829167 & 8661 & EIF3S10 & $\begin{array}{l}\text { eukaryotic translation initiation } \\
\text { factor } 3 \text {, subunit } 10 \text { theta, } 15 \\
170 \mathrm{kDa}\end{array}$ \\
\hline
\end{tabular}
annotation /// 6446 //
5852 // eukaryotic translation initiation factor 3 complex traceable author statement annotation
6412 // protein biosynthesis // inferred from electronic regulation of translational initiation // traceable author statement from electronic annotation /// 3702 // RNA polymerase II transcription factor activity // non-traceable author statement /// 4674 // protein serine/threonine kinase activity // inferred from electronic annotation /// 5524 // ATP binding // inferred from electronic annotation /// 16740 // transferase activity // inferred from electronic annotation //I 4672 // protein kinase activity // inferred from direct assay // 4672 // protein kinase activity // inferred from electronic annotation /// $16301 / /$ kinase activity // inferred from electronic annotation

3743 // translation initiation factor activity // inferred from electronic annotation /// 8135 // translation factor activity,

nucleic acid binding // traceable author statement 
homeostasis // inferred from direct assay /// 42789 // mRNA transcription from RNA

polymerase II promoter // inferred from direct assay /II 6350 // transcription // inferred rom electronic annotation /I/ 6355 // regulation of transcription, DNA-dependent $/ /$ inferred from electronic annotation /// 7049 // cell cycle // inferred from electronic annotation /// 7050 // cell cycle arrest // inferred from electronic annotation /// 6955 // mmune response // inferred from electronic annotation // 6355 // regulation of

transcription, DNA-dependent // traceable author statement // 6974 // response to DNA damage stimulus // traceable author statement /// 74 // regulation of progression through cell cycle // nontraceable author statement from electronic annotation 5634 // nucleus // traceable author statement /// 5634 // nucleus // inferred from electronic annotation /// 16020 // membrane // inferred from electronic annotation /// $5634 / /$ nucleus // $\mathrm{n}$

// nucleus // inferred from

inferred from electronic annotation /// 3677 // DNA binding // inferred from electronic annotation /// $3723 / /$ RNA binding // traceable author statement /// 5515 //

protein binding // inferred from physical interaction /// $8270 / /$ zinc ion binding // inferred

from electronic annotation /II 46872 // metal ion binding // inferred from electronic annotation /// 3677 // DNA binding // inferred from direct assay /// 3676 // nucleic acid binding // inferred from electronic annotation /// 3723 // RNA binding // inferred from electronic annotation /// $3700 / /$ transcription factor activity // inferred from electronic nnotation /II 43565 // sequence-specific DNA binding // inferred from electronic annotation /// 46983 $/ /$ protein dimerization activity // inferred from electronic annotation /// 5164 // tumor necrosis factor recepto binding // inferred from electronic annotation /// 3714 // transcription corepressor activity // traceable author statement /// 3700 //

transcription factor acti 


\section{scavenger receptor class $\mathrm{B}$} member 2

\section{5 // cell adhesion // inferred}

from electronic annotation

203898_at

$-0.589967833$

27297

RCP9

calcitonin gene-related peptidereceptor component protein

7340 // acrosome reaction // nontraceable author statement

220104_at $\quad-0.585244333$

56829

ZC3HAV1

zinc finger $\mathrm{CCCH}$-type, antiviral
$6471 / /$ protein amino acid ADPelectronic annotation
9584

RBM39

RFWD2

\section{Gene Ontology}

Cellular Component

Molecular Function

5624 // membrane fraction //

traceable author statement ///

5765 // lysosomal membrane //

not recorded /// 5887 // integral

to plasma membrane //

traceable author statement /II

16020 // membrane // inferred

from electronic annotation /II

5764 // lysosome

-

5634 // nucleus // inferred from

electronic annotation

(a)

1552617_a_at -0.581591167 ing finger and WD repeat domain 2
RNA binding motif protein 39

\section{via spliceosome // inferred} from electronic annotation /II $6350 / /$ transcription // inferred $6355 / /$ regulation of

transcription, DNA-dependent // inferred from electronic annotation /// 6397 // mRNA

processing // inferred from RNA processing // traceable

author statement

6512 // ubiquitin cycle // inferred 5634 // nucleus // inferred from from electronic annotation electronic annotation
98 // nuclear mRNA splicing, from electronic annotation /II electronic annotation /// $6396 / /$
5634 // nucleus // inferred from electronic annotation /// $5654 / /$ nucleoplasm // traceable author statement
5

$5515 / /$ protein binding // inferred from electronic annotation /// 8270 // zinc ion binding // inferred from electronic annotation /// 16874 // ligase activity // inferred from // metal ion binding // inferred from electronic annotation electronic annotation /// 46872

4948 // calcitonin receptor statement

if // nucleic acid binding annotation /// 3950 // NAD+ ADP-ribosyltransferase activity // inferred from electronic annotation /// 8270 // inc ion binding // inferred electronic annotation /// inferred from electronic annotation annotation /// 3676 // nucleic acid binding // inferred from electronic annotation /// 3723 // RNA binding // inferred from electronic annotation 


\begin{tabular}{|c|c|c|c|c|c|c|c|}
\hline \multirow[b]{2}{*}{ Probe Set ID } & \multirow[b]{2}{*}{ Log Ratio } & \multirow[b]{2}{*}{ Entrez Gene } & \multirow[b]{2}{*}{ Gene Symbol } & \multirow[b]{2}{*}{ Gene Descriptor } & \\
\hline & & & & & Biological Process & Cellular Component & Molecular Function \\
\hline 225088_at & -0.569844167 & 123811 & C16orf63 & $\begin{array}{l}\text { chromosome } 16 \text { open reading } \\
\text { frame } 63\end{array}$ & - & - & - \\
\hline 1555760_a_at & -0.564309 & 64783 & RBM15 & RNA binding motif protein 15 & $\begin{array}{l}45449 \text { // regulation of } \\
\text { transcription // inferred from } \\
\text { electronic annotation }\end{array}$ & $\begin{array}{l}5634 / / \text { nucleus // inferred from } \\
\text { electronic annotation }\end{array}$ & $\begin{array}{l}166 \text { // nucleotide binding // } \\
\text { inferred from electronic } \\
\text { annotation /// } 3723 \text { // RNA } \\
\text { binding // inferred from } \\
\text { electronic annotation /// } 3676 / / \\
\text { nucleic acid binding // inferred } \\
\text { from electronic annotation // } \\
5488 \text { // binding // inferred from } \\
\text { electronic annotation }\end{array}$ \\
\hline 1569263_at & -0.5610785 & 9123 & SLC16A3 & $\begin{array}{l}\text { Solute carrier family } 16 \\
\text { (monocarboxylic acid } \\
\text { transporters), member } 3\end{array}$ & $\begin{array}{l}6810 / / \text { transport // inferred from } \\
\text { electronic annotation /// } 15711 \\
\text { // organic anion transport // } \\
\text { inferred from electronic } \\
\text { annotation /// } 15718 / / \\
\text { monocarboxylic acid transport } \\
\text { // traceable author statement }\end{array}$ & $\begin{array}{l}5624 \text { // membrane fraction // } \\
\text { traceable author statement /// } \\
5887 / / \text { integral to plasma } \\
\text { membrane // traceable author } \\
\text { statement /// } 16020 / / \\
\text { membrane // inferred from } \\
\text { electronic annotation /// } 16021 \\
\text { // integral to membrane // } \\
\text { inferred from electronic annota }\end{array}$ & $\begin{array}{l}5215 \text { // transporter activity // } \\
\text { inferred from electronic } \\
\text { annotation /// } 15293 / / \\
\text { symporter activity // inferred } \\
\text { from electronic annotation /// } \\
15355 \text { // monocarboxylate } \\
\text { porter activity // inferred from } \\
\text { electronic annotation /// } 8028 / / \\
\text { monocarboxylic acid } \\
\text { transporter activity // traceable } \\
\text { author statement }\end{array}$ \\
\hline 210016_at & -0.559203167 & 23040 & MYT1L & myelin transcription factor 1-like & $\begin{array}{l}6350 \text { // transcription // inferred } \\
\text { from electronic annotation /// } \\
6355 \text { // regulation of } \\
\text { transcription, DNA-dependent } \\
\text { // inferred from electronic } \\
\text { annotation /// } 7399 \text { // nervous } \\
\text { system development // inferred } \\
\text { from electronic annotation /// } \\
30154 \text { // cell differentiation // } \\
\text { inferred from electronic } \\
\text { annotation /// } 7275 / / \\
\text { development // inferred from } \\
\text { electronic annotation }\end{array}$ & $\begin{array}{l}5634 / / \text { nucleus // inferred from } \\
\text { electronic annotation }\end{array}$ & $\begin{array}{l}3700 / / \text { transcription factor } \\
\text { activity // inferred from } \\
\text { electronic annotation /// } 8270 / / \\
\text { zinc ion binding // inferred } \\
\text { from electronic annotation /// } \\
46872 \text { // metal ion binding // } \\
\text { inferred from electronic } \\
\text { annotation /// } 3677 \text { // DNA } \\
\text { binding // inferred from } \\
\text { electronic annotation }\end{array}$ \\
\hline
\end{tabular}




\begin{tabular}{|c|c|c|c|c|c|c|c|}
\hline \multirow[b]{2}{*}{ Probe Set ID } & \multirow[b]{2}{*}{ Log Ratio } & \multirow[b]{2}{*}{ Entrez Gene } & \multirow[b]{2}{*}{ Gene Symbol } & \multirow[b]{2}{*}{ Gene Descriptor } & \multicolumn{3}{|c|}{ Gene Ontology } \\
\hline & & & & & Biological Process & Cellular Component & Molecular Function \\
\hline 223096_at & -0.5571555 & 51602 & NOP5/NOP58 & nucleolar protein NOP5/NOP58 & $\begin{array}{l}6364 \text { // rRNA processing // } \\
\text { traceable author statement /// } \\
6608 / / \text { snRNP protein import } \\
\text { into nucleus // inferred from } \\
\text { sequence or structural } \\
\text { similarity /// } 16049 \text { // cell } \\
\text { growth // traceable author } \\
\text { statement /// } 7046 \text { // ribosome } \\
\text { biogenesis // inferred from } \\
\text { electronic annotation /// } 7046 \text { // } \\
\text { ribosome biogenesis // } \\
\text { traceable author statement }\end{array}$ & $\begin{array}{l}5634 / / \text { nucleus // inferred from } \\
\text { electronic annotation /// 5730 // } \\
\text { nucleolus // traceable author } \\
\text { statement }\end{array}$ & $\begin{array}{l}30519 \text { // snoRNP binding // } \\
\text { inferred from sequence or } \\
\text { structural similarity /// } 51082 \text { // } \\
\text { unfolded protein binding // } \\
\text { inferred from sequence or } \\
\text { structural similarity }\end{array}$ \\
\hline 200711_s_at & -0.548213167 & 6500 & SKP1A & $\begin{array}{l}\text { S-phase kinase-associated protein } \\
\text { 1A (p19A) }\end{array}$ & $\begin{array}{l}6512 / / \text { ubiquitin cycle // inferred } \\
\text { from electronic annotation }\end{array}$ & - & $\begin{array}{l}5515 / / \text { protein binding // inferred } \\
\text { from physical interaction }\end{array}$ \\
\hline 226475_at & -0.546711833 & 55007 & FAM118A & $\begin{array}{l}\text { family with sequence similarity } \\
118, \text { member A }\end{array}$ & - & $\begin{array}{l}16020 / / \text { membrane // inferred } \\
\text { from electronic annotation /// } \\
16021 \text { // integral to membrane } \\
\text { // inferred from electronic } \\
\text { annotation }\end{array}$ & - \\
\hline 212901_s_at & -0.546478167 & 23283 & CSTF2T & $\begin{array}{l}\text { cleavage stimulation factor, } 3 \\
\text { pre-RNA, subunit } 2,64 \mathrm{kDa} \text {, } \\
\text { tau variant }\end{array}$ & $\begin{array}{l}6397 / / \text { mRNA processing // } \\
\text { inferred from electronic } \\
\text { annotation }\end{array}$ & $\begin{array}{l}5634 / / \text { nucleus // inferred from } \\
\text { electronic annotation }\end{array}$ & $\begin{array}{l}166 \text { // nucleotide binding // } \\
\text { inferred from electronic } \\
\text { annotation /// 3723 // RNA } \\
\text { binding // inferred from } \\
\text { electronic annotation /// } 3676 / / \\
\text { nucleic acid binding // inferred } \\
\text { from electronic annotation }\end{array}$ \\
\hline
\end{tabular}


splicing factor proline/glutamine- 398 // nuclear mRNA splicing, rich (polypyrimidine tract binding protein associated)

ras homolog gene family, member $\mathrm{G}$ (rho $\mathrm{G}$ ) via spliceosome // inferred

from electronic annotation /I/

6281 // DNA repair // inferred

from electronic annotation ///

6310 // DNA recombination //

inferred from electronic

annotation /// 6350 //

transcription // inferred from

electronic annotation /// 6355 //

regulation of transcription,

DNA-dependent // inferred

from electronic annotation /II

8380 // RNA splicing //

traceable author statement ///

6397 // mRNA processing //

inferred from electronic

annotation /// 6974 // response

to DNA damage stimulus //

inferred from electronic

annotation /// 6397 // mRNA

processing // traceable author

statement

74 // regulation of progression

through cell cycle // traceable

author statement /// $7266 / /$

Rho protein signal transduction

// traceable author statement //

$8284 / /$ positive regulation of

cell proliferation // traceable

author statement /// 7264 //

small GTPase mediated signal

transduction // inferred from

electronic annotation
634 // nucleus // inferred from 166 // nucleotide binding //

electronic annotation /// 5634 //

nucleus // not recorded

inferred from electronic

annotation /// 3677 // DNA

binding // inferred from

electronic annotation /// 3723 //

RNA binding // inferred from

electronic annotation /// 5515//

protein binding // inferred from physical interaction /// 3676 // nucleic acid binding // inferred from electronic annotation
5622 // intracellular // inferred from electronic annotation //I 16020 // membrane // inferred from electronic annotation
166 // nucleotide binding // inferred from electronic annotation /// 3924 // GTPase activity // traceable author statement /// 5515 // protein binding // inferred from physical interaction /// 5525 // GTP binding // inferred from electronic annotation 
$6816 / /$ calcium ion transport

annotation /// 8152 //

metabolism // inferred from

electronic annotation /// $6810 / /$

transport // inferred from

electronic annotation /// 6811 //

ion transport // inferred from

electronic annotation /// $6810 / /$

transport // traceable author

statement electronic annotation /I/ 1602

// integral to membrane //

inferred from electronic

annotation

inferred from electron

annotation /// 5388 // calciumtransporting ATPase activity //

traceable author statement /II

5509 // calcium ion binding //

inferred from electronic

annotation /// 5516 //

calmodulin binding // inferred from electronic annotation //I 5524 // ATP binding // inferred from electronic annotation /// 16787 // hydrolase activity // inferred from electronic annotation /// 16820 // hydrolase activity, acting on acid anhydrides, catalyzing transmembrane movement of substances // inferred from electronic annotation /// 3824 // catalytic activity // inferred from electronic annotation /// 5388 // calcium-transporting

ATPase activity // inferred

from electronic annotation /// 15085 // calcium ion

transporter activity // inferred from electronic annotation //I 15662 // ATPase activity,

coupled to transmembrane movement of ions,

phosphorylative mechanism // inferred from electronic annotation /// 4 


$\begin{array}{lccc}\text { 218122_s_at } & -0.535398833 & 59343 & \text { SENP2 } \\ & & & \\ & & & \\ & & & \\ \text { 220797_at } & -0.532919333 & 79066 & \text { METT10D } \\ \text { 224743_at } & -0.531840167 & 54928 & \text { IMPAD1 } \\ \text { 205333_s_at } & -0.530217333 & 9986 & \text { RCE1 }\end{array}$

SUMO1/sentrin/SMT3 specific peptidase 2

methyltransferase 10 domain containing

inositol monophosphatase

domain containing 1

RCE1 homolog, prenyl protein peptidase (S. cerevisiae)

6508 // proteolysis // inferred from electronic annotation /// 6512 // ubiquitin cycle // inferred from electronic annotation /// $30111 / /$ regulation of Wnt receptor signaling pathway // nontraceable author statement /// 16055 // Wnt receptor signaling pathway // inferred from electronic annotation annotation /// 5763 //

mitochondrial small ribosomal subunit // inferred from direct assay /// 5840 // ribosome // inferred from electronic

5634 // nucleus // inferred from electronic annotation /// 5643 // nuclear pore // inferred from direct assay

(2)

6508 // proteolysis // traceable author statement
5783 // endoplasmic reticulum // inferred from electronic annotation /// 5887 // integral to plasma membrane // traceable author statement //I 16020 // membrane // inferred from electronic annotation /II $16021 / /$ integral to membrane // inferred from elec
$5515 / /$ protein binding // inferred from physical interaction //I 8234 // cysteine-type peptidase activity // inferred from

electronic annotation /// 16929 // SUMO-specific protease activity // inferred from direct assay /// 8233 // peptidase activity // inferred from electronic annotation /// 16787 // hydrolase activity // inferred from electronic annotation

$$
-
$$

8487 // prenyl-dependent CAAX protease activity // traceable author statement /// 16787 // hydrolase activity // inferred from electronic annotation

(Continued) 


\section{4_s_at $\quad-0.529476833$ \\ CASP9 \\ caspase 9, apoptosis-related} cysteine peptidase
Biological Process

6508 // proteolysis // inferred from electronic annotation /// 8632 // apoptotic program // traceable author statement // 8635 // caspase activation via cytochrome c // traceable author statement /// $42981 / /$

regulation of apoptosis // inferred from electronic annotation /// 6915 // apoptosis

// inferred from electronic annotation
Cellular Component

5622 // intracellular // inferred

from electronic annotation

Molecular Function

5515 // protein binding // inferred from electronic annotation /II 5515 // protein binding // inferred from physical

interaction /// 8047 // enzyme activator activity // traceable author statement /// 8233 //

peptidase activity // inferred from electronic annotation //I 8234 // cysteine-type peptidase activity // inferred from electronic annotation /// 30693 // caspase activity // inferred from electronic annotation /II 30693 // caspase activity // traceable author statement // 16787 // hydrolase activity // inferred from electronic annotation /// 4197 // cysteinetype endopeptidase activity // traceable author statement III 8233 // peptidase activity // traceable author statement

$6355 / /$ regulation of transcription, DNA-dependent

// inferred from electronic

annotation

管

(Continued) 
ELL elongation factor RNA

$\begin{array}{llll}\text { 218631_at } & -0.519465 & 60370 & \text { AVPI1 } \\ \text { 202208_s_at } & -0.516053333 & 10123 & \text { ARL4C }\end{array}$

ARL4C from electronic annotation /// 6355 // regulation of

transcription, DNA-dependent

// inferred from electronic

annotation /// 6366 //

transcription from RNA

polymerase II promoter //

traceable author statement

5634 // nucleus // inferred from

electronic annotation activity // traceable author statement /// 43565 // sequence-specific DNA binding // inferred from electronic annotation /// 46983 // protein dimerization activity $/ /$ inferred from electronic annotation /// 5515 // protein binding // inferred from

physical interaction /// 3677 // DNA binding // inferred from electronic annotation /// $3700 / /$ transcription factor activity // inferred from electronic annotation /// 4867 // serinetype endopeptidase inhibitor activity // inferred from electronic annotation polymerase II

6350 // transcription // inferred from electronic annotation 6355 // regulation of transcription, DNA-dependent // inferred from electronic annotation /// 6368 // RNA elongation from RNA

polymerase II promoter // traceable author statement

arginine vasopressin-induced 1 ADP-ribosylation factor-like $4 \mathrm{C}$
6364 // rRNA processing // inferred from electronic annotation /// 7264 // small

GTPase mediated signal

transduction // inferred from electronic annotation /// 7046// ribosome biogenesis // inferred from electronic annotation
5634 // nucleus // inferred from electronic annotation

5622 // intracellular // inferred from electronic annotation // 5634 // nucleus // traceable author statement /// 5634 // nucleus // inferred from electronic annotation
8159 // positive transcription elongation factor activity // traceable author statement /// 3746 // translation elongation factor activity // inferred from electronic annotation

166 // nucleotide binding // inferred from electronic annotation /// 3924 // GTPase activity // traceable author statement /// 5525 // GTP binding // inferred from electronic annotation 
eukaryotic translation initiation factor $1 \mathrm{~A}, \mathrm{X}$-linked

201329_s_at $\quad-0.512355167 \quad 2114 \quad$ ETS2 $\quad \begin{array}{r}\text { v-ets erythroblastosis virus E26 } \\ \text { oncogene homolog } 2 \text { (avian) }\end{array}$

213025_at $\quad-0.5109205 \quad 55623$

1554549_a_at $-0.505288 \quad 91833$

222195_s_at $\quad-0.505278667$

51531

212438_at

$-0.5002295$

11017

THUMPD

WDR20

C9orf156

THUMP domain containing

WD repeat domain 20

chromosome 9 open reading

frame 156

RY1 putative nucleic acid binding protein RY-1

\begin{tabular}{|c|c|c|c|c|}
\hline 227161_at & -0.499864667 & 64434 & NOM1 & $\begin{array}{l}\text { nucleolar protein with MIF4G } \\
\text { domain } 1\end{array}$ \\
\hline 228810_at & -0.498836167 & 151195 & FLJ40432 & hypothetical protein FLJ40432 \\
\hline
\end{tabular}

Biological Process

6412 // protein biosynthesis //

inferred from electronic

annotation /// 6413 //

translational initiation //

inferred from electronic

annotation /// 6413 //

translational initiation //

traceable author statement
1501 // skeletal development // traceable author statement // 6355 // regulation of

// inferred from electronic

annotation transcription, DNA-dependent

Molecular Function

3723 // RNA binding // inferred from electronic annotation /II 3743 // translation initiation factor activity // inferred from electronic annotation /// $3676 / /$ nucleic acid binding // inferred from electronic annotation /// 8135 // translation factor activity, nucleic acid binding // traceable author statement

5634 // nucleus // inferred from electronic annotation

$3700 / /$ transcription factor activity // non-traceable author statement /// 43565 // sequence-specific DNA binding // inferred from electronic annotation /// 3677 // DNA binding // inferred from electronic annotation /// $3700 / /$ transcription factor activity // inferred from electronic annotation /// 3677 // DNA binding // traceable author statement

$-\frac{1}{-}+$

398 // nuclear mRNA splicing, 5634 // nucleus // inferred from via spliceosome // inferred electronic annotation

from electronic annotation /I/ 6397 // mRNA processing // inferred from electronic

annotation

74 // regulation of progression through cell cycle // inferred from electronic annotation
(Continued) 
MADS box transcription enhancer factor 2, polypeptid

D (myocyte enhancer factor 2D)
$6350 / /$ transcription // inferred from electronic annotation // 6355 // regulation of

transcription, DNA-dependent // inferred from electronic annotation /// 6366 //

transcription from RNA polymerase II promoter // not recorded /// 7517 // muscle

development // traceable author statement /// 6183 // GTP biosynthesis // inferred from electronic annotation /I/ 6228 // UTP biosynthesis // inferred from electronic annotation /// 6241 // CTP biosynthesis // inferred from electronic annotation /// 9209 // pyrimidine ribonucleoside triphosphate biosynthesis // inferred from electronic annotation
5634 // nucleus // inferred from electronic annotation

(20)

166 // nucleotide binding //

inferred from electronic annotation /// 4674 // protein serine/threonine kinase activity // inferred from electronic annotation /// 4871 // signal transducer activity // inferred from electronic annotation /// 5524 // ATP binding // inferred from electronic annotation //I 16740 // transferase activity // inferred from electronic annotation /// 4672 // protein kinase activity // inferred from electronic annotation /// 16301 // kinase activity // inferred from electronic annotation $3700 / /$ transcription factor activity // inferred from electronic annotation /// $3700 / /$ transcription factor activity // non-traceable author statement /// 3713 // transcription coactivator activity // not recorded /// 43565 // sequence specific DNA binding // inferred from electronic annotation /// 3677 // DNA binding // inferred from

electronic annotation /// 166 // nucleotide binding // inferred from electronic annotation //I 287 // magnesium ion binding $/ /$ inferred from electronic annotation /// 4550 //

nucleoside diphosphate kinase activity // inferred from electronic annotation /// 5524 // ATP binding // inferred from electronic annotation /// 16301 // kinase activity // inferred from electronic annotation /// 16740 // transferase activity // inferred from electronic annotation 
adaptor-related protein complex

3 , mu 2 subunit

\begin{tabular}{|c|c|c|c|c|}
\hline 217686_at & -0.491685 & 5770 & PTPN1 & $\begin{array}{l}\text { protein tyrosine phosphatase, } \\
\text { non-receptor type } 1\end{array}$ \\
\hline
\end{tabular}

\section{sestrin 2}

$\begin{array}{lrrrl}\text { 223196_s_at } & -0.490453667 & 83667 & \text { SESN2 } & \text { sestrin 2 } \\ \text { 203728_at } & -0.489473 & 578 & \text { BAK1 } & \text { BCL2-antagonist/killer 1 }\end{array}$

Biological Process

6886 // intracellular protein

transport // inferred from

electronic annotation /// $6810 / /$

transport // inferred from

electronic annotation /// 15031

// protein transport // inferred

from electronic annotation

$6470 / /$ protein amino acid dephosphorylation // inferred from electronic annotation // 7165 // signal transduction // traceable author statement

statement /// 30125 // clathrin

vesicle coat // inferred from

electronic annotation /// 30662

// coated vesicle membrane //

inferred from electronic annotation

5625 // soluble fraction // not recorded /// 5737 // cytoplasm // not recorded /// 5783 // endoplasmic reticulum // inferred from electronic annotation

7050 // cell cycle arrest // inferred 5634 // nucleus // inferred from from electronic annotation electronic annotation

6917 // induction of apoptosis // 16020 // membrane // inferred traceable author statement /II 8637 // apoptotic from electronic annotation /II mitochondrial changes // $16021 / /$ integral to membrane // inferred from electronic 42981 // regulation of annotation apoptosis // inferred from electronic annotation /// 6915 // apoptosis // inferred from electronic annotation

6464 // protein modification // inferred from electronic annotation
$4725 / /$ protein tyrosine phosphatase activity // traceable author statement /// 16787 // hydrolase activity // inferred from electronic annotation /// 4721 // phosphoprotein phosphatase activity // inferred from electronic annotation /// 4725 // protein tyrosine phosphatase activity // inferred from electronic annotation

$$
\text { - }
$$

42802 // identical protein binding // inferred from physical

interaction /// 46982 // protein heterodimerization activity // inferred from physical interaction /// 5515 // protein binding // inferred from

physical interaction 


$-$

$7126 / /$ meiosis // inferred from electronic annotation
201269_s_at
$-0.479001833$
23386
205021_s at
$-0.476169333$
NUDCD3
CHES1
NudC domain containing 3 checkpoint suppressor 1

coiled-coil domain containing 131
77 // DNA damage checkpoint // traceable author statement /// $85 / /$ G2 phase of mitotic cell cycle // traceable author statement /// 6350 //

transcription // inferred from electronic annotation /// $7049 / /$ cell cycle // inferred from electronic annotation /// 45892 // negative regulation of transcription, DNA-dependent // inferred from direct assay //I $6355 / /$ regulation of

transcription, DNA-dependent

// inferred from electronic annotation

6396 // RNA processing // inferred from electronic annotation
$5507 / /$ copper ion binding /I inferred from electronic annotation /// 5515 // protein binding // inferred from physical interaction /// 8270 // zinc ion binding // inferred from electronic annotation /// 46870 // cadmium ion binding // inferred from electronic annotation /// 46872 // metal ion binding // inferred from electronic annotation /// 46872

// metal ion binding // not recorded

166 // nucleotide binding // inferred from electronic annotation /// 3676 // nucleic acid binding // inferred from electronic annotation /// 3723 // RNA binding // inferred from electronic annotation

$3700 / /$ transcription factor activity // inferred from electronic annotation /// 5515 // protein binding // inferred from physical interaction /// 16564 // transcriptional repressor activity // inferred from direct assay /// 43565 // sequencespecific DNA binding // inferred from electronic annotation /// 3677 // DNA binding // inferred from electronic annotation
5622 // intracellular // inferred from electronic annotation
5488 // binding // inferred from electronic annotation 
endocytosis // traceable author statement /// 7242 //

intracellular signaling cascade // inferred from electronic annotation /// 6810 // transport // inferred from electronic annotation /// $15031 / /$ protein transport // inferred from electronic annotation

\begin{tabular}{|c|c|c|c|c|c|c|c|}
\hline 224739_at & -0.456507333 & 415116 & PIM3 & pim-3 oncogene & $\begin{array}{l}6468 / / \text { protein amino acid } \\
\text { phosphorylation // inferred } \\
\text { from electronic annotation }\end{array}$ & - & $\begin{array}{l}166 \text { // nucleotide binding // } \\
\text { inferred from electronic } \\
\text { annotation /// } 4674 \text { // protein } \\
\text { serine/threonine kinase activity } \\
\text { // inferred from electronic } \\
\text { annotation /// } 5524 \text { // ATP } \\
\text { binding // inferred from } \\
\text { electronic annotation /// } 16740 \\
\text { // transferase activity // inferred } \\
\text { from electronic annotation /// } \\
4672 \text { // protein kinase activity } \\
\text { // inferred from electronic } \\
\text { annotation /// 16301 // kinase } \\
\text { activity // inferred from } \\
\text { electronic annotation }\end{array}$ \\
\hline 228435_at & -0.451847667 & 55527 & FEM1A & Fem-1 homolog a (C.elegans) & - & - & $\begin{array}{l}5488 / / \text { binding // inferred from } \\
\text { electronic annotation /// } 4872 / / \\
\text { receptor activity // inferred } \\
\text { from electronic annotation }\end{array}$ \\
\hline 209712_at & -0.451743167 & 23169 & SLC35D1 & $\begin{array}{l}\text { solute carrier family } 35 \text { (UDP- } \\
\text { glucuronic acid/UDP-N- } \\
\text { acetylgalactosamine dual } \\
\text { transporter), member D1 }\end{array}$ & $\begin{array}{l}6810 \text { // transport // inferred from } \\
\text { electronic annotation /// } 15789 \\
\text { // UDP-N-acetylgalactosamine } \\
\text { transport // non-traceable } \\
\text { author statement /// } 30206 \text { // } \\
\text { chondroitin sulfate } \\
\text { biosynthesis // non-traceable } \\
\text { author statement }\end{array}$ & $\begin{array}{l}5783 \text { // endoplasmic reticulum // } \\
\text { inferred from electronic } \\
\text { annotation /// } 16020 \text { // } \\
\text { membrane // inferred from } \\
\text { electronic annotation /// } 16021 \\
\text { // integral to membrane // } \\
\text { inferred from electronic } \\
\text { annotation /// 30176 // integral } \\
\text { to endoplasmic reticulum } \\
\text { membr }\end{array}$ & $\begin{array}{l}5351 / / \text { sugar porter activity // } \\
\text { inferred from electronic } \\
\text { annotation /// } 5463 / / \text { UDP-N- } \\
\text { acetylgalactosamine } \\
\text { transporter activity // non- } \\
\text { traceable author statement }\end{array}$ \\
\hline
\end{tabular}

// phosphoinositide binding //

inferred from electronic annotation 

electronic annotation /// 51082 // unfolded protein binding // inferred from electronic annotation

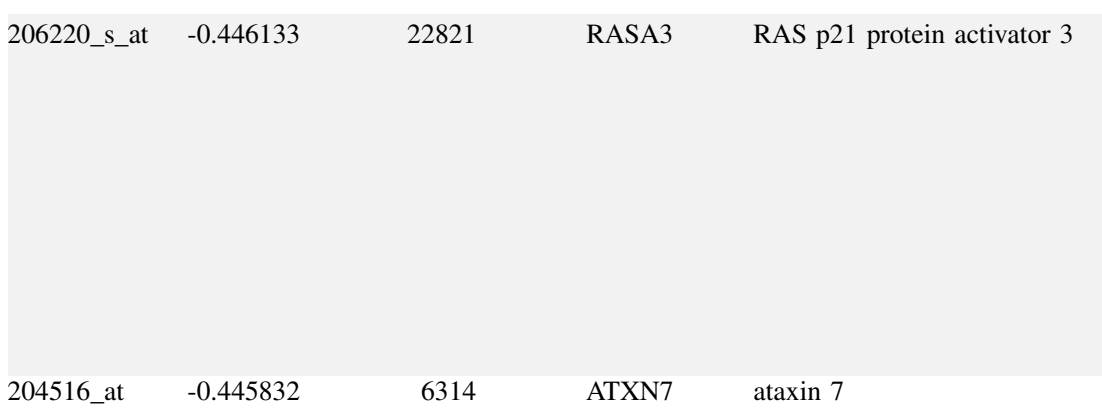

$\begin{array}{lcccc}\text { 239788_at } & -0.44527 & 55234 & \text { SMU1 } & \begin{array}{c}\text { Smu-1 suppressor of mec-8 and } \\ \text { unc-52 homolog (C. elegans) }\end{array} \\ \text { 209675_s_at } & -0.443053 & 11100 & \text { HNRPUL1 } & \begin{array}{c}\text { heterogeneous nuclear }\end{array}\end{array}$

209675 s at $\quad-0.443053$

HNRPUL

RBM3

7242 // intracellular signaling

6997 // nuclear organization and

ribonucleoprotein U-like 1

RNA binding motif (RNP1, $\mathrm{RRM}$ ) protein 3 cascade // inferred from

electronic annotation /// 51056

// regulation of small GTPase

mediated signal transduction //

inferred from electronic

annotation /// 7165 // signal

transduction // traceable author

$$
\text { statement }
$$
biogenesis // traceable author statement /// $7601 / /$ visua perception // traceable author statement from electronic annotation // 6355 // regulation of transcription, DNA-dependent // inferred from electronic annotation

5622 // intracellular // inferred from electronic annotation /I/ 5886 // plasma membrane // traceable author statement

396 // RNA processing // traceable author statement
5622 // intracellular // inferred from electronic annotation // 5634 // nucleus // traceable author statement /// 5634 // nucleus // inferred from electronic annotation

5634 // nucleus // inferred from electronic annotation

5634 // nucleus // inferred from electronic annotation /// 30529 // ribonucleoprotein complex // inferred from electronic annotation

$-$

5096 // GTPase activator activity // inferred from electronic annotation /// 5096 // GTPase activator activity // traceable author statement /// $8270 / /$ zinc ion binding // inferred from electronic annotation /// 46872 // metal ion binding // inferred from electronic annotation

3676 // nucleic acid binding // inferred from electronic annotation /// $5515 / /$ protei binding // inferred from physical interaction /// $8270 / /$ zinc ion binding // inferred from electronic annotation

3677 // DNA binding // inferred from electronic annotation /// 3723 // RNA binding // inferred from electronic annotation

166 // nucleotide binding // inferred from electronic annotation /// 3676 // nucleic acid binding // inferred from electronic annotation /// 3723 // RNA binding // traceable author statement /// 3723 // RNA binding // inferred from electronic annotation 


\begin{tabular}{|c|c|c|c|c|c|c|c|}
\hline & & & & $\begin{array}{l}\text { and } \mathrm{Y} \text { (unique) } 155 \text { expressed } \\
\text { sequence, isoform } 1\end{array}$ & $\begin{array}{l}\text { transcription, DNA-dependent } \\
\text { // non-traceable author } \\
\text { statement /// } 7165 \text { // signal } \\
\text { transduction // non-traceable } \\
\text { author statement /// } 42113 / / \text { B } \\
\text { cell activation // non-traceable } \\
\text { author statement /// 30187 // } \\
\text { melatonin biosynthesis // } \\
\text { inferred from electronic } \\
\text { annotation /// 48511 // } \\
\text { rhythmic process // inferred } \\
\text { from electronic annotation /// } \\
\text { 6412 // protein biosynthesis // } \\
\text { traceable author statement }\end{array}$ & from electronic annotation & $\begin{array}{l}\text { inferred from electronic } \\
\text { annotation /// } 5184 \text { // } \\
\text { neuropeptide hormone activity } \\
\text { // inferred from electronic } \\
\text { annotation /// } 8168 \text { // } \\
\text { methyltransferase activity // } \\
\text { inferred from electronic } \\
\text { annotation /// } 8171 / / \text { O- } \\
\text { methyltransferase activity // } \\
\text { inferred from electronic } \\
\text { annotation /// } 16740 / / \\
\text { transferase activity // inferred } \\
\text { from electronic annotation /// } \\
\text { 17096 // acetylserotonin O- } \\
\text { methyltransferase activity // } \\
\text { inferred from electronic } \\
\text { annotation /// } 8171 \text { // O- } \\
\text { methyltransferase activity // } \\
\text { traceable author statement }\end{array}$ \\
\hline 28634_s_at & -0.434112833 & 8531 & CSDA & Cold shock domain protein A & $\begin{array}{l}122 \text { // negative regulation of } \\
\text { transcription from RNA } \\
\text { polymerase II promoter // } \\
\text { traceable author statement /// } \\
6350 / / \text { transcription // inferred } \\
\text { from electronic annotation // } \\
6355 / / \text { regulation of } \\
\text { transcription, DNA-dependent } \\
\text { // inferred from electronic } \\
\text { annotation /// } 9409 / / \text { response } \\
\text { to cold // traceable author } \\
\text { statement }\end{array}$ & $\begin{array}{l}5634 / / \text { nucleus // inferred from } \\
\text { electronic annotation /// } 5737 / / \\
\text { cytoplasm // traceable author } \\
\text { statement }\end{array}$ & $\begin{array}{l}3677 \text { // DNA binding // inferred } \\
\text { from electronic annotation /// } \\
3690 / / \text { double-stranded DNA } \\
\text { binding // traceable author } \\
\text { statement /// } 3700 \text { // } \\
\text { transcription factor activity // } \\
\text { non-traceable author statement } \\
\text { /// } 3702 \text { // RNA polymerase II } \\
\text { transcription factor activity // } \\
\text { traceable author statement /// } \\
3714 \text { // transcription } \\
\text { corepressor activity // traceable } \\
\text { author statement /// } 3676 \text { // } \\
\text { nucleic acid binding // inferred } \\
\text { from electronic annotation }\end{array}$ \\
\hline 24570_s_at & -0.433634667 & 359948 & IRF2BP2 & $\begin{array}{l}\text { interferon regulatory factor } 2 \\
\text { binding protein } 2\end{array}$ & - & - & $\begin{array}{l}5515 / / \text { protein binding // inferred } \\
\text { from electronic annotation /// } \\
8270 / / \text { zinc ion binding // } \\
\text { inferred from electronic } \\
\text { annotation }\end{array}$ \\
\hline
\end{tabular}


64065

PERP

PERP, TP53 apoptosis effector

6915 // apoptosis // inferred from

6596 // polyamine biosynthesis //
AZIN1

antizyme inhibitor 1

CSNK1G2 casein kinase 1, gamma 2
8037 // cell recognition // nontraceable author statement // 8283 // cell proliferation // non-traceable author statement electronic annotation /// $7155 / /$ cell adhesion // inferred from electronic annotation inferred from electronic annotation

5886 // plasma membrane // inferred from direct assay /II 5887 // integral to plasma membrane // non-traceable author statement /// 16020 // membrane // inferred from electronic annotation /// 1602 // integral to membrane // inferred from electronic anno

5856 // cytoskeleton // inferred from electronic annotation /I/ 16020 // membrane // inferred from electronic annotation //I $16021 / /$ integral to membrane $/ /$ inferred from electronic annotation

$6468 / /$ protein amino acid phosphorylation // inferred from electronic annotation /I/ $6468 / /$ protein amino acid phosphorylation // traceable author statement /// 7165 //

signal transduction // traceable author statement /// 16055 //

Wnt receptor signaling

pathway // inferred from electronic annotation

-

Molecular Function

$5044 / /$ scavenger receptor activity // inferred from electronic annotation /// 5515 // protein binding // inferred from physical interaction /// 4872 // receptor activity // non-

traceable author statement //I 4888 // transmembrane receptor activity // nontraceable author statement

5198 // structural molecule activity // inferred from electronic annotation /// 5515 // protein binding // inferred from electronic annotation

- 38

3824 // catalytic activity // inferred from electronic annotation /// 4857 // enzyme inhibitor activity // traceable author statement

166 // nucleotide binding // inferred from electronic annotation /// 4672 // protein kinase activity // inferred from electronic annotation /// 4674 // protein serine/threonine kinase activity // inferred from

electronic annotation /// $4681 / /$ casein kinase I activity //

traceable author statement /// 5524 // ATP binding // inferred from electronic annotation //I 16740 // transferase activity // inferred from electronic annotation /// $16301 / /$ kinase activity // inferred from electronic annotation 


218884_s_at $-0.414758833 \quad 60558 \quad$ GUF1 GUF1 GTPase homolog (S.
cerevisiae)

\section{8_at $\quad-0.393608$}

4155

MBP

myelin basic protein

211507_s_at $\quad-0.383815333 \quad 8897 \quad$ MTMR3 myotubularin related protein 3

6412 // protein biosynthesis // inferred from electronic annotation /// 6413 // translational initiation // inferred from electronic annotation /// 7264 // small GTPase mediated signal transduction // inferred from electronic annotation

6955 // immune response // traceable author statement //I 7268 // synaptic transmission // traceable author statement /I/ 7417 // central nervous system development // traceable author statement /// 8366 // nerve ensheathment //

traceable author statement

$6470 / /$ protein amino acid dephosphorylation // inferred from direct assay /// 46839 // phospholipid

dephosphorylation // inferred from electronic annotation /I/ $6470 / /$ protein amino acid dephosphorylation // inferred from electronic annotation
5622 // intracellular // inferred

from electronic annotation

3743 // translation initiation

factor activity // inferred from electronic annotation /// $5525 / /$ GTP binding // inferred from

electronic annotation

5624 // membrane fraction // inferred from direct assay /I/ 5737 // cytoplasm // inferred from direct assay myelin sheath // infered from electronic annotation /// $5198 / /$ inferred from electronic

annotation
4437 // inositol or phosphatidylinositol

phosphatase activity // inferred from electronic annotation /// 4722 // protein serine/threonine phosphatase activity // inferred from direct assay /// 4725 // protein tyrosine phosphatase activity // inferred from direct assay /// 8270 // zinc ion binding // inferred from

electronic annotation /// 16787 // hydrolase activity // inferred from electronic annotation /// 46872 // metal ion binding // inferred from electronic annotation /// 4721 // phosphoprotein phosphatase activity // inferred from electronic annotation /// 4725 // protein tyrosine phosphatase activity // inferred from electronic annotation
(Continued) 
DENN/MADD domain containing $4 \mathrm{~A}$

6350 // transcription // inferred from electronic annotation /I/ $6355 / /$ regulation of transcription, DNA-dependent

$/ /$ inferred from electronic annotation /// 6306 // DNA methylation // inferred from electronic annotation

$\begin{array}{ccc}\text { 203883_s_at } & -0.376042833 & 22841 \quad \text { RAB11FIP2 } \\ & \text { RAB11 family interacting protein } \\ 2 \text { (class I) }\end{array}$

212892_at $\quad-0.375620167 \quad 8427 \quad$ ZNF282 zinc finger protein 282

\section{4}

RAB30
$15031 / /$ protein transport //

inferred from electronic

annotation /// 6810 // transport // inferred from electronic annotation

$6350 / /$ transcription // inferred from electronic annotation /II 6355 // regulation of transcription, DNA-dependent // inferred from electronic annotation /// 6355 //

regulation of transcription, DNA-dependent // traceable author statement

RAB30, member RAS oncogene family
7264 // small GTPase mediated signal transduction // inferred from electronic annotation /I/ $15031 / /$ protein transport // inferred from electronic annotation
5622 // intracellular // inferred from electronic annotation // 5634 // nucleus // inferred from electronic annotation /// 5634 // nucleus // non-traceable author statement

5795 // Golgi stack // traceable author statement /// 16020 // membrane // inferred from electronic annotation
3677 // DNA binding // inferred from electronic annotation /II 8170 // N-methyltransferase activity // inferred from electronic annotation

3676 // nucleic acid binding // inferred from electronic annotation /// 3677 // DNA binding // inferred from electronic annotation /// $8270 / /$ zinc ion binding // inferred from electronic annotation /// 8270 // zinc ion binding // nontraceable author statement /// 16564 // transcriptional

repressor activity // traceable author statement /// 46872 // metal ion binding // inferred from electronic annotation 66 // nucleotide binding // inferred from electronic annotation /// 3924 // GTPase activity // traceable author statement /// 5525 // GTP binding // inferred from electronic annotation 
annotation /// 5634 // nucleus // inferred from electronic annotation
6508 // proteolysis // traceable author statement /// 6629 // lipid metabolism // traceable author statement /// 8217 // blood pressure regulation // traceable author statement /I/ 9653 // morphogenesis // traceable author statement /II 6508 // proteolysis // inferred from electronic annotation
5886 // plasma membrane // traceable author statement // 5887 // integral to plasma membrane // traceable author statement /// 16020 // membrane // inferred from electronic annotation /// 16021 // integral to membrane // inferred from electronic annotati inferred from electronic annotation /// 4842 // ubiquitinprotein ligase activity // inferred from electronic annotation /// 5515 // protein binding // inferred from electronic annotation /// $8270 / /$ zinc ion binding // inferred from electronic annotation /// 46872 // metal ion binding // inferred from electronic annotation

4252 // serine-type endopeptidase activity // traceable author statement /// 5044 // scavenge receptor activity // inferred from electronic annotation /// 8233 // peptidase activity // inferred from electronic annotation /// 4252 // serinetype endopeptidase activity // inferred from electronic annotation /// 16787 //

hydrolase activity // inferred from electronic annotation 201961_s_at $\quad-0.331560333 \quad 10193 \quad$ RNF41 ring finger protein 41

SPATA5 spermatogenesis associated 5

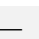

$5515 / /$ protein binding // inferred from electronic annotation /// $8270 / /$ zinc ion binding // inferred from electronic annotation /// 46872 // metal ion binding // inferred from electronic annotation

166 // nucleotide binding // inferred from electronic annotation /// 5524 // ATP binding // inferred from electronic annotation /// 17111 // nucleoside-triphosphatase activity // inferred from electronic annotation 
direct assay /// 5737 //

inferred ir cytoplasm // inferred from direct assay /// 5634 // nucleus

$/ /$ inferred from electronic annotation

\begin{tabular}{|c|c|c|c|c|c|}
\hline 210681_s_at & -0.322542667 & 9958 & USP15 & ubiquitin specific peptidase 15 & $\begin{array}{l}6511 / / \text { ubiquitin-dependent } \\
\text { protein catabolism // inferred } \\
\text { from electronic annotation /// } \\
6512 / / \text { ubiquitin cycle // } \\
\text { inferred from electronic } \\
\text { annotation }\end{array}$ \\
\hline
\end{tabular}

annotation /// 19209 // kinase activator activity // inferred

from direct

kinase binding // inferred from physical interaction /// 46872 //

metal ion binding // inferred

from electronic annotation

4197 // cysteine-type

endopeptidase activity //

traceable author statement ///

$4221 / /$ ubiquitin thiolesterase

activity // inferred from

electronic annotation /// 8233 // peptidase activity // inferred

from electronic annotation /II 4197 // cysteine-type endopeptidase activity // inferred from electronic annotation /// 8234 // cysteinetype peptidase activity // inferred from electronic annotation /// 16787 // hydrolase activity // inferred from electronic annotation //I 4843 // ubiquitin-specific protease activity // traceable author statement

5215 // transporter activity // inferred from electronic electronic annotation /// 6839 // from electronic annotation /II mitochondrial transport // inferred from electronic annotation

$5743 / /$ mitochondrial inner

membrane // inferred from annotation /// 5488 // binding // inferred from electronic annotation

// membrane // inferred from

electronic annotation /// 1602

// integral to membrane //

inferred from el 
5634 // nucleus // inferred from

$6350 / /$ transcription // inferred

from electronic annotation /II

$6355 / /$ regulation of

transcription, DNA-dependent

// inferred from electronic

annotation /// 6915 // apoptosis

// inferred from electronic

annotation /// 7049 // cell cycle

// inferred from electronic

annotation /// 8630 // DNA

damage response, signal

transduction resulting in

induction of apoptosis //

traceable author statement /II

45786 // negative regulation of

progression through cell cycle

// inferred from electronic

annotation

Chromosome 9 open reading

frame 10 opposite strand

PQ loop repeat containing 2
$3700 / /$ transcription factor

activity // traceable author

statement /// 5515 // protein

binding // inferred from

physical interaction /// $8270 / /$

zinc ion binding // inferred

from electronic annotation ///

46872 // metal ion binding //

inferred from electronic

annotation /// 3677 // DNA

binding // inferred from

electronic annotation /// $3700 / /$

transcription factor activity //

inferred from electronic

annotation

\begin{tabular}{ccccc} 
239391_at & -0.301317167 & 158293 & C9orf10OS & $\begin{array}{c}\text { Chromosome 9 open reading } \\
\text { frame 10 opposite strand }\end{array}$ \\
220453_at & -0.211763667 & 54896 & PQLC2 & PQ loop repeat containing 2 \\
\hline
\end{tabular}

